HOW A PRINCIPAL'S ACTION AS AN INVITATIONAL LEADER WITH A SOCIAL JUSTICE ORIENTATION CAN SERVE AS A FACTOR IN RECRUITING AND RECIPROCALLY RETAINING TEACHERS AT HIGH-POVERTY, HIGH-MINORITY, HIGH NEEDS URBAN HIGH SCHOOLS

A Dissertation
presented to
the Faculty of the Graduate School
at the University of Missouri-Columbia
In Partial Fulfillment
of the Requirements for the Degree
Doctor of Education
Br. Barbara N. Martin, Dissertation Supervisor
William E. McDowell

December 2020 
The undersigned, appointed by the dean of the Graduate School, have examined the dissertation entitled

HOW A PRINCIPAL'S ACTION AS AN INVITATIONAL LEADER WITH A SOCIAL JUSTICE ORIENTATION CAN SERVE AS A FACTOR IN RECRUITING AND RECIPROCALLY RETAINING TEACHERS AT HIGH-POVERTY, HIGH-MINORITY, HIGH NEEDS URBAN HIGH SCHOOLS

presented by William E. McDowell

a candidate for the degree of doctor of education, and hereby certify that, in their opinion, it is worthy of acceptance.

Dr. Barbara N. Martin

Dr. Bryan McDonald

Dr. Sandy Hutchinson

Dr. Jason Morton 


\section{DEDICATION}

I dedicate this to the people who I would not understand the meaning of Ubuntu without you. My wife Jessica, who I am grateful everyday for your invitational leadership to start our relationship that day on a picnic table and your social justice leadership has an effect that ripples through our children and the students who you teach a culturally responsive curriculum every day. You picked up all the times I had to step away and allowed me the space to take a bit longer to find the right study to move ahead. To our children Liam and Winifred who were patient with me when I had to say I could not and who move forward in this world inviting and seeing the

humanity in all. To my mother Geralyn, the person who modeled and taught her children what it means to use our voices for social justice. There is no piece of paper that will ever be able represent your level of understanding the human condition.

I also dedicate to this to all people who are categorized in, "otherness.” I see you; I value you, and I will use this learning to create pathways to equity in opportunity for all. 


\section{ACKNOWLEDGEMENTS}

I would like to first thank Dr. Barbara N. Martin. She accepted me for who I was every step of this journey. She guided me to find the theories to which I could best connect the person I was and had an even greater desire to grow. Gratitude to my sisters in doctoral learning and life learning, Dr. Crystal Ward and Dr. Tina Chaney. Your cheerleading, patience, and trust when I offered ideas of support allowed me to get where I wanted to be. I am grateful to Julie Blaine, my professional and personal mentor who surrounded me with the great team at the Central RPDC. To the National Math and Science Initiative a great thank you. The organization put me on planes and trusted me to support 70 schools. Then when I wanted to start sharing with our schools about Invitational Education, they trusted me to put it out there and are allowing me to keep building. Nicole Beeman-Cadwallader and Tenesha Villanueva, you were the leaders and thought partners who had both the patience and persistence in encouragement I needed to push this through the finish line. I would also like to show appreciation for my committee members who I had the honor of also having as professors in the classroom in Dr. Sandy Hutchinson and Dr. Bryan McDonald. Your leadership has helped my deeper understanding of K-12 leadership from the elementary principal to the superintendency. Dr. Jason Morton, who I know is doing the great work in our community and was willing to support this work in the final leg of thejourney. 


\section{TABLE OF CONTENTS}

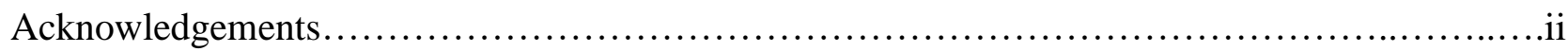

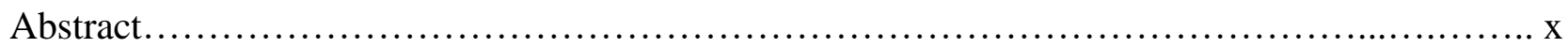

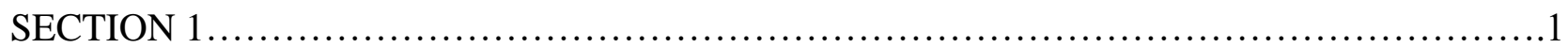

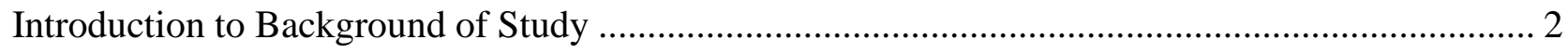

Statement of the Problem......................................................................................................... 4

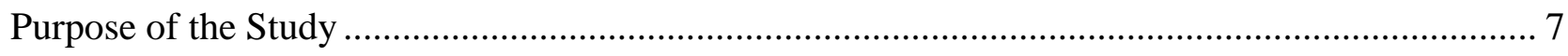

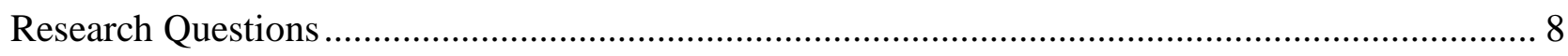

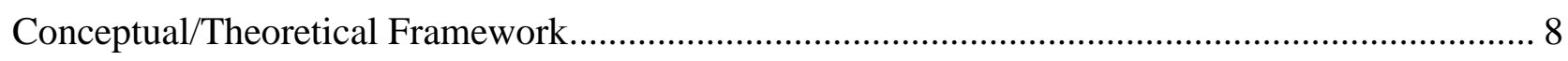

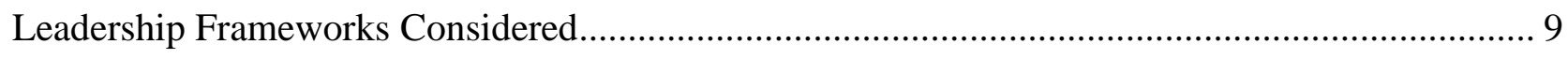

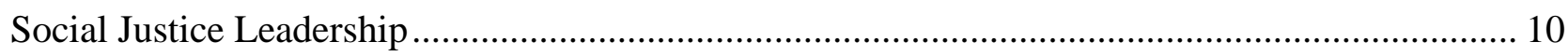

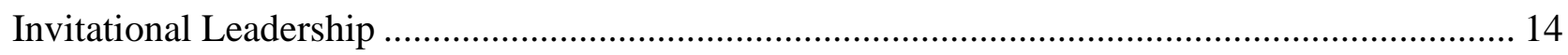

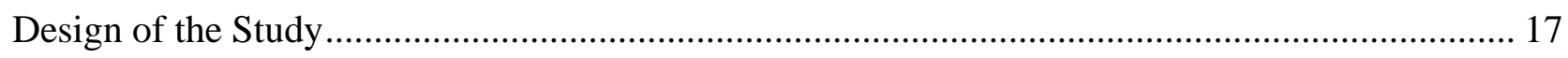

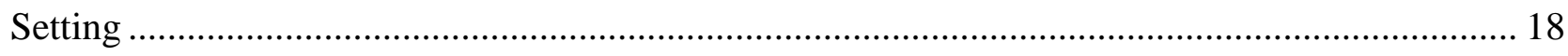

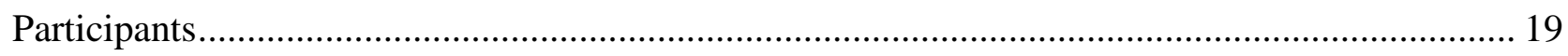

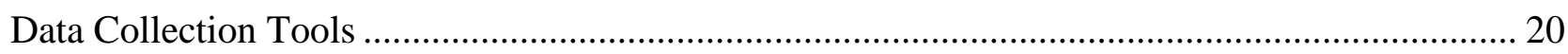

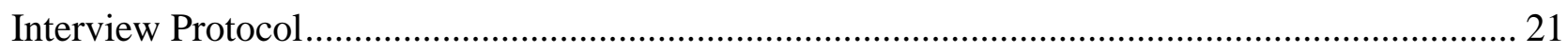




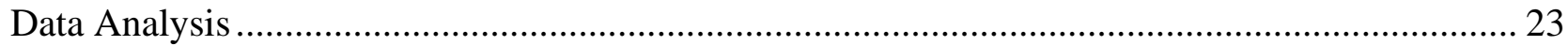

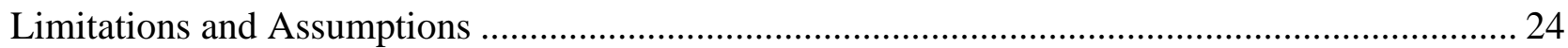

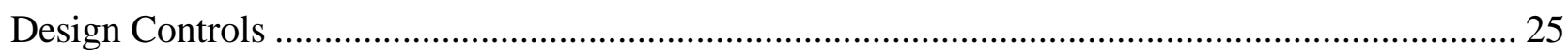

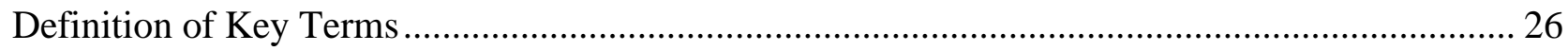

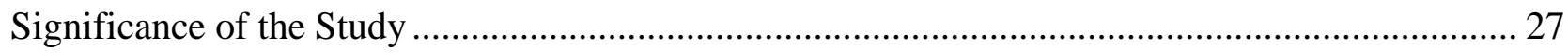

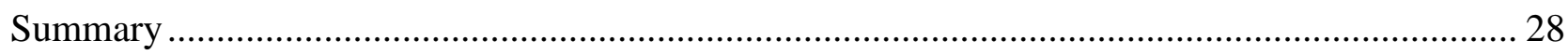

SECTION TWO: PRACTIONER SETTING FOR THE STUDY ........................................... 30

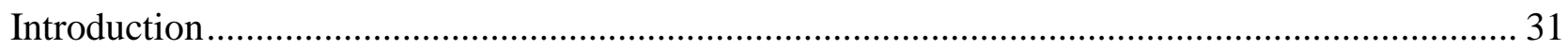

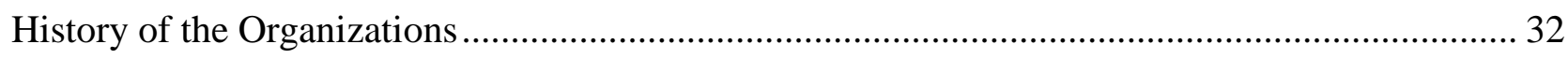

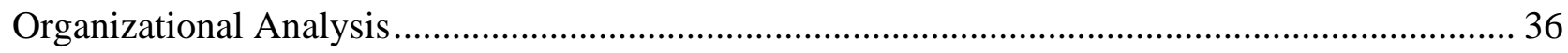

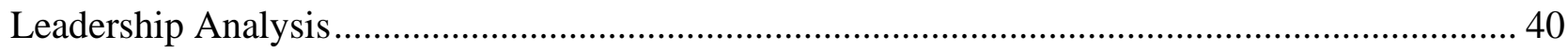

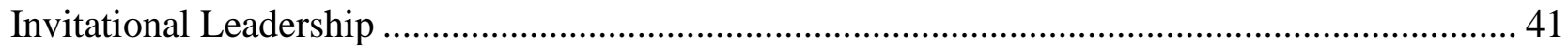

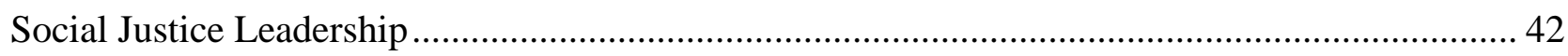

Implications for Research in the Practitioner Setting ......................................................... 44

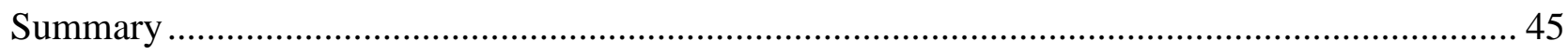

SECTION THREE: SCHOLARLY REVIEW FOR THE STUDY …................................... 47

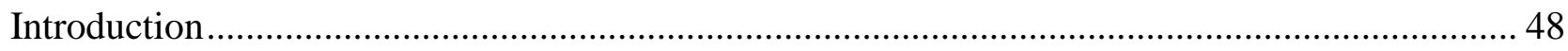


Existing Gap in Literature

Review of the Extant Scholarship ............................................................................................... 53

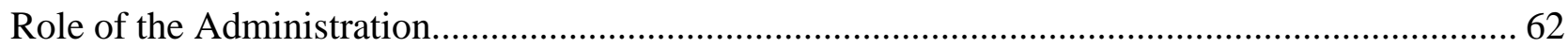

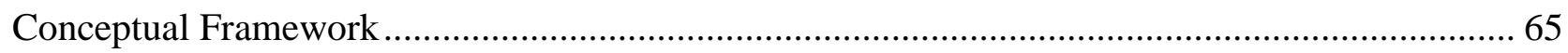

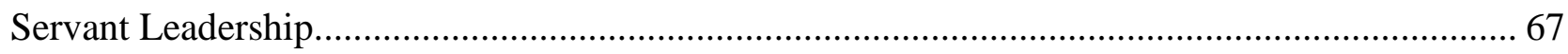

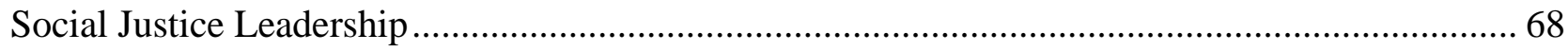

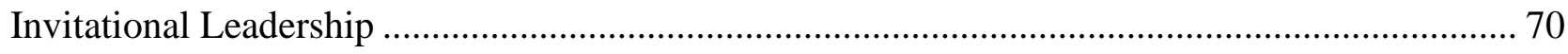

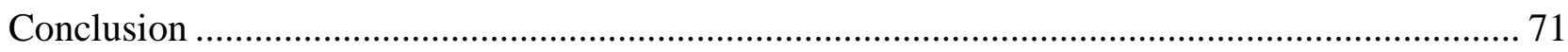

SECTION FOUR: CONTRIBUTION TO PRACTICE ……………............................................

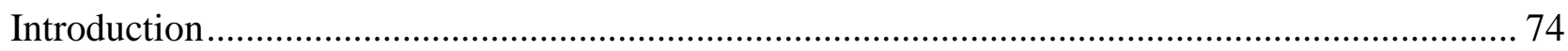

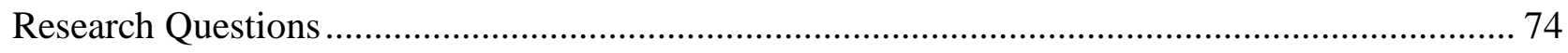

Connection to Conceptual/Theoretical Framework ………............................................................ 75

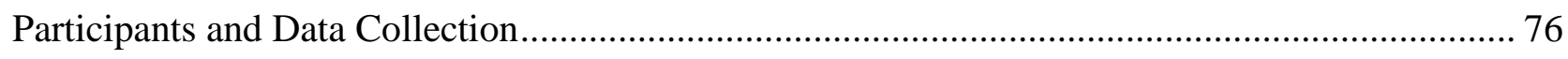

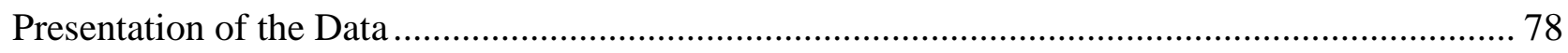

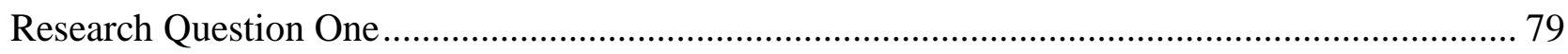

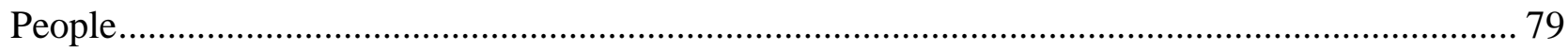

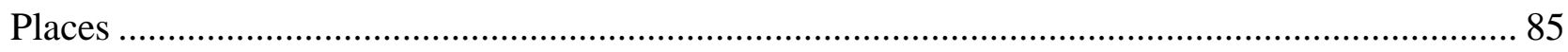

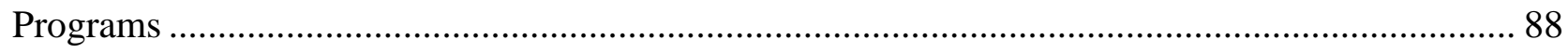


Policies

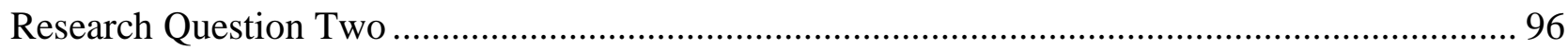

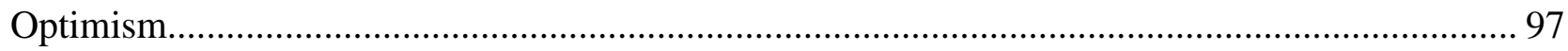

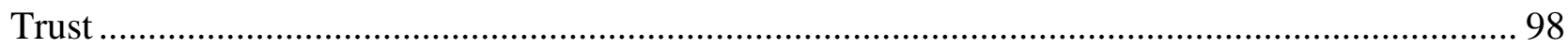

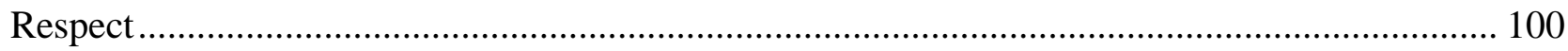

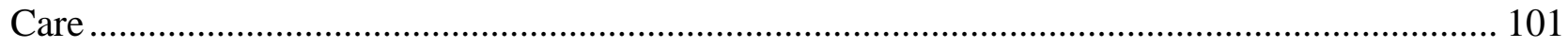

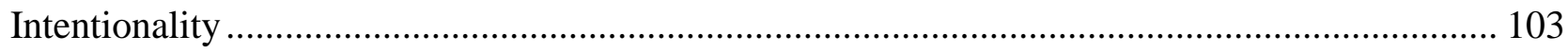

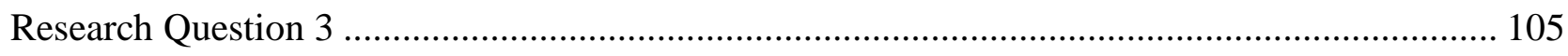

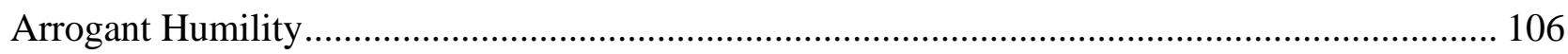

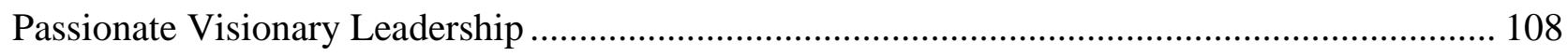

Tenacious Commitment to Justice .................................................................................... 110

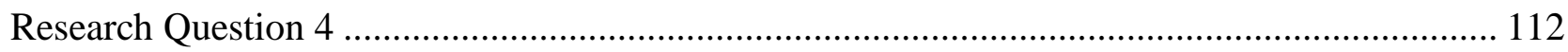

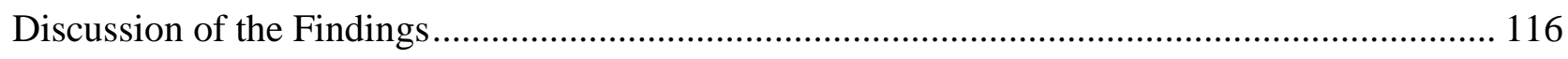

Theme: The Actions of the Principal Being Intentionally Inviting ..................................... 117

Theme: Social Justice Orientation Created a Vision Team Members Wanted to be Committed to

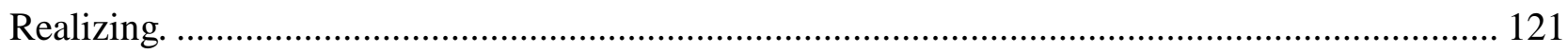

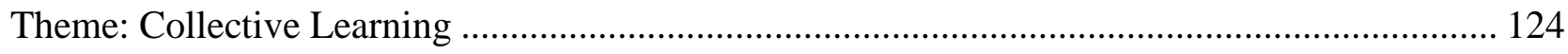

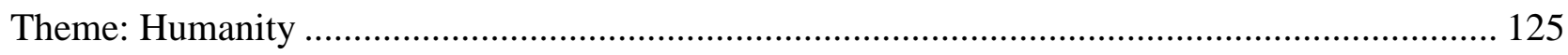

Theme: Commitment to Students and the Community ..................................................... 126 
Implications for Practice

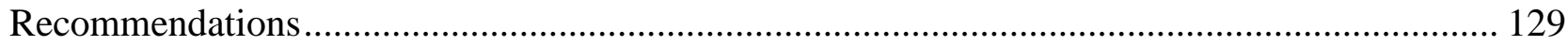

Plan for Dissemination of Practitioner Contribution ............................................................. 133

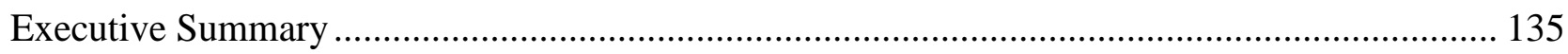

Can a principal's action as and invitational leader with a social justice orientation serve as a factor in recruiting and reciprocally retaining teachers at a high-poverty, high-minority, high-needs,

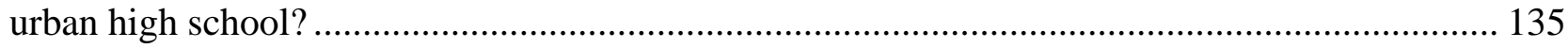

Description of organizational setting for the research ................................................... 136

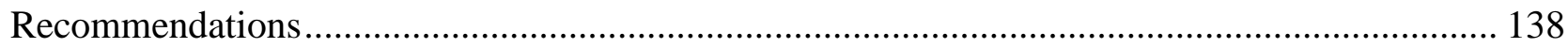

SECTION FIVE: CONTRIBUTION TO SCHOLARSHIP .............................................. 140

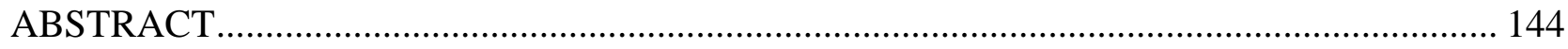

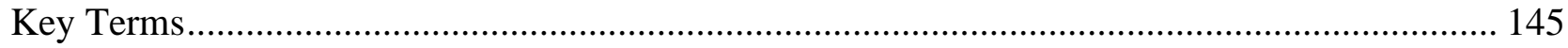

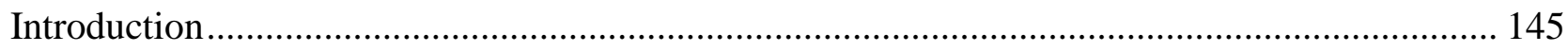

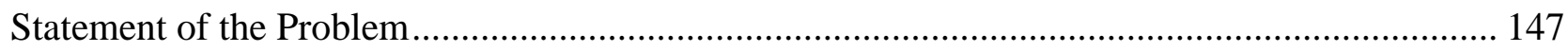

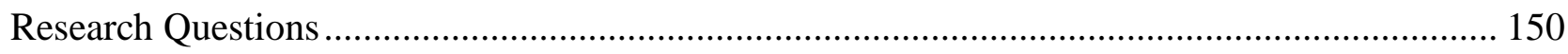

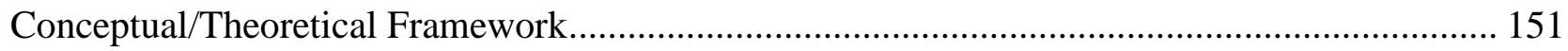

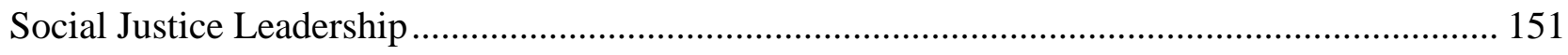

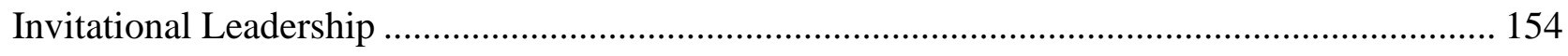

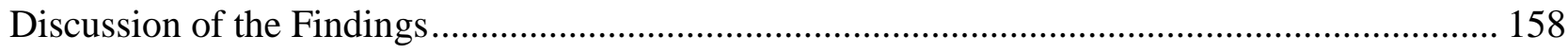


Theme: The Actions of the Principal Being Intentionally Inviting

Theme: Social Justice Orientation Created a Vision Team Members Wanted to be Committed to Realizing.

Theme: Collective Learning ...... 165

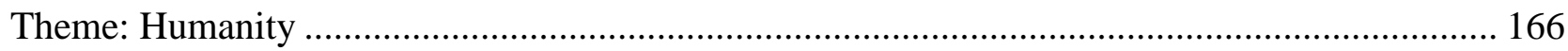

Theme: Commitment to Students and the Community ............................................................. 167

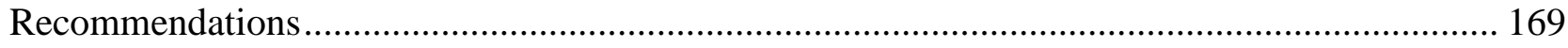

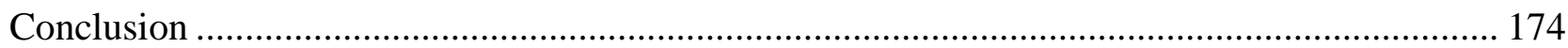

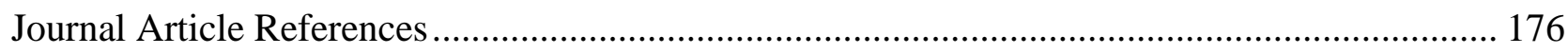

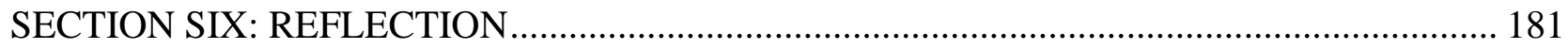

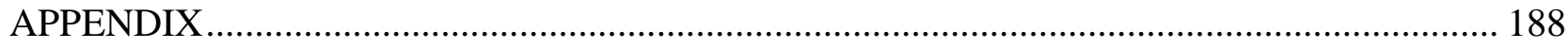

Gatekeeper Permission for Administrator and Educator Participation ........................................... 192

Please return to: William E. McDowell, 4115 Campbell St., Kansas City, MO64110................... 192

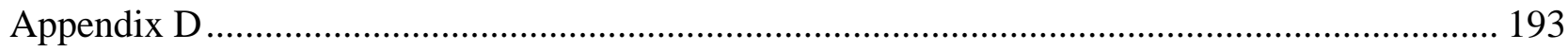

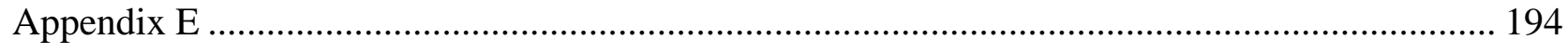

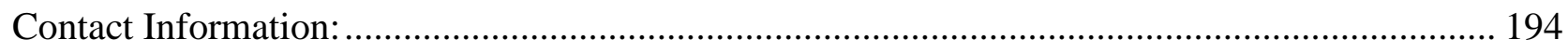

Please return to: William E. McDowell, 4115 Campbell St., Kansas City, MO 64110 ................. 194

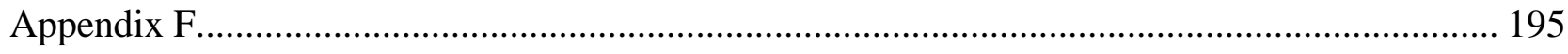

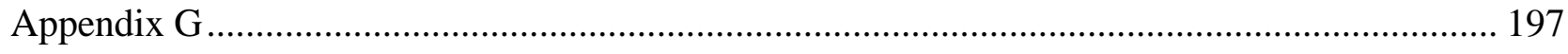


Appendix H Document Analysis Protocol............................................................................ 199

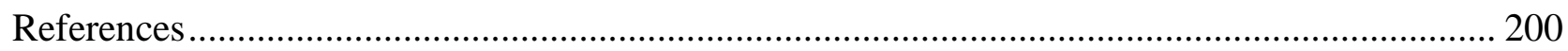

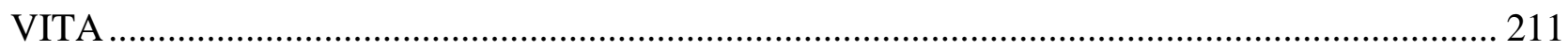




\begin{abstract}
The number of individuals going into the teaching profession was dwindling at a time when the rate of retirement and people leaving the profession was increasing. Sutcher et al. (2016) noted that in 2015-16, the United States was short 64,000 qualified teachers. They predicted this to grow to as much as 300,000 teachers needed per year by 2020 and up to 316,000 by 2025 . The COVID-19 pandemic may exacerbate this challenge even more (Page, 2020). Teachers need to be recruited, supported, and retained in high-poverty, high-minority, highneeds, urban high schools (Freedman \& Appleman, 2008; Greenlee \& Brown, 2009; Hughes, 2012; Petty, et. al, 2012; Podolsky, et. al., 2016; Simon \& Johnson, 2015; Stotko, et. al., 2006; Waddell, 2010). In a time when inequities are being exacerbated in the field of education, the principals and the teachers will be called upon to do more with less (Page, 2020). Empowerment of school principals who are willing to take on the schools that are the most challenging (Bartanen, 2019; Levin \& Bradley, 2019) is needed. They must to be trained to demonstrate leadership dimensions and supporting actions (Martin \& Miller, 2017) that can guide them to build a team of team of irreplaceable teachers (The Irreplaceables, 2012), which will build collective efficacy (Hattie, 2016) to help students furthest from opportunity reach their high potential in academic and personal achievement. In the contention of Martin and Miller, (2017) aligning the dimensions of invitational leadership (Purkey \& Novak, 2016; Purkey \& Siegel, 2003) with action and self-reflection of social justice leadership for principal leadership will better prepare principals leading schools with diverse populations. This study further contends that if the principal's action as an invitational leader with a social justice orientation it will serve
\end{abstract}


as a factor in recruiting and retaining teachers in the schools where they are needed most. 
SECTION ONE:

INTRODUCTION TO THE DISSERTATION-IN-PRACTICE 


\section{Introduction to Background of Study}

In October of 2016, a research team working with the Learning Policy Institute (LPI) out of Stanford University created two seminal reports regarding the supply and demand of educators entering and staying in the teaching profession. The team from LPI, including long time social justice education advocate Linda Darling-Hammond, sounded the alarms of a teacher pipeline that was quickly dwindling and needed answering. With the publishing of A Coming Crisis in Teaching?: Teacher Supply, Demand, and Shortages in the U.S. (Podolsky et al., 2016) and Solving the Teacher Shortage: How to Attract and Retain Excellent Educators (Sutcher, DarlingHammond, \& Carver-Thomas, 2016) the team identified the problem of the teacher shortage with the reasons why it exists and detailing solutions. While their research added to a heavily researched topic searching for these answers of teacher shortage, recruitment and retention (Bornman \& Dowling, 2008; Heineke et al. 2014; Hughes, 2012; Ng, 2003; Petty, et al., 2012;

Sachs, 2004; Simon \& Johnson, 2015; Stotko et al., 2007; Waddell, 2010), these studies offered a one-stop, cumulative, extensive resource. The reasons they gave for the teacher shortage included among others the projected supply and demand, increased demands of teachers, the pressure of accountability measures, cost of entry into the profession, decision-making power, experiences with professional development, and lack of parental support or involvement. They would go on to argue that attrition was most significant in high poverty schools due to lower salaries and more impoverished working conditions (Podolsky et al., 2016, Sutcher, et al., 2016). 
Made were policy recommendations to turn the tide to more effectively recruit and retain teachers in the following five areas: Salaries and compensation; Preparation and costs to entry; Hiring and personnel management; Induction and support for new teachers; and, Working conditions, including school leadership, professional collaboration, shared decision-making, accountability systems, and resources for teaching and learning (Sutcher et al., 2016). Consequently, while the principal may not influence each on these suggestions, their actions do matter considerably with ideas in hiring and personnel management, induction and support, and school-working conditions (Burkhauser, 2016; Grissom, 2011; Sutcher et al., 2016; Waddell, 2011; Watkins, 2005). Sutcher et al. (2016) validated this observation:

A comprehensive research review of attrition in high-poverty schools finds that the most significant workplace conditions associated with teacher attrition are teachers' perceptions of their principal, collegial, and school culture.... When teachers strongly disagree that their administrator encourages and acknowledges staff, communicates a clear vision, and generally runs a school well, turnover rates for movers and leavers jump to nearly one in four, more than double the rate of those who feel their administrators are supportive (p. 51).

Unfortunately, the rate of principal turnover in high-poverty, high-minority, and highneed urban high schools was also significant (Clotfelter et al., 2007). In fact, by 2022, the demand for k-12 principals had increased by six percent nationwide due to population increases. Similarly, while the cost to recruit, hire, prepare, mentor, and continue training principals cost the typical high poverty, high-minority, high-needs urban principal $\$ 75,000$ to qualify (NASSP.org, 2020). Meanwhile, during the 2016-17 academic year, more than a third of principals did not surpass two years at the same school. Conversely, only eleven percent stayed 
at the same school for a decade or more (Levin \& Bradley, 2019). Additionally, in the ranking of 252 influences and effect sizes related to student achievement, student mobility ranks $248^{\text {th }}$, one step worse than corporal punishment in the ranking (Hattie, 2018). This agitated school principals, teachers, and students in high needs schools.

This mix of principals, teachers, and students in and out of the school led the researcher to examine whether there is a connection between the leadership practices of two principals in low-income, high-minority, urban settings. One high school had a predominately Latino population in California, and the other school demographic was predominantly Black, in a Midwestern city. Each school possessed a lower teacher turnover rate, as compared to similar schools within their region, and thus were selected as the cases examined within the inquiry.

Presented within this chapter is the problem, and the purpose of the research, along with the research questions to guide the study. As well, discussed is the conceptual framework, research design, research methodology, and significance of the study.

\section{Statement of the Problem}

The number of individuals going into the teaching profession was dwindling at a time when the rate of retirement and people leaving the profession was increasing. Sutcher et al. (2016) noted that in 2015-16, the United States was short 64,000 qualified teachers. They

predicted this to grow to as much as 300,000 teachers needed per year by 2020 and up to 316,000 by 2025 . These numbers would put the United States at an average shortage of 112,000 teachers per year with the main drivers of this being a decline in teacher preparation enrollments, district efforts to return to pre-recession pupil-teacher ratios, increasing student enrollment, and high teacher attrition (Sutcher et al., 2016). 
The schools serving high-poverty, high-minority, high-needs populations are some of the hardest hit by these teacher shortages where up to one-half of the teachers leave within the first five years (Ingersoll, 2001). In several studies (Greenlee \& Brown, 2009; Ingersoll, 2003; Ronfeldt, et al., 2013) it has been shown that those schools who serve populations of highminority students from urban, low socio-economic and low academic achievement backgrounds have higher rates of turnover than schools in more affluent, higher academic achieving predominantly White schools. This level of turnover becomes extremely expensive and diverts money away from other school needs that could support students (Shernoff et al., 2011). Additionally, having waves of new teachers created a myriad of other problems including staff reconfiguration, novice teachers tried to help other novice teachers learn the job, inability to build sustaining collegial relationship among staff or trusting relationships with students, and a lack of social capital where teachers were willing to take on leadership roles (Simon \& Johnson, 2015). Similarly, Borman and Dowling (2008) explored several factors that catalyzed teacher turnover including student body characteristics such as race, socioeconomic status, achievement abilities; teacher demographics such as gender, race, and age; the level of training, experience, and expertise of the teacher; and contextual factors of the school like class size, school location, working conditions, and teacher salary.

Notably, while educators had more than half a century of efforts to integrate student populations, still more students attend racially concentrated schools where the student population was either more than $75 \%$ White or $75 \%$ of students of color than those who did not (Edbuild.org, 2019). Considering an overwhelming 84\% majority of the teaching population in the United States was White, while the student population is $47 \%$ of students of color could create challenges (Waddell \& Ukpolodu, 2012). Many of these teachers come from middle-class 
backgrounds, and their ability to relate to students becomes difficult (Fergus, 2017; Kozol, 2005). When matching the demographics of the teachers available being White middle class with the demographics of most high poverty, urban high schools being students of color there needs to be time to develop skills to overcome general biases such as deficit thinking, colorblindness, and racial discomfort that negatively correlate with a teacher's self-efficacy (Fergus, 2017). One must be intentional over time to be able to learn how to be a culturally responsive educator where one understands how to engage students in the productive struggle to close the achievement gap while the students become independent learners (Hammond, 2015, p. 12). The opportunity to build the needed professional capital of teachers that would have a historical context of the school, community, and students is not there from year to year. As a result, a majority of new staff must reinvent what the school will do to serve that year's cohort of students (Hargreaves \& Fullan, 2012).

The supports teachers want to include school leadership, collegial relationships, and elements of school culture (Simon \& Johnson, 2015, p. 5). Burkhauser (2016) argued the person who can play a more significant role than any other in creating a school environment where teachers will want to stay with the principal. Fullan (2014) noted that two of the criteria that are most important for teachers to stay is the quality of their colleagues and the quality of school leadership, "Humans are fundamentally motivated by two factors: doing things that are intrinsically meaningful to themselves, and working with others - peers, for example - in accomplishing worthwhile goals never before reached" (2014, p. 7). This is echoed by Buckingham and Goodall (2019) when they found that people would come for the mission but stay for the team with whom they worked. They went on to note when teams share vision and values, they engage and accomplish at higher rates, 
This inquiry examined the connection of a leader's commitment at a high-poverty, high minority urban school to following the tenets of invitational leadership. Furthermore, this examination attempted to reveal how that connection leads to a commitment from teachers, parents, outside stakeholders, and the principal to continue to engage in the development of students beyond the two-year tenure of many high needs schools (Bradley \& Levin, 2019). There have been inquiries regarding the benefits of invitational leadership within high needs urban high schools (Martin \& Miller, 2017), and examinations of what principals can do to attract and retain excellent educators in high needs urban schools (Burkhauser, 2016; Johnson \& Simon, 2015; Podolsky et al., 2016; Waddell, 2010). Little has been studied on the connection between the retention of teachers in high poverty settings due to the tenets of invitational leadership, integrating the actions of a social justice leader being present through the principal's leadership.

\section{Purpose of the Study}

With a strong leader establishing a vision of what the school is trying to achieve, great strides can take place in the culture within 5-7 years (Fullan, 2001). Teachers want strong school leadership, collegial relationships, and elements of a positive school culture where they have a better chance to be successful in teaching and students' learning (Simon \& Johnson, 2015). Teachers in high poverty schools yearn for an environment where the principal who leads with integrity, while knowing pedagogy, trusts them as professionals to give them autonomy to deliver their curriculum and engages them in shared decision making (Greenlee \& Brown, 2009). A competent principal will recognize he or she cannot do it alone (Fullan, 2015; Poldolsky et al., 2016; Simon \& Johnson, 2015). Specifically, the purpose of this research was to determine the connection between adherence of the school leader to the principles of invitational leadership theory, while integrating social justice in high poverty urban high schools. 


\section{Research Questions}

Within the context of this study using qualitative inquiry, the researcher sought to answer the following research questions:

1. What tenets of invitational leadership are evident within the leadership style of the principal?

2. How do the tenets of the invitational leadership style of the principal impactthe retention of teachers within a high poverty school setting?

3. What behaviors of the principal and teachers demonstrate the desire to act in the orientation of social justice?

4. How are the tenets of invitational leadership and the orientation of social justice displayed within the school community by the stakeholders (principal, teachers, and community)?

\section{Conceptual/Theoretical Framework}

Intending to realize fully and provide the framework needed to understand the significance of this study, presented are two separate frameworks: social justice leadership (Theorharis, 2007) and invitational leadership (Purkey \& Novak, 2016). Martin and Miller (2017) recognized the connection between the two when one of the emerging themes in their work included, “Addressing Social Justice Inequities through the Six P's.” The six P's is a reference to the six P's of invitational education (Purkey \& Novak, 2016). Following their line of inquiry, this research will have a greater focus on the connection of sustained engagement through invitational leadership practices employed by the school principal. This focus on two high poverty, high minority, high needs urban high schools also invited the exploration into the 
principal's engagement in socially just leadership practices. Presented below are the two frameworks.

\section{Leadership Frameworks Considered}

The leadership framework theory allows us to understand how a leader's practices can influence the people's level of commitment to the organization. Considered were several leadership theories for the conceptual framework: servant leadership theory (Northouse, 2013), critical race theory (Capper, 2015; Santamaria, 2013), social justice theory (Shields, 2004; Theorharis, 2007), and invitational leadership theory (Novak \& Purkey, 2001). It is of great importance for school leaders to understand how race and equity play into their ability to have a clear perspective on these attributes outlined by Rector-Aranda (2016) and be aware of what implicit biases they may have if they are to help students from marginalized populations succeed (Fergus, 2017). Because of the need for an urban principal to be a leader in the community where they serve, servant leadership was naturally under consideration. The term coined by Greenleaf (1970) and further developed through his forty years of work at AT\&T explored how leaders can better serve society (Northouse, 2013). Greenleaf encouraged that leaders must engage and value the communities in which they serve to build trust, respect, interdependence, and individual growth (Northhouse, 2013).

Servant leadership works well for the followers who believe in it and want to have this kind of close relationship with their superior. However, others equate servant leaders as trying to micromanage and do not desire to expose themselves to the person in a supervisory role (Northouse, 2013, p. 227). Teachers are looking for emotional, environmental, and instructional support in an age where accountability systems are driving up to $25 \%$ of the non-retiring teachers 
out of the profession. (Podlosky et al., 2016, p. 44). For these reasons, not considered as an appropriate fit for this inquiry, was servant leadership inquiry.

When further reviewing the literature to narrow the study to find an association between leadership practices and social justice, examined was critical race theory (CRT). The essential principle of CRT is a belief in white privilege and dominance that impacts race relations. This theory rejects the usual discourses of objectivity, neutrality, color-blindness, meritocracy, and equality under the law (Rector-Aranda, 2016). However, eliminated was critical race theory due to the purpose of this study to examine how to entice teachers to join a high poverty school for the mission and stay. The researcher believed there was a need for a more encompassing theory.

As stated by Martin and Miller (2017), "Undeniably, an inquiry has only begun to identify some of the issues, and challenges principals confront when they employ social justice leadership orientations in their school settings to create inviting environments (p. 199).” Furthermore, Martin and Miller (2017) argued that the self-reflective and action orientations of social justice leadership align with the dimensions of invitational leadership. Within this inquiry existed the contention that these practices combined will have teachers believing that they have joined a movement where they are changing lives for the better (Sinek, 2014) and a social justice leader using invitational practices is the leader who can create the sustaining culture where the team of teachers and community come together and stay together.

\section{Social Justice Leadership}

In much of the high poverty, high minority, urban high schools, the proportion of White females teaching Black, Latino, and Native American students has increased while Black and Latino students were primarily attending schools with only Black and Latino students has risen (Fergus, 2019). Therefore, teachers in these schools need leaders grounded in social justice, as 
defined by Theoharis (2007). The latter, "make issues of race, class, gender, disability, sexual orientation, and other historically and currently marginalizing conditions in the United States central to their advocacy, leadership, practice, and vision" (p. 223). Accordingly, the social justice theory will be an overarching theory further explored. Theorharis's (2008) definition of social justice leadership “.... is to mean that these principals advocate, lead, and keep at the center of their practice and vision issues of race, class, gender, disability, sexual orientation, and other historically and currently marginalized conditions in the United States" (Theoharis, 2008, p. 5).

The conditions in highly segregated, high poverty schools led to teachers leaving the profession early or at least not staying multiple years (Grissom, 2011; Podolsky et al., 2016; Stotko, 2006). With so much focus on this turnover of teachers, few had noticed that the principal turnover rate surpassing the teacher turnover rate (Bartanen, Grissom, \& Rogers, 2019). Consequently, the turnover with a principal exacerbated the rate at which teachers left, creating a level of adult professional unrest that unsurprisingly coincided with student test scores falling in a school (Bartanen et al., 2019). Compile this with high poverty schools (Samuels, 2012; Podolsky et al. 2016) it becomes vital that the school finds a leader who is willing to build a team where teachers will come for the mission while staying for the team (Buckingham \& Goodall, 2019).

Compared to other leadership theories, the social justice theory in educational leadership literature was comparatively new (Bogatch, 2000). Bogatch sought the creation of a comprehensive view of different perspectives, such as what social justice leadership should entail. He argued that the ongoing struggle for social justice in education has gone on for decades. He saw that in educational leadership, "an individually-minded principal is often called a maverick; an individually-minded teacher leader is called a trouble-maker. Neither areincluded 
under the banner of loyalty to the system" (2000, p.6). He challenged educational leaders to create social and political space for social justice advocacy by arguing four parameters in the name of educational leadership. These parameters are:

1. There can be no fixed or predictable meanings of social justice before actually engaging in social and academic discourses;

2. The center or unity of any educational reform is so dynamic that it cannothold together for long;

3. The result of our work (just and unjust) are always fragile and fleeting; and, therefore,

4. All social justice/educational reform efforts must be deliberately and continuously reinvented and critiqued - again and again. (Bogatch, 2000 p.10)

For Bogotch (2000), one could not challenge themselves to be a real educational leader without advocating for social justice. "And at every step, articulate how our actions connect to social justice inside and outside of schools" (p.10).

Subsequently, Theoharis (2008) conveyed the following leadership traits were evident in principals following the ethos of social justice leadership.

1. Arrogant humility: Leaders hold a headstrong belief that they are the right person to lead the team toward the vision of social justice for the students and families they serve while paradoxically being filled with self-doubt. They are humble enough to know after self-reflection when they need to admit when they are wrong. They wonder if they indeed are the right person for the role of principal.

2. Passionate visionary leadership: These social justice principals stand as transformational leaders who are driven by such deep care, commitment, and enthusiasm toward championing a strong vision. These components becomerealized 
in such a passion that there is a tightly interwoven connection between the principal position and the person doing that job.

3. Tenacious commitment to justice: The leader maintains a fierce and sustaining commitment to equity and justice not only for their staff but also for themselves ( $p$. 17).

These sentiments were further echoed when Santamaria (2014) in referencing the concept argued during a 2011 ruling by Supreme Court Justice Sonia Sotomayor when she stated, "Inequality in education is the most pressing issue in diversity in the United States" contributes to, “...make educational equity and diversity mainstream issues for practitioners, scholars, and policymakers to consider" (p. 247). Social justice leadership is an inclusive leadership that engages relationships not only in dialogical, collaborative, reciprocal, and horizontal ways; they also promote equity and justice through caring fluid relationships among various leaders (Wang, 2018).

Any principal in a high-poverty, high-minority, high-needs, urban high school is taking on a role where persistent inequalities concerning distinguished groups, including among others race, sexual orientation, ethnicity, social class, and language of origin continue to exist (Dantley \& Tillman, 2010). Yet, the promising literature on social justice leadership lacked in specific skill sets employed by these leaders (Furman, 2012). Therefore, within this inquiry, it was contented the social justice leader would be recognized as a maverick, while also needing many troublemakers as denoted by Bogatch (2000). Therefore, he or she must have taken an invitational posture to gain the vision, buy-in, and clear structure needed to retain teachers within the high-poverty, high-minority, high needs urban high school (Novak, 2001; Purkey \& Novak, 2016). 


\section{Invitational Leadership}

Considering the desire for accessible actions, invitational leadership (Novak \& Purkey, 2001, 2016) became the primary theory used for this study. Invitational leadership affords a school leader an immediate structure to work through an inviting stance after which the actions are taken to affect the people, place, policies, programs, processes, and politics of the school building lead to an inviting environment (Martin \& Miller, 2017). If the schools are going to find success, teachers in high need, high poverty communities, must stay for at least five years (Stotko, 2007).

The solutions offered to retain teachers in high needs schools include culture (Borman \& Dowling, 2006; Ingersoll \& Smith, 2003; Watkins, 2005), structures for leadership opportunities (Yonezawa et al., 2011), collegial support (Simon \& Johnson, 2015), and the chance to shape and influence within the school (Rice, 2010). This, coupled with working conditions cited by Podolsky et al. (2016), included school leadership, professional collaboration, and shared decision-making, accountability systems, and resources for teaching and learning (Podolsky et al., 2016, p. 8). Addressing all these variables was the framework of invitational leadership (Purkey \& Novak, 2016).

Being an invitational leader encompasses all aspects of one's life as the leader calls forth all around them to pursue a life of purpose when they "invite their colleagues, family, friends, loved ones, and community to do the same" (Purkey \& Siegel, 2003, p.3). A school's climate contributes to psychological well-being, student achievement, positive youth development, and how stakeholders perceive the school (Anderson, 2019; Heineke et al., 2014; Kardos \& Johnson, 2007). An inviting educational environment will carry themes of passionate partnership, motivational inspiration, and organic nous of affinity (McKnight \& Martin, 2013). The high 
school principal can have the most significant effect of any individual on the school to create such an environment (Borman \& Dowling, 2006; Ingersoll \& Smith, 2003; Watkins, 2005). The principal can influence a productive school climate through “the leaders' demonstrated emotional self-control and emotional management of others" (Anderson, 2019, p. 47). A leader can do this by following the tenets of Invitational Education theory.

Novak (2002) referenced, “...being an invitational educational leader is like being on a tennis court with another" (p. 70). The leader controls what can be controlled then delivers the idea or concept to the other. The goal is to make solid contact, then in a dialogical fashion, allow the other to receive it. The leader bases this in an inviting stance (Novak, 2002). Novak defined the principles of invitational leadership to be:

Care - $\quad$ Possessing full receptivity to the other through de-centering oneself and listening for interests and meaning expressed by the other.

Respect - Give the other person time to own their part of the relationship.

Trust - $\quad$ Recognize the interdependence of people. Possessing confidence and predictability of others' abilities and integrity.

Optimism - Understanding that human potential is untapped, and there is a better chance of good things happening if there are a positive mindset and belief of others.

Intention - Leaders know the direction they are going while being proactive using a variety of methods, yet self-correcting. (p.72)

The principal can integrate these principles into his or her stance through ensuring the most intentionally inviting environment using the Five Ps: people, places, policies, programs, and processes. (Novak \& Purkey, 2001, p.12). Educational leaders at the principal level have an 
opportunity not to limit themselves to live in this inviting stance at the professional level, yet inviting educational leadership seeks human potential in all areas of the leader's life in these domains. (Novak, 2002, p. 14; Novak \& Purkey, 2001, p. 16 - 19). These domains within the invitational leadership framework are:

People - $\quad$ People are the emissaries of the school. They create and maintain the environment where relationships are built on a sense of collegiality.

Places - $\quad$ The area that is the easiest to change, the landscape, and upkeep of the school can announce that inhabitants of the school are invited and welcomed.

Policies - A significant influencer on how the school is perceived concerning fairness, inclusivity, democracy, and respectfulness.

Programs - Formal or informal, the programs must work for the benefit of everyone where they reflect an invitational environment.

Processes - Created using a democratic process where the end-users are involved in their creation and ongoing revisions creating an attitude of, "We are all in this together.” (Novak \& Purkey, 2001, p. 19)

Furthermore, explored were the levels of functioning within invitational leadership (Black \& Ornelles, 2012, p. 27; Purkey \& Novak, 2001, p. 20). Examples of these functions are: Intentionally Disinviting Level 1 People are pushed to the out group through the leader purposefully devaluing the human spirit. Unintentionally Disinviting Level 2 Leaders are unaware of the harm they are causing through insensitivity, abruptness, or lack of forethought. 
Unintentionally Inviting Level 3 Leaders carry a great spirit, however they lack in intentionality and commitment. When the magic wears off and they do not know why, they begin to disengage.

Intentionally Inviting Level 4 Leaders are intentional with their practices to ensure a deep commitment to caring and democratic purposes. They carry and appreciation for people and their development. (p. 20)

Being an invitational leader gave the leader direction, purpose, and skill in their actions (Purkey \& Siegel, 2003), while leading with social justice orientations (Furman, 2012; Martin \& Miller, 2017), where they carried themselves with arrogant humility, passionate vision, and a tenacious commitment to justice (Theoharis, 2008). Therefore, invitational leadership as the overarching theoretical framework combined with social justice theory will be the preeminent and most concise lens in which to address the problem of practice for this research study.

\section{Design of the Study}

For this qualitative study, the data were collected and analyzed with the intention where, “...the researcher drives a general abstract theory of a process, action, or interaction grounded in the views of participants" (Creswell, 2014, p. 14) using grounded theory. The researcher had worked directly in four different schools and been a professional consultant in over seventy, where school leadership teams received training on effective practices. In the visits within the schools chosen, there were definite signs of intentionally inviting practices as they served a student population of over a $70 \%$ minority and $70 \%$ low-socioeconomic status that was defined by using the number of students in the school who qualify for free and reduced lunch. The 
researcher was most "interested in understanding how people interpret their experiences, how they construct their worlds, and what meaning they want to understand their experiences" (Merriam, 2009, p. 5). The research aimed to understand the practices of the adults through semistructured qualitative investigations (Merriam, 2009) on why they continued to engage in the school as an employee or a community partner concerning the invitational educational leadership practices of the principal (Purkey \& Novak, 2016) or enhanced by the leader's social justice orientation (Martin \& Miller, 2017). The research told the story of two different high schools serving high minority populations from low socio-economic backgrounds with words in a qualitative fashion, rather than numbers in a quantitative manner (Creswell, 2014). The first, School A, in a major city located in California, serving a predominantly Latino student population. The second, School B, in a major Midwestern town serving a majority black population. With semi-structured interviews taking place with administrators, front office personnel, teachers, and community partners, grounded theory as discussed by Creswell (2009) will be appropriate to provide, "comparison of data with emerging categories and theoretical sampling of different groups to maximize the similarities and differences of information" (p.13).

\section{Setting}

For the setting, the researcher selected the use of a purposeful sample (Creswell, 2014; Merriam, 2009) to meet the parameters established by the literature. Merriam based purposeful sampling on the premise of wanting "to discover, understand, and gain insight ... [to] select a sample from which the most can be learned" (p. 63). These two settings were purposefully selected based on the following criteria: high minority student population, high poverty, the principal in the school for over three years, and lower teacher turnover. Due to the travel restrictions by the COVID-19 pandemic and desire to keep the health of both the subjects and the 
researcher, conducted through videoconferencing and telephone interviews with people who work or partner with two different high schools was this inquiry. School A had a student body of over 1400 students, predominantly Latino and a minority of Asian-American origin located in the Silicon Valley of California. The school served a high poverty population with over $84 \%$ qualifying for free and reduced lunch. According to the state Department of Education website, School B had a student body of approximately 400 students that are $82 \%$ Black, 4\% Latino, and the remaining identified as White. The students came from homes where $100 \%$ qualified as lowsocioeconomic. In the researchers' visits to each of the schools, the researcher has seen evidence of invitational behaviors by both the leaders and staff as well as physical evidence of being invitational throughout the building. The discussions with each school principal had displayed evidence of social justice orientations, as outlined by Theoharis (2008). Each of the staff has had members share stories with the researcher describing a culture that keeps them coming back as being ones where they see themselves as advocates for the students who need them most even in the face of inequitable resources.

\section{Participants}

To gain the most profound insight into the possible connection between the principal leading through the creation of an inviting school climate with a social justice orientation (Martin \& Miller, 2017), chosen were two principals. They were selected due to their leading schools that met the criteria of being a high minority, high poverty high schools in urban settings where there was evidence of teachers and community members staying engaged year over year. Also, the principals had been leading their schools for over three years. The researcher started by interviewing the principal of each school $(n=2)$. 
Maximum variation sampling (Merriam, 2009) took place next to include a variety of adults to achieve multiple lenses. As such, following the interview of the principal was that of the support administrators as they are presumed to be the most closely connected in understanding and integrating the vision of the principal at the day-to-day school level $(\mathrm{N}=4)$. Included in additional interviews was the front office, administrative assistant, as she was the person who serves as the threshold to access to the principal $(\mathrm{N}=2)$ and a school counselor $(\mathrm{N}=2)$, as they had a direct connection to hear from students regarding cultural successes and challenges within the building. Subsequentially, using a snowball method (Merriam, 2009) was handled through the suggestion of the principal and assistant principal to identify at least five teachers who have been at the school for more than five years (Simon \& Johnson, 2015; Podolsky et al., 2016) (N=10). Additionally, the snowball method was used once again to identify community members to understand why they continue to engage with and have confidence in the school $(\mathrm{N}=4)$. Therefore, the total of participants was twenty-two participants.

\section{Data Collection Tools}

As the researcher was familiar with both schools due to a three-year relationship with School A and a two-year relationship with School B that included several face-to-face visits at each school, the initial intent of the research was to include effective data collection processes that included observations, interviews, documents, and audio-visual materials (Creswell, 2014). Unfortunately, due to the 2020 Covid-19 Pandemic, both schools were closed well beyond the time the observations were to take place, disqualifying the researcher from being able to complete this type of data collection. Another intention was to use a focus group format for the community partners. However, due to the loss of face-to-face ability to have the discussions, the researcher decided that to try to meet with the group where topics that are sensitive, highly 
personal, and culturally inappropriate to talk about in the presence of strangers (Creswell, 2014) would not be the best choice. However, document analysis occurred along with interviews using a videoconferencing or phone interview formats.

Before gathering any data, a gatekeeper letter was explained and signed following the ethical guidelines of the University of Missouri IRB (Appendix B). This was followed by signed informed consent forms recognizing the study subjects' rights to voluntarily participate in the study, to withdraw from participation at any time, to ask questions, and to have confidentiality respected throughout the research project (Creswell, 2014: Merriam, 2009). No research was conducted without signed letters of informed consent during the interview procedure. These consent forms met with the approval of the Human Subjects Review Committee of the University of Missouri-Columbia (Appendix C). The researcher conducted all interviews in the absence of any direct supervisors. Each participant was given multiple days to read the form while reflecting upon his or her participation. Upon the entry into the study, a number was assigned to each participant to ensure the protected privacy of the participant (Creswell, 2014; Merriam, 2009)

\section{Interview Protocol}

As previously stated, the data collection protocols used in this study entailed semistructured interviews with a total of twenty- two participants to explore further any connection between the principal of the school, creating an inviting school climate with a social justice orientation (Martin \& Miller, 2017). Before choosing participants, the researcher created the semi-structured, open-ended questions protocol (Appendix F) that was submitted to the University of Missouri Institutional Review Board for approval (Creswell, 2014; Merriam, 2009). The wording of the questions were constructed as not to lead the interviewee, nor display 
any bias of the interviewer (Creswell, 2014) and were modified according to their role. Before the interview, reviewed by a group of educators not engaged in this inquiry was the interview protocol. The questions were modified, and the process helped to establish face validity (Creswell). The interviews took place on an individual face-to-face basis through live videoconferencing or phone interviews as not to disqualify any participants due to lack of internet access during the state-mandated or individually chosen quarantine period of 2020. Recorded were these videoconferences. As the questions will be geared toward adults who have chosen to participate in the research in the reflection of their experiences at the school, confidentiality was held to the utmost degree (Merriam, 2009). There was no direct contact with students in either high school, therefore, avoiding the compromised safety of any vulnerable populations (Creswell, 2014).

The interview questions were semi-structured to allow for a consistent guide through the more than twenty participants that enabled specific data to be mined (Creswell, 2014; Merriam, 2009). The interview questions were open-ended with probing questions to allow the stories told in the words of the interviewees (Creswell, 2014). The semi-structured format also allowed for flexibility for perspectives that lean to being unique from others (Merriam, 2009). Each of the interviews were recorded so the interviewer will be able to take the time to focus on the dialogical conversation while not being preoccupied with writing down each step of the answer (Creswell, 2014; Merriam, 2009).

\section{Documents}

Throughout the data analysis, research notes helped to document the importance of elements of the data and reflected the initial concepts followed by the refining categories and then into themes. In addition to the raw data materials, such as school handbooks, faculty 
agendas, and written correspondence to teachers and parents, these documents served to triangulate (Creswell, 2014) the analysis. Also, other documents were analyzed as suggested by the principals, respectively, utilizing the developed protocol (Appendix H).

\section{Data Analysis}

Merriam (2009) referenced while data collection is something that a researcher can get better with through practice, "Analyzing these data is a much more daunting task" (p. 175). She further discussed the data collection should be simultaneous with analysis because the researcher will never know what data they will find. Therefore, the researcher began the initial analysis during and in between the collection of data throughout the process (Creswell, 2009; Merriam, 2009). The interview questions were open-ended; hence, the impact of the process will be to aggregate common words and emotions into five to seven themes (Creswell, 2014; Merriam, 2009).

As the data was hand-coded as it is collected, the words and emotions from the targeted groups of principals, teachers, and community partners, common themes emerged to tell the story of what kept all of the individuals coming back year over year (Creswell, 2014; Krueger \& Casey, 2009; Merriam, 2009). The categories, then themes, emerged through a review of the transcripts were, breaking data down into bits of information and then assigning these bits to categories or classes which bring these bits together again (Merriam, 2009). The process followed were the steps recommended by Creswell (2014).

1. Organize and prepare the data for analysis through transcriptions, cataloging visual material, and arranging into different types.

2. Read and look at all data to gain the general ideas, depth, and credibility of information and write notes to collect general thoughts. 
3. Coding the data where the information is bracketed into the chunks. (p. 197).

\section{Limitations and Assumptions}

There was limitations and assumptions in this study. It is essential to note the biases this researcher may have had regarding the location, topic, and people studied (Creswell, 2014). The researcher spent five years as a principal serving in a low-income, high minority, and lowachievement school. He then spent three years building a relationship with the leader of the school in Silicon Valley and two years getting to know the leadership in the Midwestern city. He had a stake in seeing both succeed. While no longer currently serving as a direct consultant to either of the schools at the time of the study, the organization for which the researcher worked still had a direct relationship with the schools during the study. To limit this bias, there was multiple interviews with stakeholders who had not had direct interactions with the researcher. The researcher stayed focused on the themes that arise from the conversation.

Another limitation was the limited ability to spend prolonged time in the field, as recommended by Cresswell (2014). Due to the COVID 19 Pandemic, the researcher was unable to travel directly to the site of either school due to the expectation they were closed during the study. To elicit on-site evidence of the leadership theories being in place, the researcher had to use evidential artifacts from past visits as well as the school's webpage. Similarly, the information was collected in the designated setting of the room from where the video call took place, which included the interviewee's homes, rather than in the natural setting of the school (Creswell, 2014).

Communication consists of words, tone, and body language (Mehrabian \& Weiner, 1967). While the researcher was able to capture words and tone which account for just $45 \%$ of communication, he was be able to maximize the $55 \%$ of the body language communicated as the 
interviews tool place on videoconference, the preferred method with in-person not being an option, or the telephone. The researcher did all that he could to ensure that rapport was built for a successful interview over these mediums (Merriam, 2009). All interviews were completed and no participants ended the interviewed early or asked that their information not beincluded.

The qualitative design of the study was limited, as it does not have external validity (Creswell, 2014; Merriam, 2009). While the two schools were in two different parts of the country, serving two different predominant minority groups, Merriam (2009) noted, "External validity is concerned with the extent to which the findings of one study can be applied to other situations" (p. 223). However, using schools from different parts of the country does enhance external validity (Merriam, 2009) and the transferability of the findings (Creswell, 2014).

\section{Design Controls}

To reduce bias in the research conducted, the researcher used the following controls. While experiences in each of the schools have been expansive, the researcher put the personal experiences aside while focusing upon the participants' experiences and opinions (Merriam, 2009). Furthermore, open-ended questions were used in the interview to generate honest communication (Krueger \& Casey, 2009). The intent was to delve critically into the connection of an intentionally inviting leader with an orientation for social justice (Martin \& Miller, 2017). Along with examining the reciprocal retention of teachers where both the teacher wanted to return to the school, and the administrator intentionally invited and developed the teacher as a critical contributor to the success of the school (Martin \& Miller, 2017; Novak, 2001; Purkey \& Novak, 2016). Initially set up to be done in person in consequent visits to the school by the researcher were the interviews. However, due to the Covid-19 pandemic and an inability to visit the schools in person, the interviews were conducted using a live computerized video feed where 
the researcher could see and hear the interviewees in real-time as the preferred method. If there were availability challenges or limited access to the internet of some participants, interviews were done through telephone calls. Due to the difficulties of multiple people on the screen at a time talking over one another as all body-language communication could be lost for cueing the questions in a focus group, all interviews were done individually. The researcher took care to be objective while reviewing the data.

The researcher had gained a level of trust within the building as a consultant who had visited each school over the prior three years in School A and the prior two years in School B. While not all participants had a direct working relationship with the researcher, the use of the snowball method, the circle of influence who know the researcher and the interviewees, and the building of rapport in the outset of the interview allowed for an open, honest conversation (Creswell, 2014; Merriam, 2009).

\section{Definition of Key Terms}

To enhance understanding of this inquiry, the following terms are defined:

Disproportionality - The over- and underrepresentation of racial/ethnic minorities concerning their overall enrollment (Fergus, 2017, p. 2).

High School: A school serving students in the grade range of $9-12$ with an age demographic population of $14-18$ years old.

Invitational Education - Encompasses all aspects of one's life as the leader calls forth all around them to pursue a life of purpose when they "invite their colleagues, family, friends, loved ones, and community to do the same" (Purkey \& Siegel, 2003, p.3). 
5 P's of Invitational Education: refers to people, place, policy, process, and programs that Novak and Purkey (2008) indicate are present in all schools and impact the overall culture of the school to make it invitational.

Principal - The positional leader of the school who stands in the middle line of the school district hierarchy, they have both line authority and daily influence on the operators, the teachers (Mintzberg, 2005).

Reciprocal Teacher Retention - A teacher returns to the same school due to being invited back the following year.

Social Justice Leadership - A leader who "makes issues of race, class, gender, disability, sexual orientation, and other historically and currently marginalizing conditions in the United States central to their advocacy, leadership, practice, and vision" (Theoharis, 2007, p. 223).

\section{Significance of the Study}

The purpose of this study was to examine the connection between a high-school level principal having a social justice orientation (Martin \& Miller, 2017; Theoharis, 2008) while enacting the practices of invitational leadership (Martin \& Miller, 2017; Purkey \& Novak, 2016) and the consistent reciprocal retention of teachers in high-poverty, high-minority, high-needs urban schools. This research aimed to find if invitational leadership directly led to a primary reason for the complementary retention of teachers, where teachers who were invited back by the principal did return. While there have been research on the benefits of invitational leadership within high poverty, high minority, high needs urban high schools (Martin \& Miller, 2017) and there was plenty of research of what principals can do to attract and retain excellent educators in these schools (Burkhauser, 2016; Johnson \& Simon, 2015; Podolsky et al., 2016; Waddell, 
2010), little has been studied on the connection between the retention of teachers, principals, and stakeholders returning year over year to support the same school due to the tenets of invitational leadership with a social justice orientation being present through the principal's leadership.

The researcher recognized tenets of invitational leadership (Purkey \& Novak, 2016) with a social justice orientation (Martin \& Miller, 2017; Theoharis, 2008) of both leaders happening throughout multiple visits during multiple years into the school the Silicon Valley in California with a majority Latino population and the one in a large Midwestern city that served a majority Black population. The schools that were losing principals the most quickly were the ones that had higher percentages of their students that came from low-income families, high-minority, and high-need schools (Levin \& Bradley, 2019). Unfortunately, the schools with high teacher turnover reflected these same descriptors of the student populations (Freedman \& Appleman, 2008; Petty et al., 2012; Podolsky et al., 2016; Stotko, 2007). The alignment of the dimensions of invitational leadership with the reflection and action of social justice leadership as outlined by Martin and Miller (2017) provided a framework to stop the overturn of teachers and result in the reciprocal retention of teachers in the schools where they are needed most.

\section{Summary}

According to the meta-studies led by Hattie (2016), the collective efficacy of a teaching staff ranks the highest of the 252 influences on student achievement. The schools that lose principals (Levin \& Bradley, 2019; Watkins, 2005) and teachers (Freedman \& Appleman, 2008; Petty et al., 2012; Podolsky et al., 2016; Stotko, 2007) the most often are those who serve lowincome, high-minority, and high-needs students. Teachers gain effectiveness when they are in a supportive environment where they stay working within a strong teacher network (Shernoff, et al. 2011; Sutcher et al., 2016). Principals are more likely to stay if they are prepared for the role 
and viewed as more effective by teachers and supervisors (Levin \& Bradley, 2019). Therefore, if a principal is prepared with and understands a framework that aligns the dimensions of invitational leadership (Purkey \& Novak, 2016) with an orientation toward of social justice leadership (Theoharis, 2008) as outlined by Martin and Miller (2017), the principal may be more likely to retain the necessary staff long enough for them to become collectively effective and maximize the achievement of students in their high-poverty, high-minority, high-need, urban high school. An expansive series of qualitative interviews (Creswell, 2014; Merriam, 2009) collected the perceptions and ideas of the principals serving the descriptive populations before using a snowball method (Merriam, 2009) to capture the same from teachers and community members who were reciprocally retained year over year for multiple years. This dissertation in practice was shared with both school staff and their districts. Besides was submitted to academic scholarly journals for publication to begin the process of contributing to scholarly work on invitational leadership with a social justice orientation (Martin \& Miller, 2017) and how it could improve teacher retention in hard to staff, high-poverty, high-minority, high-need, urban high schools. 
SECTION TWO:

PRACTIONER SETTING FOR THE STUDY 


\section{Introduction}

There is a crisis in America's schools regarding the challenge of recruiting and retaining teachers (Podolsky et al. 2016). This possibility of the lack of teachers coming through the pipeline being exacerbated to be an even greater crisis as university budgets get cut, unemployment soars (Burnette, 2020) and the cost of entry into the profession becomes prohibitive due to the economic downturn being caused by the Covid-19 pandemic (Sutcher et al., 2016; Haberman, 2004). In a poll taken by USA Today released on May 26, 2020, 1 in 5 teachers stated, "they are unlikely to go back to their schools if they reopen in the fall, a massive wave of resignations (Page, 2020)." This was all compiled on top of the historical higher turnover rates at high-poverty, high-minority, high-needs and low-achievement schools already facing the most significant rate of teacher (Freedman \& Appleman, 2008; Petty et al., 2012; Podolsky et al., 2016; Stotko, 2007) and principal (Levin \& Bradley, 2019; Watkins, 2005) turnover. This has left a greater need for social justice leaders (Theoharis, 2008), who can come with an aligning framework in invitational leadership that will allow them to recruit and reciprocally retain teachers (Martin \& Miller, 2017; Purkey \& Novak, 2016). With this level of support from a known staff, school principals, in turn, will stay longer themselves (Levin \& Bradley, 2019). The time for such leaders was needed in 2020 to draw more people into the profession as the close of May, and the start of June 2020 had brought massive demonstrations from the local to international levels in protest of the inequitable treatment of Black and Brown Americans. The socially just energy may be the exact right time for school leaders to harness as they intentionally invite people who want to expand opportunities for all people in this country (Martin \& Miller, 2017). As Northouse (2013) beckoned, “...leadership is concerned with the process of developing mutual purposes...” (p. 13), and later stamped leadership as “...using 
influence to bring individuals toward a common goal...” (p. 15). These sentiments align with Purkey and Novak (2016), calling on leaders to invite everyone in the school to experience success.

In this section of the dissertation-in-practice proposal, the researcher presented an overview of the schools before analyzing the organizational attributes connecting them to organizational scholarship. Next, an analysis of the alignment of invitational leadership dimensions with a social justice orientation attempted to provide a guiding theory that allowed urban principals in high-poverty, high-minority, and high-need schools to recruit and retain teachers in a time of increasing uncertainty. In summary, explored are the implications for this type of research.

\section{History of the Organizations}

School A was located in a major city in the Silicon Valley of California where, according to bestplaces.net, the median home cost was over a million dollars and more than four timesthe $\$ 231,200$ home price cost in the United States. According to the 2018 Silicon Valley Dichotomy Study (Keen, 2018), the Latino and Black populations of the area were decreasing due to the low wages for less educated people, making it challenging to meet the economic demands of day to day living. Other at-risk groups include the immigrant Vietnamese and Filipino populations. The ability to move up the socio-economic ladder for these minority groups was complicated as many families lacked the financial capital to invest in their career goals and were unable to get the required training or entry-level jobs into the jobs in the high paying, high-skills industries in the area. Accordingly, there was evidence of employment opportunities being unequal based on race compiled with time and fiscal deficits disallowing educational opportunities. In an atmosphere where "working harder wasn't enough to achieve self-sufficiency" (Keen, 2018, p.17), families were left working multiple wage jobs, having numerous families living in single dwelling units, 
cutting back on non-housing goods and services, and investing less in education. In the 25 to 29 age group, only $22 \%$ of native-born and $9 \%$ of foreign-born Latinos had a higher degree, juxtaposed against 70\% of non-Hispanic White immigrants having a higher degree. Within this setting, the opportunity gap is stark, and the need for inviting social justice leaders was vital for the populations lacking in opportunity.

An illustrative example of the importance of the role this school needed to play was evident in an interview that was done with radio station WBUR on the radio program Here and Now in October 2020 with Nisha Patel, managing director of narrative change and national initiatives for Robin Hood, a New York City-based nonprofit focused on fighting poverty. (WBUR, 2019)

So, for example, you mentioned we went to Silicon Valley, and we went there because it is one of the communities historically for children who are born into poverty, where they have the best fighting chance of getting out. So we wanted to say, 'Well, what's going on there? What's the context? And is that still true today? It's true historically. Is it true today?' And so we were having a conversation, breaking bread, having lunch with some parents, primarily women in the Mayfair community in east San Jose. This is the neighborhood where Dolores Huerta and Cesar Chavez began their organizing. We kept talking about over lunch this idea of being in Silicon Valley. And we're having this conversation in simultaneous Spanish-English interpretation so that everyone could participate in their language, in their voice. And one of the women stopped us, and she said in Spanish, 'What is this word you keep using? What is Silicon Valley?

She lived in the heart of Silicon Valley, and you could hear a pin drop because I think it struck many of the folks in our group, particularly the academic scholars, how sort of, I 
think, illustrative that is of both the cultural and economic divide that exists. These are families living within 30 minutes of the largest tech companies on the planet, yet never the twain shall meet.

The district in which School A was located had 18 schools that served grades 9-12. The district had varying levels of racial and socioeconomic diversity, with one school having a demographic make-up of over 2900 students, $18.2 \%$ socio-economically disadvantaged, $5.3 \%$ English learners, and .1\% in foster care (caschooldashboard.org). As standard in the research, the academic indicators of a school made of a population of high income and predominantly White had above standard educational outcomes which resulted in a 95\% graduation rate and an above standard, "very high" college and career readiness score (Kozol, 2005; Matsko \& Hammeress, 2014; Marshall, 2004; Podlosky, 2016). On the other end of the spectrum was School A with just over 1,430 students, $85 \%$ socioeconomically disadvantaged, $26 \%$ English learners, and .4\% in foster care (caschooldashboard.org). In socio-economic status, School A was in the bottom $20 \%$ in the district. The primary academic performance indicators of School A are, on average, two steps below the comparison school in the district with a graduation rate of $83.1 \%$ and a college and career readiness score in the "low" scoring category.

School B was in a large mid-western city in an area that had suffered through significant disproportionality in school funding, racial segregation, and teacher turnover throughout its history (Kozol, 2005). At the close of the $19^{\text {th }}$ century, the city's school district would set the course for urban schools across the country when architect William Ittner set the trend that urban high schools should be as civic monuments rather than utilitarian structures (Rothstein, 2014). The buildings set the trend of an open plan where spaces were created to be conducive to learning; 50 built in the district as the design spread to 430 schools throughout the country. At 
the district's height of enrollment in the district, there were over 115,000 students.

Unfortunately, the city also served as a model for red-lining and segregation (Rothstein, 2014).

The consequences were devastating to Black students, noted as a "separate and unequal system" by the former head of the American Federation of Teachers, Local 420 (Bryant, 2017). The

finances to compete were not in the district favor as the tax base continues to dwindle as the city was once home to twenty-three Fortune 500 Companies was now down to nine, while aid from the state was 9 percent below the state's average (Bryant, 2017). The resources of the city were further dispersed on the state ruling in 1998 that charter schools were able to open in only that district and the other significant, predominantly minority, the low-socioeconomic district in the state. To keep students in the district, they had gone to a magnet model where 13 schools are selective admission (Bryant, 2017).

School B became the first public, co-ed school in its city in 1853 (slps.org). According to the school website, it had overcome significant challenges, including a tornado in 1927 that caused it to lose its physical building. Integration came about in the 1950s at the time of limited popularity for the predominantly White population (Rothstein, 2014). In 1984, the school merged with the magnet school when it became the school known today. At the height of its enrollment, the school served 1,700 students in the 1930s. According to the state Department of Education website, the school serves a population of approximately 400 students that are $82 \%$ Black, $4 \%$ Latino, and the remaining identifying as White. The students come from homes that qualify as $100 \%$ low socioeconomic, and almost $20 \%$ identify as homeless. Students overcome challenges to get to school at an attendance rate above $90 \%$. The four-year graduation rate is $95 \%$ for all students. $50 \%$ of students leave intending to attend a four-year school while an additional $29 \%$ plan on going to college, $16 \%$ straight to employment, and 5\% planning to join the military. 
Like school A in California, the city in which School B is located had extreme segregation along racial and socioeconomic lines. So much so, the argument can be made that it is more dramatic than in other Midwestern cities with a long history of racial mistrust where the protection of the privilege and property of Whites were the general guideposts for decision making regarding laws and policies (Cooperman, 2014). When the Covid-19 pandemic came to the county in which the city is located, the disparities in access to healthcare and underlying unhealthy conditions for the Black population were evident when 55\% of positive cases by April, 2020 were Black. At the same time, only $24.9 \%$ of the overall population is Black. Consequently, of the first 17 deaths as of April 12, 2020, 14 of those who perished were Black (Cachero, 2020). Another consistency by race in both the city and county is the unemployment rate from 2013-2018 wherein the city Black unemployment had registered as high as four times the rate of Whites, while in the county it has often been more than doubled and almost tripled (St. Louis Dispatch, 2019). According to CBS News (2019), the city had the highest murder rate per capita in the United States, with 60.9 murders per 100,000 people. This combination of lack of food security, employment opportunities, and violent crime rate, had left the population of students in the district lacking some of the most basic needs on Maslow's scale (Maslow, 2005). School B may have been the only place where students were adequately fed and where the teacher-pupil relationships could build a trusting relationship that led to the satisfaction of both teachers and students, hence a greater need for consistency in staff (Shann, 1998).

\section{Organizational Analysis}

To find if a leader can genuinely affect whether a teacher will stay or leave, it is helpful to understand both the level of influence from where they operate (Mintzberg, 1980) and the from the framework they operate (Bolman \& Deal, 2013). Mintzberg's structural design has five 
sectors that group the various functions within an organization (1980). This includes the sectors of the operating core, middle line, strategic apex, techno-structure, and support staff. This structure aligns with the structural framework as proposed by Bolman and Deal that delineates roles within a professional bureaucracy (2013). Both school districts in which the studied schools reside, follow the superintendent and boards serving in the role of the strategic apex, the building level principals serving in the middle line, and the operating core where the teachers are creating the products, the lessons, and relationships, consumed by the students (Bolman \& Deal, 2013).

Both districts were large. While School A was in a district comprised of only high schools, there were 18 schools that the district serves, making it impossible for a superintendent to be at each school daily or even weekly. Even more challenging was a personal level of influence for the superintendent of the district in which School B resided with 72 schools in operation. As principals stand in the middle line of the hierarchy, they had both line authority and daily influence on the operators, the teachers (Mintzberg, 2005). This positioned the administrator of each school to be able to allocate the building level resources support and personal influence to create a culture wherein the professional bureaucracy, "Control relies heavily on professional training and indoctrination. Professionals are insulated from formal interference, freeing them to apply their expertise” (Bolman \& Deal, 2013, p. 83).

The structure may allowed an intentionally invitational (Purkey \& Novak, 2016) culture to flourish as the time of invitation for employment, indoctrination to an intentionally inviting culture with a socially just mindset could be established in the interview process, before reinforcing these ideals in the process of training on this type of culture. Conversely, this structure could also stumble when greater control is implemented over the operating core (Bolman \& Deal, 2013). The teachers, as members of the operating core, may have said and 
supported the ideals through the interview and onboarding process. However, they could have wielded their level of autonomy afforded them by union protections in both districts to no longer follow the agreed-upon attributes of an intentionally inviting and socially just cultural practices, which could have created strife between the operating core of teachers and principal in the middle line (Bolman \& Deal, 2013).

Due to the consistent structure in both districts of having building-level principals with assistant principal support and a central office where the superintendent resided in the seat of the strategic apex (Bolman \& Deal, 2013), the frameworks upon which they explored and reflected upon their implementation are similar. Because of the level of crisis in the pipeline decreased and the needs increased in the recruitment and retention of teachers (Podolsky et al., 2016), the principal needed to operate effectively in the remaining frameworks suggested by Bolman and Deal (2013) regarding the political, human resource and symbolic frames.

The two schools were located in high-poverty, high-minority, high-need urban communities where teachers stayed the shortest (Bornman \& Dowling, 2008; Heineke et al. 2014; Hughes, 2012; Ng, 2003; Petty et al., 2012; Sachs, 2004; Simon \& Johnson, 2015; Stotko et al., 2007; Waddell, 2010), therefore principals had to show they were advocates for the community and act in politically astute ways. Teachers would leave due to a lack of vision and an influential culture being created (Petty et al., 2012; Watkins, 2005). If the principal did not get staff to buy in to gain their support, the principal may have also left due to political reasons by their choosing or someone else's (Levin \& Bradley, 2019). As Bolman and Deal (2013) noted, "Constructive politicians know how to fashion an agenda, map the political terrain, create a network of support, and negotiate with allies and adversaries" (p. 228). Through creating an intentionally inviting culture as mapped out by Purkey and Novak (2016) with having a social 
justice orientation (Theoharis, 2008) where a moral stance is taken, the inner-workings within the school building should have been one with opportunities for collaboration, recognizing the importance of long-term relationships and reflect the values and principals of the school principal (Bolman \& Deal, 2013). The environment can be one where the principal moves beyond compliance and handed down justification, but instead created the inviting culture (Purkey \& Novak, 2016) and moved in the opposite direction of being a manager who relied, "too much on reason and too little on the relationship (Bolman \& Deal, 2013; p. 218).

In the human resources frame, Bolman and Deal (2013) reminded us, "In organizations, it is argued that people's skills, attitude, energy, and commitment are vital resources that can make or break and enterprise" (p.121). Furthermore, they noted, "organizations exist to serve human needs" (p. 121). Public schools exist to meet the needs of their students and communities (Hattie, 2002), this need could be exacerbated even more in the low-income, high minority, lowachievement schools (Freedman \& Appleman, 2008, Kozol, 2004; Stotko et al., 2007). Each of the school leaders studied had shown a desire to serve populations of students and teachers through continuing to serve in the same schools year after year, and the reciprocal retention of teachers whom they believed were best for students. Their leadership styles were ones where they managed not by the carrot or the stick, but called forth people's talents to align with those of the school where they offered something that mattered and contributed to the greater good (Bolman \& Deal, 2013). In both schools, the school leaders knew there were schools within a few minutes-drive who could offer salaries much higher than they had, therefore they had to hire the right people and to keep employees rely upon the fact, "They don't have the attractive pay and benefits, but they can align to make them feel a part of something" (Bolman \& Deal, 2013, p.143). In alignment with the vision of invitational leadership as noted by Novak (2002, p. 3) 
"To encourage and sustain the sustaining the context in which imaginative acts of hope thrive," Bolman and Deal (2013) suggested success comes when the leaders, "Empower employees through providing information and support while encouraging autonomy and participation. They forgo allowing workers to work in isolation and instead come with a willingness of team decision making” (p. 164).

In the symbolic framework by Bolman and Deal (2013), "The frame of the leader is one who brings a diverse group of people in where the stories are kept, and the people are engaged through not only the work, but the rituals and spirits to reinforce the values of the work. The importance of creating a soul" (p. 282). Each hour of each day, there is evidence of the principals of each school working to engage the stakeholders of the school community through hosting of events, among other activities seen by others as a district-level leader advocating for not only their students but the students of others and engaging with external partners to help their schools become stronger.

\section{Leadership Analysis}

The year of 2020 had brought challenging health and economic circumstances with the COVID 19 pandemic, and the racial and additional economic civil unrest caused by the murder of George Floyd by the Minneapolis police (Burnette, 2020). This had resulted in subsequent discourse being played out in protests on the streets and the debate in the governing bodies on local, state, national, and international levels that had led to calls for shifting money away from the police to schools (Napolitano, 2020). The educational landscape may have evolved at a faster pace than ever before. It is widely contended that one in five teachers did not plan toreturn to their positions in the fall of 2020 (Page, 2020). That left schools with the highest financial resources, and most stabilized funding to have the ability to backfill positions in emergent 
situations while exacerbating the problem of high minority districts (Burnette, 2020) being left to rely on underqualified and uncertified teachers teaching subjects in which they have no background (Page, 2020). Thus, warranted is a culture where school principals will need to sell a vision of an internal coalition that will use their bases of influences to try to affect the behavior of the team of teachers in the school (Mintzberg, 2005).

\section{Invitational Leadership}

Bolman and Deal (2008) argued, "If people feel the organization is responsive to their needs and supportive of their personal goals, you can count on commitment and loyalty" (p. 331). In this current socio-political climate, high poverty, high minority schools need to effectively recruit and retain teachers in their building to build collective efficacy (Hattie, 2016). Martin and Miller (2017) contended, “...the use of aligning invitational leadership dimensions with the self-reflection and action of social justice leadership will allow for the enhancement of social justice leadership orientation within school settings" (p.199). With the pipeline for school principals facing a shortage (Levin \& Bradley, 2019), and the subsequent need for more teachers at an unprecedented precipice, there seemed to be a great need for "a framework combining the calls to the meaning the rituals and spirits to reinforce the values of the work" (Bolman \& Deal, 2013, p. 282). The soul of which Bolman and Deal spoke in their symbolic frame becomes active within invitational leadership in every aspect with the intentionality of the $5 \mathrm{P}$ 's that include:

People - $\quad$ People are the emissaries of the school. They create and maintain the environment where relationships must be built on a sense ofcollegiality. 
Places - $\quad$ The area that is often the easiest to change, the landscape and upkeep of the school can announce that inhabitants of the school are invited and welcomed.

Policies - A great influencer on how the school is perceived in relation tofairness, inclusivity, democracy, and respectfulness.

Programs - Formal or informal, the programs must work for the benefit of everyone where they reflect an invitational environment.

Processes - These must be created using a democratic process where the end users are involved in their creation and ongoing revisions creating an attitude of, "We are all in this together." (Novak \& Purkey, 2001, p. 19)

Being an invitational leader encompasses all aspects of one's life as the leader calls forth all around them to pursue a life of purpose when they "invite their colleagues, family, friends, loved ones, and community to do the same" (Purkey \& Siegel, 2003, p.3).

\section{Social Justice Leadership}

Bogotch (2002) set the stage for what social justice leaders can be when he stated, "an individually-minded principal is often called a maverick; an individually-minded teacher leader is called a trouble-maker. Neither are included under the banner of loyalty to the system" (p.6). Social justice leaders advocate for their young people. When the principal of School A shared a message from an outside funder from the tech companies of Silicon Valley that his students were going to need to be prepared with the technological and collaboration skills of tomorrow, he shot back,

I can have our teachers help them learn to make the technology sing, but what I cannot do is make them White. Please send the message back that I need for Silicon Valley to hire 
our students who possess the skills required while accepting them for their authentic selves (Personal Conversation with Researcher, September 2019).

His statement underscored the need for having people in leadership who not only had their teachers' backs but are unafraid to push back against negativity and racial microaggressions of their stakeholders and advocate on behalf of their students of color when others will not.

When the principal of School B, a Black woman who is known for her challenging of the system in the name of what is best for her students and students from similar situations like hers, spoke out at a professional development training she was encouraged by the presenter to keep pushing. She was tabbed as a "disagreeable giver." She wore the title as a badge of honor.

Capper et al. (2006) called for the preparation of leaders for social justice to continue to develop and test ways to build the knowledge, skills, and dispositions that, “...brings forth the leaders' moral obligations to create the languages, the relationships, and the place for dialogue toward overcoming the harms done when educators remain silent about color and culture (2006; p. 10). Capacity building of leaders is possible with the use of equity audits, a useful tool in the guidance of finding a school's equity challenge (Capper et al., 2006).

Subsequently, Theoharis (2008, p. 13) conveyed the following leadership traits were evident in Principals following the ethos of social justice leadership.

1. Arrogant humility: Leaders hold a headstrong belief that they are the right person to lead the team toward the vision of social justice for the students and families they serve while paradoxically being filled with self-doubt. They are humble enough to know after self-reflection when they need to admit when they are wrong. They wonder if they indeed are the right person for the role of principal. 
2. Passionate visionary leadership: These social justice principals stand as transformational leaders who are driven by such deep care, commitment, and enthusiasm toward championing a strong vision. These components become realized in such a passion that there is a tightly interwoven connection between the principal position and the person doing that job.

3. Tenacious commitment to justice: The leader maintains a fierce and sustaining commitment to equity and justice not only for their staff but also forthemselves.

In a time of educational inequities, social justice leadership is an inclusive leadership that engages relationships not only in dialogical, collaborative, reciprocal, and horizontal ways; they also promote equity and justice through caring fluid relationships among various leaders (Wang, 2018).

\section{Implications for Research in the Practitioner Setting}

We are amidst a crisis in the pipeline for high-poverty, high-minority, high-need urban high schools for the last twenty years (Ingersol, 2001; Ng, 2003; Sutcher et al. 2016). Teacher turnover harms student achievement (Hattie, 2016; Ronfeldt, et al., 2013). The need is great to keep good teachers and not just overfill the pipeline with short-term fixes (Ingersoll \& Smith, 2003; Podolsky et al., 2016). Preparation programs have studied what they can do to get teachers ready (Ingersol, et al., 2001, 2012; Waddell \& Ukpokodu, 2012). Likewise, creating networks with colleagues can make a difference in a teacher's decision to stay or go in a school (Kardos et al., 2001; Yonezawa et al., 2011; Waddell, 2010; Williams, 2013). There are promising strategies for attracting and retaining successful urban teachers (Freedman \& Appleman, 2008; Greenlee \& Brown, 2009; Hughes, 2012; Petty et al., 2012; Podolsky et al., 2016; Simon \& Johnson, 2015; Stotko, et. al., 2006; Waddell, 2010). A principal can make a difference in the culture of a school 
to the point where it is a place where teachers want to come to teach while accepting an invitation to come back year over year in the process of reciprocal retention (Bartanen, et. al., 2019; Burkhauser, 2016; Grissom, 2011; Watkins, 2006). Unfortunately, principals are turning over at a rate surpassing the rate of teacher turnover (Bartanen et. al., 2019; Levin \& Bradley, 2019).

The reality was that there were schools that have leaders who were intentionally inviting teachers into their schools in low-income, high-minority, high needs, urban high schools where the principal and the teachers were staying. Through qualitative examination of two high schools over 2,000 miles apart in urban centers in the United States, the focus of this inquiry was finding a blueprint for school principals of these kinds of schools. The researcher sought to discover if there was a connection between the principal's actions of aligning the principles of invitational leadership dimensions with the self-reflection and actions of a social justice leadership to the reasons for the reciprocal retention of teachers.

\section{Summary}

Teachers need to be recruited, supported, and retained in high-poverty, high-minority, high-needs, urban high schools (Freedman \& Appleman, 2008; Greenlee \& Brown, 2009; Hughes, 2012; Petty, et. al, 2012; Podolsky, et. al., 2016; Simon \& Johnson, 2015; Stotko, et. al., 2006; Waddell, 2010). In a time when inequities are being exacerbated in the field of education, the principals and the teachers will be called upon to do more with less (Page, 2020). Empowerment of school principals who are willing to take on the schools that are the most challenging (Bartanen, 2019; Levin \& Bradley, 2019) is needed. They must to be trained to demonstrate leadership dimensions and supporting actions (Martin \& Miller, 2017) that can guide them to build a team of team of irreplaceable teachers (The Irreplaceables, 2012), which 
will build collective efficacy (Hattie, 2016) to help students furthest from opportunity reach their high potential in academic and personal achievement. In the contention of Martin and Miller, (2017) aligning the dimensions of invitational leadership (Purkey \& Novak, 2016; Purkey \& Siegel, 2003) with action and self-reflection of social justice leadership for principal leadership was in need of further examination. 
SECTION THREE:

SCHOLARLY REVIEW FOR THE STUDY 


\section{Introduction}

Teaching is a stressful and challenging profession. Combine the high stakes accountability measures of the last nineteen years through No Child Left Behind (NCLB) and the testing culture that has become prevalent, an alarming number of teachers have become affected negatively to such pressure they change jobs. As a profession, either $14 \%$ of teachers migrate to other schools, or 9\% leave the profession entirely on a yearly basis (Shernoff, et. al., 2011). Compared to other professions, teaching has a high turnover rate. As many as $39 \%$ of people who start in the career of teaching leave the profession within the first five years (Ingersoll, 2001). While the level of stress is felt by many teachers, $46 \%$ experience a high level of daily stress. This, along with nursing, is the highest rate of all occupation groups (Metropolitan Life Survey, 2013). Yet, the percentage of schools offering stress management services to teachers has declined 10\% since 2000 to only 26\% (Center for Disease Control, 2015). Historically when the economy has struggled, the percentage of people gaining a teaching credential increased, nevertheless, after the Great Recession of 2008, this trend did not hold and the supply of teachers is low. Enrollment in teacher education programs nationally dropped 35\% from 691,000 to 451,000 (Sutcher et. al., 2016) from 2009 to 2014. While at the same time, demand for teachers has increased as the schools in low-poverty are reinstating classes eliminated during the Great Recession and pursuing lower teacher-pupil ratios to get back to pre-recession levels. It is projected in 2021 the United States demand for teachers will be above 300,000 while the supply will be below 200,000 (Podolsky et. al, 2016; Sutcher, et. al, 2016). This shortage will have the greatest effect on hard to staff schools in high-poverty rural and urban schools (Sutcher, et. al. 2016). 
In comparison to the general teaching population, the retention of teachers of underserved students is an even more of a challenge where up to one-half of the teachers leave within the first five years (Ingersoll, 2001). Hence, resources are already limited due to limited tax bases or family wealth of the students become even scarcer when funds shifted to recruiting, hiring and training a teaching faculty that is chronically revolving (Shernoff, et. al., 2011). In several studies (Greenlee \& Brown, 2009; Ingersoll, 2003; Ronfeldt, et. al., 2013) it has been shown that those schools who serve populations of high-minority students from urban, low socio-economic and low academic achievement backgrounds have higher rates of turnover than schools in more affluent, higher academic achieving predominantly White schools (Greenlee \& Brown, 2009; Ingersoll, 2003; Ronfeldt, et. al., 2013). In New York City middle schools, the attrition rate is so high that $66 \%$ of teachers exit in the first five years (Marinell, 2013). In Title 1 eligible schools (high poverty schools), the attrition rate of full-time teachers in 2012 was 55\% higher than lower-poverty schools (Bishop, Darling-Hammond, Kini, \& Poldolsky, 2016). In a national study of the 2013-14 academic year, there were four times as many uncertified teachers in high-minority schools (Sutcher, et. al., 2016).

Another challenge facing schools is an overwhelming $84 \%$ majority of the teaching population in the United States is White, while the student population is $47 \%$ students of color (Waddell \& Ukpolodu, 2012). Many of these teachers come from middle class backgrounds and their ability to relate to students becomes challenging (Fergus, 2017; Kozol, 2005). Emdin (2016) noted when White teachers try to impose their White culture on minority students, problems may arise:

As long as White middle-class teachers are recruited to schools occupied by urban youth of color, without any consideration of how they affirm and reestablish power dynamics 
that silence students, issues that plague urban education (like achievement gaps, suspension rates, and high teacher turnover) will persist. (p. 9)

Often, the high poverty schools do not have adequate classroom space, an equitable access to technology or other tangible teaching resources, or students who have had a rich educational experience (Grissom, 2011). Teacher pay becomes a great challenge for teachers to stay when they see that the best paid teachers in high poverty schools make $35 \%$ less than their same experienced peers in low poverty schools (Bishop, et. al., 2016). Estimates for the cost of retraining teachers range from $\$ 2.2$ billion annually (Borman \& Dowling, 2008) to $\$ 7.2$ billion (Barnes, Crowe, \& Schaefer, 2007). Without a consistent teaching faculty who understands the population they serve, the chances of success for the students in these impoverished urban centers are at greater risk of not achieving to their true capabilities (Haberman, 2004; Podolsky et. al, 2016).

The greatest variance in student achievement that is around 50\% (Hattie, 2003) is what the student will bring to the table themselves. Other variances include home environments at 5$10 \%$, school settings at 5-10\%, peers at 5-10\%. However, the third greatest variance is what the teacher knows, does, and cares about which is much higher at 30\% (Hattie, 2003). The teacher is the most important person in a child's education during a school year, therefore minimizing the turnover for teachers serving in high poverty schools is vital to young people in each of the K-12 levels (Hattie, 2003).

The purpose of this literature review was to explore what role school leadership can play in the recruitment and retention of teachers in low income, high minority, and high needs urban schools at the high school level. There is such a turnover rate that a Washington Post headline warned: "High Poverty schools often staffed by rotating substitutes" (Sutcher et. al, 2016; p. 8). 
Principals play a pivotal role in a school improvement plan that can take 5-7 years to achieve positive results (Fullan, 2015). If the team of teachers is consistently turning over, it will be extremely difficult for the capacity to enact such a plan, which prioritizes a principal's need to retain and develop quality teachers (Fullan, 2015; Watkins, 2005). Educators further need to investigate as to why the profession is losing teachers, and what have systems utilized to increase the chances of new teachers in high poverty schools staying in the profession at that same school. First, the existing research were examined deterring where the gaps exist in the literature, and then the extant literature will be reviewed, followed by the conceptual framework guiding the inquiry.

\section{Existing Gap in Literature}

A great deal of the research concerning teacher retention relies on extensive survey-based data that is quantitative in nature (Grissom, 2011; Sutcher, et. al., 2016). While the research shows attributes like shared leadership (Watkins, 2005) and the importance of collegial (Kardos, et. al., 2001; Podolsky et. al., 2016; Williams, 2013) mentoring relationships (Stotko, et. al. 2007; Waddell, 2010), there exists a gap in the literature of complementing qualitative research that will allow for more precise actions taken within the buildings where teachers stay (MooreJohnson \& Simon, 2015; Podolsky et. al., 2016). To further this, the researcher was unable to find qualitative research related specifically to teachers who stayed in the role of teacher in high poverty urban settings due to a specific leadership style. The research did reveal that teachers at the middle level leave at a higher rate (Brill \& McCartney, 2008), as do teachers in urban settings (Ingersoll, 2001; Shernoff et. al., 2011) and special education (Sutcher, et. al., 2016).

Furthermore, the research noted the positive difference that principals can make in the working conditions that encourage teachers to stay (Burhauser, 2016; Grissom, 2011). The more 
information known about effective practices of those successful in these settings, the greater chance these practices can implemented on a greater scale. Watkins (2005) suggested a principal encouraging teachers to take control, granting autonomy with clear guidance and expectations, involve them in decision making, and integrating them into a learning community enhances teacher retention. Consequently, reviewed is research (Ingersoll, 2001; Shernoff et. al., 2011) that identified the negative effects of turnover on students, the reasons teachers leave, who needs to be recruited to the profession, how those who come need to be trained in pre-service. Along with actions the primary professionals of the principals, mentor teachers and teachers themselves can take to be successful in their role as a school teacher in a high-poverty school over an extensive period.

Unfortunately, principals are leaving the schools at a faster rate than teachers, leaving behind a school where test scores fall and teacher turnover increases in the in both the first and second years following a principal transition (Bartanen et. al., 2019). After the two years, the student scores begin to rebound leading Bartanen, et. al., (2019) to make the argument that keeping a developing principal may be of greater benefit to student achievement than replacing them with another principal, who often has less experience than the principal who is being replaced. Fullan (2015) argued that it would take 5-7 years for a principal to lead a school improvement plan to positive results. Of the 252 influences on student achievement, Hattie's (2016) meta-studies produced that collective teacher efficacy is the number one factor. Burhauser (2016) argued, “...schools with teacher turnover should assess climate and use that information to advise and support principals" (p. 13). Students also benefit from consistency of the teacher (Podolsky, et. al. 2016) and the principal (Bartanen, 2019; Burkhauser, 2016; Grissom, 2011). 


\section{Review of the Extant Scholarship}

The extant research concerning teacher supply and demand revealed the demand is outpacing the supply, and could soon be at crisis level for the learning success of our students (Sutcher, et. al., 2016). The most vulnerable will be students in poverty, especially minority students (Ingersoll, 2001; Shernoff, et. al.; 2011, Sutcher, et. al, 2016). Discussed in the following section are the negative effects of teacher attrition.

\section{Negative Effects of Teacher Turnover}

Teacher turnover is harmful to student achievement in general (Ingersol, 2001), however, concerning math and ELA, "the negative effect of teacher turnover on student achievement was larger in schools with higher proportions of low achieving Black students" (Ronfeldt, Loeb \& Wycoff., 2013, p. 250). Unfortunately, the teachers who the students may need the most, ones with strong academic backgrounds, holders of graduate degrees, and score high on standardized tests of achievement themselves are often the first to leave (Hughes, 2012; Shernoff, et. al., 2011). Cost estimates for the recruiting and retraining of teachers range from $\$ 2.36$ billion annually (Borman \& Dowling, 2008) to an estimate of $\$ 7.34$ billion (Barnes, Crowe, \& Schaefer, 2007). Moreover, the opportunity to build the needed professional capital of teachers that would have historical context of the school, community, and students is not there from year to year; therefore, a majority new staff of each building consistently reinvents what the school will do to serve that year's cohort of students (Hargreaves \& Fullan, 2012). As a result, often there would not be anyone there to mentor the new teachers, as they all would be new perpetuating the vicious cycle of getting a few years teaching experience before moving on to a school that has higher income with a stronger organizational structure (Ingersoll \& Smith, 2003). 
Consequently, the administrations of these schools are pressured with disciplinary action for low student achievement on standardized tests (Simon \& Johnson, 2015). Additionally, administrators face being removed from their position, only to be replaced by another principal with limited experience due to low student achievement (Bartanen, 2019; Samuels, 2012). When those schools hired new principals, they usually continued to underperform in the first two years (Bartanen, 2019; Samuels, 2012). The cohesiveness needed for success among the families, teachers and students is not attained, as the necessary relationships can never be built (Ingersoll, 2001; Simon \& Johnson, 2015; Podolsky, et. al, 2016) in such a short time. Subsequently, the research confirmed the student achievement in teachers' classrooms that stay in schools with high-turnover is also harmed ((Freedman \& Appleman, 2008; Greenlee \& Brown, 2009; Hughes, 2012; Petty, et. al, 2012; Podolsky, et. al., 2016; Ronfeldt, et. al., 2013; Simon \& Johnson, 2015; Stotko, et. al., 2006; Waddell, 2010).

\section{The Reasons for Leaving}

The National Comprehensive Center for Teacher Quality (NCCTQ, 2007) working in partnership with the Midwest Regional Education Laboratory conducted a survey with 642 first year teachers in high school and middle school. The results highlighted the heightened level of frustration that teachers had with finding the profession not to be what they truly wanted to be doing, low student motivation, or not believing that all children can learn when compared to their elementary teaching counterparts. Furthermore, teachers felt a lack of support from their peer teachers in lesson planning and teaching, were worn down by the lack of unmotivated and disruptive students, and they were lacking in how to best support students with special needs (NCCTQ, 2007). The report further went on to elaborate the disparity of those first-year teachers who were working in high needs schools where more than half of the students received free or 
reduced lunch. When compared to their peers in more affluent schools, the teachers in high needs school were more likely to feel that they had the children who were the hardest to reach, lacked training in how to communicate with parents and had administrations that were not strong in providing instructional leadership (NCCTQ, 2007).

Another reason for leaving is new teachers are often placed in the schools that are hard to staff, located in urban centers where there is high-poverty, and where many of the students' basic needs are not being met (Shernoff et. al., 2011). Feeling unable to meet these needs of their students, one-third to one-half of these teachers leaves the profession in their first five years (Ingersoll, 2001). Borman and Dowling (2008) noted that these new teachers are given the most difficult assignments, do not get the same level of resources as veteran teachers, and feel generally isolated from other teachers. Other researchers (Greenlee \& Brown, 2009; Haberman, 2004; Ingersoll, 2003) have identified common factors referenced for leaving are student discipline, administrative support, heavy workload and lack of autonomy.

In urban schools, heightened rates of stress result from lack of parental involvement, actions of students, lack of motivation, and low academic achievement leading teachers to question their choice to enter the profession (Hughes, 2012). Those who are leaving at the highest rates include White women, with higher scores on college admission exams, with master's degrees, and those who have not built professional capital in their first few years teaching (Borman \& Dowling, 2008). Coupled with the challenges presented earlier, middle school teachers leave at a higher rate due to the challenges associated with adolescence (Brill \& McCartney, 2008).

Simon and Johnson (2015) further posited these teachers who leave these high needs schools and yet stay in the profession usually transfer to schools serving wealthier, Whiter 
student populations where they perceive there to be a stronger organization with better school leadership, collegial relationships among the staff, and a more positive school culture.

Conversely, Hughes (2012) found a greater number of teachers teaching student populations of low socio-economic status (SES) were planning to teach until retirement. Thus, although SES was the only factor in the study, extrapolating if the right people are found and supported, they may be willing to stay.

\section{Who needs to be recruited to the Profession?}

The main motivators for people choosing to teach middle school are related to student age, content level, and the employment market (Radcliffe \& Mandeville, 2007). The teachers believe the students are ready to learn at a mature level while building relationships with both the teachers and the content (Radcliffe \& Mandeville). Furthermore, many middle level teachers who accepted the job due to the more open job market are not staying long enough to gain an understanding of who are the students they serve (Brill \& McCartney, 2008). With a shortage of teachers who are entering teacher preparatory programs, coupled with the increased demand for teachers, areas that were already difficult to staff are on the path to become even more challenging (Sutcher et. al., 2016).

Concerning urban education Haberman (2004) indicated that the selection of teachers is even more important than training. He outlined the qualities needed in urban teachers referred to as, "mid-range functions." There are seven mid-range functions Haberman believes can be assessed in interviews include: persistence, protecting students' learning, putting theory into practice, approach to at-risk students, professional versus personal orientation, attitude toward burnout, and fallibility. Conversely, there are seven functions not easily assessed including emotional and physical stamina, organizational ability, how to effectively plan, coaching, 
commitment to students with special needs, interaction with parents and community, and the ability to create student ownership (Haberman, 2004). The awareness level of these attributes can be an indicator to how successful a teacher will be in urban high needs settings. The key attributes of a successful urban teacher have been narrowed to sociocultural awareness, contextual interpersonal skills, self-understanding, risk taking and efficacy (Sachs, 2004). Kunjufu (2002) argued for effective urban teachers to become coaches when stating:

Coaches understand the child and their neighborhood and provide complementary curriculum and pedagogy. They are less concerned about discipline and order and more concerned about creating lesson plans that excite and engage students. Star teachers convince students that effort is more important than ability. (p.47)

Dweck, (2006) echoed this call for educators to believe in the possibility of their own work and the work of the student through effort as noted:

When teachers are judging them, students will sabotage the teacher by not trying. But when students understand school is for them - a way for them to grow their minds - they do not insist on sabotaging themselves. (p. 201)

The teachers cannot allow themselves to fall into the pattern that many do of allowing early setbacks to put them on a path of investing less effort, becoming more critical of students and avoid trying new strategies (Shernoff, et.al, 2011). They instead may need to focus on the needed attributes of an effective urban teacher as researched by Sachs (2004) such as sociocultural awareness, contextual interpersonal skills, self-understanding, risk taking and efficacy.

\section{Preparation before the Teacher Sets Foot in the Classroom}

Teacher education programs have shown the ability to train teachers in urban specific programs that will guide the teachers to see urban teaching as a destination. One example was 
the experience of the 2002 cohort of the Multicultural Urban Secondary English (MUSE) program at the University of California, Berkeley where the teachers stayed in urban education at a $73 \%$ rate versus $54 \%$ rate nationally. A similar program at Center X at the University of California, Los Angeles had very similar results (Freedman \& Appleman, 2008). These numbers are also not limited to California, as the University of Missouri, Kansas City's Urban Teacher Education Program (UTEP) had 94\% of their students earn teaching assignments upon graduation, and 88\% remained in teaching beyond their first year (Waddell \& Ukpokodu, 2012). Lee et al. (2010) identified effective training methods that will support pre-service teachers in their preparation to have urban teaching as a long-term career. These include finding candidates with a willingness to explore urban education as a possibility, explore their attitudes to diversity and multiculturalism, and increase their efficacy in working with urban students. Several strategies enhance this focus. Programs can extend their time in the field by partnering with effective practicing master teachers and having frequent (weekly) observations with university supervisors while collaborating in intensive curriculum development with written feedback. And importantly, having the hard discussions that can become heated and uncomfortable yet allow students to process the challenging parts of the field (Freedman \& Appleman, 2008). Teacher preparation programs can also focus on recruiting students of color with urban life experiences. Build partnerships with the community to become communityminded and having culturally relevant teachers committed to social justice before placing them in partnering schools where they will have mentors, support, high expectations, and extensive field experiences. At the same time, they are immersed in urban education (Waddell \& Ukpokodu, 2012). 
The University of Chicago's Urban Teacher Program takes the approach of working with the public schools of their city to create a pre-service teacher training that involves the essential knowledge a practicing teacher would need including, but not limited to the community and neighborhood histories, district curricula and policies that must inform teaching and learning (Matsko \& Hammerness, 2014). The common thread among these researched programs is getting the pre-service teachers engaged in the kinds of urban, high-poverty schools where they will work.

Although it is clear these teacher education programs focused on urban education are having high levels of success, the supply side does not appear to be significant enough for the need. UTEP in Kansas City, MO, only has 12 to 18 students joining their cohorts each year (Waddell \& Ukpokodu, 2012) in a city where over 23,000 students are going to public district and charter district schools that are considered high needs urban (MO DESE, 2015). In the state of Illinois in 2008, one of every four students lived in the eight largest cities, where not one of the districts made the expected annual yearly progress. Two-thirds of these districts were lowincome (Lee et al., 2010). In contrast, Haberman's (2004) historical analysis of how many colleges and universities built their teacher education programs for rural White women where the education of White Anglo-Saxon protestant children was the focus. Lee et al. (2010) posited it would be beneficial for each state education department to question whether their teacher preparation programs are doing enough to prepare pre-service teachers to live and teach in urban schools.

Of deeper consideration, if teacher programs were examining their practices with a critical analysis toward preparing teachers for urban teaching, this may lessen the need for alternative certification programs. By Haberman's (2004) calculations, of the approximately 
1,250 traditional teacher education programs who prepare one-half million teachers, only $1.5 \%$ will be working in urban education three years later. The pipeline from teacher education programs at colleges and universities dropped 35\% between 2009 and 2014 (Sutcher, 2016). This has led to situations where urban schools need to lean of alternatively certified teachers, uncertified teachers or programs like Teach for America. In some parts of the United States, there are now as many teachers certified through alternative certification programs as there are in traditional programs (Humphrey et al., 2008).

Nonetheless, there is evidence that alternatively certified teachers leave at a higher rate than traditionally certified teachers $(\mathrm{Ng}, 2003)$. In the case of Teach for America, many see teaching as a time of service for two years, not as a profession where one can grow to see it as a career for years beyond (Heineke et al., 2014). With just a five-week training before being placed in a classroom, only $14.8 \%$ of Teach for America teachers start their fifth year in the same school as the initial placement (Donaldson \& Johnson, 2011).

The research further suggested those who have longer-term plans on teaching and who have taken education courses in college rather than going through a fast track program are more prepared and stay in the profession longer (Donaldson \& Johnson, 2011). Lee et al., (2010) argued if more traditional teacher programs valued diversity by increasing investment in training of pre-service teacher preparation programs explicitly targeted to urban teaching by denoting: Then as future teachers gain experience with personal and analytical understandings of ethnic, racial, socioeconomic, gender, sexual, linguistic, religious, and other forms of human diversity, they will become more skilled in how to negotiate, critique, and address the societal implications of identity issues within diverse settings. (p. 114) 
The implications of this could be that teachers who have had pedagogical training could be more prepared for urban settings, and the level of need on the supply side would be diminished (Ingersoll \& Smith, 2003).

\section{Importance of Retention}

For teachers to be effective, the debate often centers on knowing what to teach and how to teach it (Ingersoll et al., 2012). Consistency in a teaching staff not only saves a school financial expenditure associated with retraining but can also lead to organizational stability (Shernoff et al., 2011). Perhaps the answer may be more in understanding how to retain the teachers (Ingersoll, 2003) and more importantly how to reverse the trend of the teachers who are the ablest to increase student achievement being the most likely to leave (Borman \& Dowling, 2008; Shernoff et al., 2011). Simon and Johnson (2015) illustrated it is challenging to have an effective school when staffed by a higher ratio of less effective novice teachers. While, Stotkp et al., (2007) noted the challenge of disruptions in teaching assignments due to shifts in qualified staff to teach different classes and to lack the continuity to the level of relationships between teachers, students, families and community members that are needed for success (Yonezawa et al., 2011). In these schools, with such high turnover, it is difficult for those who stay. First, it is difficult to get the level of support that they need in professional development as the vast majority of professional development funds go to novice teachers to launch their careers. Additionally, the students do not trust the adults who will be there as long as students (Ronfeldt et al., 2013).

In the 2012 report, The Irreplaceables, it is argued when a teacher who is helping students make more than the average expected gain leaves a school, it can take up to eleven replacements to find another teacher who can emulate such results. The report goes on to argue 
that the best way for low performing schools to break cycles of failure and earn respect for the teaching profession is to provide further value to the irreplaceable teachers than the low performers (TNTP.org, 2012). Just as it has been in other professions aspiring to excel, schools need to get the right people on the bus in the right seat (Collins, 2001).

\section{Organizational Characteristics}

The focuses of the previous studies have often been on the teachers or the students, whereas the following will argue that greater emphasis should be school context. Urban schools serving underprivileged populations are often plagued by a myriad of conditions including, disruptive behaviors of students, lack of student motivation; lack of the necessary supplies of books, desks, and safe physical plants, larger class sizes; lack of effective mentors, lack of highly qualified staff; lower salaries, or new administration (Haberman, 2005; Simon et al., 2015). Yet with all despite these challenges, Petty et al. (2012) confirmed with a specific focus, teachers could be retained in these hard to staff, urban, underserved high schools with limited costs. The focus could be creating a culture of caring administrators with a supportive administration and a positive school environment (Petty et al., 2012). Moreover, it could be setting up transparent systems where they are active parts of professional learning communities with coaches and mentors learning with them (Shernoff et al., 2011; Williams, 2013). Furthermore, Watkins (2005) postulated creating a robust induction and retention program centered on the components of intense mentoring and coaching, along with action research and study groups.

\section{Role of the Administration}

Teachers stay in schools where they have strong leadership and coworkers who support them (Heineke et al., 2014). Principals may be even more critical in high poverty schools as researchers (Grissom, 2011; Waddell, 2012; Watkins, 2005) have argued a competent principal 
completely offset teacher turnover in disadvantaged schools. Collins (2001) highlighted a principal could be a great leader by putting people and relationships at the forefront of their work. Waddle (2010) further noted the principal could create the needed elements that have limited financial costs of valuing teachers, fostering relationships, and nurture the internal characteristics that generate a commitment to teaching in an urban school. By effectively using their time promoting the use of data, observations of teaching, strengthening school culture, developing leadership, and engaging with teachers in professional development (Fullan, 2015) the administration can transform the organization to one where administrators and teachers are seen as learners (Borman \& Dowling, 2008).

The administration needs to be effective in their management of the building and instruction, encourage leadership, and be inclusive in their decision-making as teachers seek leaders who have the managerial, social, instructional, and political skills that school leaders need for success (Simon \& Johnson, 2015). There cannot merely be mandates sent by administrators to teachers, but they must create time for collaborative time (Dufour, 1998; Kardos et al., 2001; Yonezawa, 2011). Not to be overlooked, administrators must hire early in the year, as too often, the urban schools are hiring in late July and early August when the strongest teaching candidates have already been hired leaving them with candidates who maynot have the right qualifications for the openings (Stotko et al., 2007). Similarly, when teachers have support from the administration, they are more likely to stay in the profession (Borman \& Dowling, 2008; Podolsky et al., 2016).

\section{Role of the Peer Teachers}

Kardos et al. (2001) revealed the influence of their teaching peers are integral to novice teachers' success. These peers can create collegial connections, faculty cohesiveness, and 
supportive community through the creation of an integrated professional culture where the novices are supported by their veteran counterparts but are also valued for their new ideas and willingness to learn in this professional culture (Kardos et al., 2001). Williams (2013) further noted teachers have a desire to work in teams and not by themselves. Experienced teachers can create an integrated professional culture where novices are assimilated in with the expectation that the responsibility for the well-being of the school, students, and one another is shared with experienced teachers and novices alike (Williams, 2013). It is a culture where novices are encouraged to seek help and expected to grow in their skills of teaching. Teachers who are teaching the same classes are sharing in their planning. Celebrated and shared are any special skills. The celebrations continue when success occurs even in the smallest forms (Podolsky et al., 2016; Williams, 2013).

Data are examined collaboratively with experienced and novice teachers in a culture where punitive action for the lower score does not occur but encouraged is a reflection at what is happening in the other class (Kardos \& Johnson, 2007). The relationships are horizontal, and the learning is shared (Dufour, 1998; Fullan, 2015). Sutcher, et al., (2016) highlighted,

...if a teacher receives basic mentoring, plus collaboration, a strong teacher network, and extra resources (a reduced number of preparation periods and a teacher's aide), first-year turnover (leaving school or profession) is cut by more than half, from $41 \%$ to $18 \%$. (p.

\section{4)}

However, instead of working toward this ideal, the educational system in the United States is headed in the opposite direction. The number of first-year teachers reporting that they had a mentor and periodic conversations with their principal dropped from $75 \%$ in 2008 to $59 \%$ in 2012, with only 2.5 having the level of support outlined above (Sutcher et al., 2016). 


\section{Role of the Teacher}

The novice teacher must be ready to learn about multiculturalism and about the demographic gap that may exist between teachers and students (Lee et al., 2010). As when transitioning into any group of new people, the teacher must seek to understand the language, standards, traditions, and goals in the profession and culture of the served community. They must have openness to learning throughout this time (Bruffee, 2002; Kardos et al. 2001). The research of Stotko et al. (2007) encouraged successful urban educators to achieve a variety of dispositions. They included knowing it is not easy to improve student learning; they must have persistence and not give up on their students. They should possess a willingness to modify pedagogy to meet the needs of their students while holding high standards, align their instruction to the state standards in a way to ensure students are learning the necessary concepts and skills, collaborate with other teachers, administrators, parents, students and leaders in their community and to model being learners themselves (Stotko et al., 2007).

\section{Conceptual Framework}

When exploring what leadership framework would be the most suitable theory for the immediate, practical solutions to training high school leaders in high poverty urban schools, considered were Critical Race Theory (CRT), Servant Leadership Theory (SLT), Social Justice Leadership Theory (SJLT) and Invitational Leadership Theory.

Although the teaching population is predominantly white, it is often through urban schools where people from all backgrounds will try to begin their teaching career (Haberman, 
2005; Howard, 2006; Waddell \& Ukpokodu, 2012). Yet, the highest rates of turnover occur in urban schools (Howard, 2006). With the teacher having the third strongest variance on student achievement level, it is imperative to have effective teachers with the students with the greatest need (Hattie, 2003). Often, "educators have misconceptions about their students that affect relationships and lead to deficit thinking and inequitable practices" (Furman, 2012, p. 207). Needed is a principal who can lead from a stance of development of all stakeholders is required.

Considered for this paper due to the public schooling system in the United States viewed as racially segregated was Critical Race Theory (CRT). Fergus (2017) argued the work of desegregation had not been sustained due to hiring practices in the teaching profession after integration forcing people of color to entrust the education of their children to White teachers who had previously lived, worked, and socialized separately from Blacks. School leaders who come from a different social identity other than the communities in which they serve may also come with, "a range of bias-based beliefs based on these social identities: beliefs such as deficit thinking, color blindness, and poverty disciplining” (Fergus, 2017, p. 2).

Critical Race Theory (CRT) foundationally could be argued reach as far back as 1903 in W.E.B DuBois's work The Soul of Black Folk then intensified in the scholarship of Derrick Bell, Alan Freeman, Richard Delgado, Jean Stefanic and Gloria Ladson-Billings that took place from the 1970s to the early 1990s (Capper, 2015; Santamaria 2013). In the latter part of the 1990s, its use in educational research was a theoretical, methodological, and analytical framework (Capper, 2015; Santamaria, 2013). According to Rector-Aranda (2016), the critical tenants of CRT in education are threefold, racism is normal, whiteness as property, and interest convergence. 
The fundamental principles of CRT frame a perspective on white dominance and race relations that rejects the usual discourses of objectivity, neutrality, color-blindness, meritocracy, and equality under the law (Rector-Aranda, 2016).

It is of significant importance for school leaders to understand how race and equity play into their ability to have a clear perspective on these attributes outlined by Rector-Aranda (2016) and be aware of what implicit biases they may have if they are to help students from marginalized populations succeed (Fergus, 2017). However, in the goal to entice teachers to come to join the school for the mission, a more encompassing theory is needed in the examination of the complexities of teacher retention and principal leadership in urban settings.

\section{Servant Leadership}

As on focus of an urban principal is to be a leader in the community where they serve, servant leadership is a theory that was naturally under consideration. The term coined by Greenleaf (1970) explored how leaders can better serve society (Northouse, 2013). The theory encouraged that leaders must engage and value the communities in which they serve to build trust, respect, interdependence, and individual growth (Northhouse, 2013). Spears (2002) would then go on to build upon Greenleaf's work to identify ten characteristics of being a servant leader that included: listening, empathy, healing, awareness, persuasion, conceptualization, foresight, stewardship, commitment to the growth of people, and building community. Taylor, Martin, Hutchinson, and Jinks (2007) noted that servant leaders should have a new perspective of leadership should be that of a steward, servant, and, perhaps, even sage to followers (p.417).

Servant leadership works well for the followers who believe in it and want to have this kind of close relationship with their superior; however, others equate servant leaders as trying to micromanage and do not desire to expose themselves to the person in a supervisory role 
(Northouse, 2013, p. 227). The quality of administrative support is often the top reason for staying in school and the overall profession. (Podlosky et al., 2016). Teachers are looking for emotional, environmental, and instructional support in an age where accountability systems are driving up to $25 \%$ of the non-retiring teachers out of the profession. (Podlosky et al., 2016, p. 44). Other leadership theories may better serve this need beyond that of servant leadership (Northouse, 2013).

\section{Social Justice Leadership}

Social justice leadership theory in this research (Theoharis, 2007) will be used as a broad overarching theory as it needs to be developed throughout the urban high poverty, high minority, high school building. A majority of urban school settings are racially and socioeconomically divided, creating a need for more open communications (Furman, 2012). As Martin Luther King, Jr. (1962) stated in his speech at Grinnell College in Iowa:

I am convinced that men hate each other because they fear each other. They fear each other because they don't know each other, and they don't know each other because they don't communicate with each other, and they don't communicate with each other because they are separated from each other (King, website).

Unfortunately, there continues to be a rift 57 years later where there is a need for a radical change, "in the ways in which we (academics) study, partner with, serve, and understand those in urban communities" (Milner, 2015, p. 135). As argued by Shann (1998), urban schoolteachers must have relationships with their students when it came to their commitment and job satisfaction, "Teacher-pupil relationships ranked the highest overall in terms of importance and satisfaction" (p. 67). In this time, the proportion of White females teaching Black, Latino, and Native American students has increased while Black and Latino students today are primarily 
attending schools with only Black and Latino students (Fergus, 2019). Therefore, teachers in these schools need leaders grounded in social justice, as defined by Theoharis (2007). The latter, "make issues of race, class, gender, disability, sexual orientation, and other historically and currently marginalizing conditions in the United States central to their advocacy, leadership, practice and vision" (p.223). Developing these capacities is the five dimensions for social justice leadership, including the personal, interpersonal, communal, systemic, and ecological dimensions (Furman, 2012).

Bogotch (2000) made the case that educational leaders must take a leadership stance grounded in social justice when he prodded his readers:

...to acknowledge that educational leadership must continuously confront the issues of social justice in all its guises and to deliberately make social justice a central part of educational leadership discourse and actions while, at the same time, vigilantly critique such actions and motives such that when the material conditions change, we have to start all over again. (p. 2)

Furthermore, Santamaria (2014, p. 347) argued that a 2011 ruling by Supreme Court Justice Sonia Sotomayor that stated, "Inequality in education is the most pressing issue in diversity in the United States” contributes to, “...make educational equity and diversity mainstream issues for practitioners, scholars, and policymakers to consider." Social justice leadership is an inclusive leadership that engages relationships not only in dialogical, collaborative, reciprocal, and horizontal ways; they also promote equity and justice through caring fluid relationships among various leaders (Wang, 2018).

The researcher surmises that in a time of limited interest going into an undervalued profession, school leaders are left scrambling to entice qualified teachers to come to teach in 
their schools (Podolsky et al., 2016). At the same time, they are keeping the tenets of social justice leadership in the forefront of the leader's intentions, invitational leadership practices narrow to offer a more intentional framework that will allow both seasoned and novice school leaders to follow.

\section{Invitational Leadership}

Invitational Leadership calls for leaders to systematically call forth and sustain imaginative actions of hope while living a purposeful life (Novak \& Purkey, 2001). The leader will invite others through articulating a vision where others can join them in living an educational life at a school that is the most educationally inviting place in town (Novak, 2002). The invitational leader is not presented nor perceived that is put upon, but leadership that is a, "a doing-with process that sees participants as valuable, able and responsible partners" (Novak, 2002, p. 4)

Novak (2002) defined the principles of invitational leadership to be:

Care - $\quad$ Possessing full receptivity to the other through de-centering oneself and listening for interests and meaning expressed by the other.

Respect - Give the other person time to own their part of the relationship

Trust - $\quad$ Recognizes the interdependence of people while possessing confidence and predictability of others' abilities and integrity.

Optimism - Understanding that human potential is untapped, and there is a better chance of good things happening if there are a positive mindset and belief of others.

Intention - Leaders know the direction they are going while being proactive usinga variety of methods, yet self-correcting (p. 72). 
The principal can integrate these principles into his or her stance through ensuring the most intentionally inviting environment using what is known as the Five Ps: people, places, policies, programs, and processes (Novak \& Purkey, 2001, p.12). Educational leaders at the principal level have an opportunity to avoid limiting themselves to live in this inviting stance just at the professional level, yet inviting educational leadership calls forth, human potential in all areas of the leader's life in these domains. (Novak, 2002, p. 14; Novak \& Purkey, 2001, p. 16 - 19). Expressly, Novak, and Purkey (2001) referred to people as the emissaries of the school. They create and maintain an environment where relationships must be built on a sense of collegiality. While places are the easiest to change, the landscape and upkeep of the school can announce that inhabitants of the school are invited and welcomed. And policies are the influencer on how the school is perceived concerning fairness, inclusivity, democracy, and respectfulness. Formal or informal, are the programs must work for the benefit of everyone where they reflect an invitational environment. Finally, these must be created using a democratic process where the end-users are involved in their creation and ongoing revisions creating an attitude of, "We are all in this together" (Novak \& Purkey, 2001, p. 19).

\section{Conclusion}

A school is going to be effective when influential, highly qualified teachers are committed to the mission and vision of the school, along with the community and students it serves (Hattie, 2003; Ingersoll, 2001). Identified in the literature were findings that highlighted how urban high schools were dealing with a significant shortage of qualified teaching candidates (Ingersoll, 2015; Stotko et al. 2006; Sutcher et al., 2016). Too often, teachers use urban high schools as the opportunity to cross the threshold into the teaching profession only to leave for a job in a different teaching level (Radcliffe \& Mandeville, 2007). This high level of attrition 
leaves urban high schools having to replace their teaching staff at such a rate that the supply side cannot replenish in a sustainable way (Borman \& Dowling, 2008; Ingersoll \& Smith, 2003). These schools instead must rely on alternatively certified teachers, candidates from programs such as Teach for America, or uncertified teachers who have to leave the profession at a quicker rate than traditionally accredited teachers (Heineke et al. 2014; $\mathrm{Ng}, 2003$ ).

Consequently, the supply of teachers is not meeting the demand that we have in the United States. The schools that are being most negatively affected by this are those who are in high poverty communities (Sutcher, Carver-Thomas, \& Darling-Hammond, 2016). One of the effective ways to recruit and retain teachers is recognizing that a school leader can have a significant influence on the culture by creating an environment where teachers want to come to work and stay (Fergus, 2017; Haberman, 2002; Podolsky et al., 2016). The purpose of this study was to examine if high school principals at low-income, high-minority, high needs, and urban high schools retain an equal or higher rate of their teaching staff through the alignment of invitational leadership dimensions with the tenets social justice leadership (Martin \& Miller, 2017). 
SECTION FOUR:

CONTRIBUTION TO PRACTICE 


\section{Introduction}

In October of 2016 the projection was there the United States was going to be short over 112,000 teachers and among the school demographics expected to be most greatly affected were high-poverty, high-minority, high-needs urban schools (Podolsky, et al, 2016; Sutcher et al, 2016). Unfortunately, this dearth of prepared professionals is coupled with the lack of stability of school administrators staying at the same school more than two years (Levin \& Bradley, 2019) at a time where a successful cultural change within a school takes 5 - 7 years (Fullan, 2014).

Making the situation even more dire were the challenges within the profession in response to the Covid-19 global pandemic where 1 in 5 teachers were considering leaving the profession at the conclusion of the 2019-20 academic year (Page, 2020). Within the review of the literature, ideas were found that can support the recruitment and retention of teachers. Also found were tenets of invitational leadership with a social justice orientation. There was a gap in correlating a significant leadership theory that may be used as a guiding theory needed for principals of highpoverty, high-minority, and high-need urban high schools.

\section{Research Questions}

Within the context of this study using qualitative inquiry, the researcher seeks to answer the following research questions:

1. What tenets of invitational leadership are evident within the leadership style ofthe principal?

2. How do the tenets of the invitational leadership style of the principal impactthe retention of teachers within a high poverty school setting? 
3. What behaviors of the principal demonstrates the desire to act in the orientation of social justice?

4. How are the tenets of invitational leadership and the orientation of social justice displayed within the school community by the stakeholders (principal, teachers, and community)?

\section{Connection to Conceptual/Theoretical Framework}

The leadership framework theory allowed understand how a leader's practices can influence the people's level of commitment to the organization. Considered were several leadership theories for the conceptual framework: servant leadership theory (Northouse, 2013), critical race theory (Capper, 2015; Santamaria, 2013), social justice theory (Shields, 2004; Theorharis, 2007), and invitational leadership theory (Novak \& Purkey, 2001). It was of great importance for school leaders to understand how race and equity played into their ability to have a clear perspective on these attributes outlined by Rector-Aranda (2016) and be aware of what implicit biases they may have had if they were to help students from marginalized populations succeed (Fergus, 2017). Because of the need for an urban principal to be a leader in the community where they serve, servant leadership was naturally under consideration. The term coined by Greenleaf (1970) and further developed through his forty years of work at AT\&T explored how leaders can better serve society (Northouse, 2013). Greenleaf encouraged that leaders must engage and value the communities in which they serve to build trust, respect, interdependence, and individual growth (Northhouse, 2013).

Servant leadership worked well for the followers who believed in it and wanted to have this kind of close relationship with their superior. However, others equate servant leaders as trying to micromanage and did not desire to expose themselves to the person in a supervisory 
role (Northouse, 2013, p. 227). Teachers were looking for emotional, environmental, and instructional support in an age where accountability systems are driving up to $25 \%$ of the nonretiring teachers out of the profession. (Podlosky et al., 2016, p. 44). For these reasons, not considered as an appropriate fit for this inquiry, was servant leadership.

When further reviewing the literature to narrow the study to find an association between leadership practices and social justice, examined was critical race theory (CRT). The essential principle of CRT is a belief in white privilege and dominance that impacts race relations. This theory rejects the usual discourses of objectivity, neutrality, color-blindness, meritocracy, and equality under the law (Rector-Aranda, 2016). However, eliminated was critical race theory due to the purpose of this study to examine how to entice teachers to join a high poverty school for the mission and stay. The researcher believed there was a need for a more encompassing theory.

As stated by Martin and Miller (2017), "Undeniably, an inquiry has only begun to identify some of the issues, and challenges principals confront when they employ social justice leadership orientations in their school settings to create inviting environments" (p. 199). Furthermore, Martin and Miller (2017) argued that the self-reflective and action orientations of social justice leadership align with the dimensions of invitational leadership. Within this inquiry existed the contention that these practices combined had teachers believing they had joined a movement where they were changing lives for the better (Sinek, 2014), and a social justice leader using invitational practices was the leader who could create the sustaining culture where the team of teachers and community come together and stay together.

\section{Participants and Data Collection}

The locations of the study took place in two urban high schools. School A was a comprehensive high school of over 1300 students in the Silicon Valley area of California. School 
B was a magnet performing arts high school in a large midwestern city. The populations of the high schools and demographic data are shown in Table 1 below.

Table 1

Description of Participating High Schools

\begin{tabular}{|c|c|c|c|c|c|c|c|}
\hline \multirow[b]{2}{*}{ School } & \multicolumn{3}{|c|}{$\underline{\text { Students }}$} & \multicolumn{2}{|c|}{ Teacher } & \multicolumn{2}{|c|}{ Principal } \\
\hline & Enrollment & $\begin{array}{l}\text { Prevalent } \\
\text { Race }\end{array}$ & $\begin{array}{c}\text { Socio- } \\
\text { Economically } \\
\text { Disadvantaged }\end{array}$ & $\begin{array}{c}\text { Total } \\
\text { Teachers }\end{array}$ & $\begin{array}{l}\text { Average } \\
\text { Years } \\
\text { Experience }\end{array}$ & $\begin{array}{c}\text { Years at } \\
\text { Site }\end{array}$ & $\begin{array}{l}\text { Highest } \\
\text { Degree } \\
\text { Earned }\end{array}$ \\
\hline A & 1,388 & Latinx & $85.4 \%$ & 80 & 14 & 7 & Masters \\
\hline B & 400 & Black & $91 \%$ & 29 & 13 & 13 & Doctorate \\
\hline
\end{tabular}

The participants were chosen with the desire for maximum variation sampling using the snowball method (Merriam, 2009). The hour-long individual interview sessions started with the principal of each school before moving to other participants who were suggested by the principal or other participants. The qualifications included the desire of the principal to retain each participant on the staff or in a partnership with the school. While all staff members were involved with the school for at least five years, one community partner had been with the school for just two, but was allowed as he represented the public defender's office who had been working collaboratively with the school to decrease the disproportionate number of adolescents of color being adjudicated into the criminal justice system. The details of each participant are in Table 2. 
Table 2

Individual Interview Participants

\begin{tabular}{cccccl} 
Participant & Site & Gender & $\begin{array}{c}\text { Years in } \\
\text { Education }\end{array}$ & $\begin{array}{c}\text { Years in } \\
\text { Role }\end{array}$ & Role at School \\
\hline 1 & & & & & \\
2 & A & M & 23 & 13 & Principal \\
3 & A & F & 18 & 3 & Asst. Principal \\
4 & A & M & 7 & 4 & Support Services \\
5 & A & M & 8 & 4 & Counselor \\
6 & A & M & 16 & 6 & Principal's Sec. \\
7 & A & M & 7 & 4 & Student Advisor \\
8 & A & M & 9 & 3 & ELL Teacher \\
9 & A & M & 8 & 5 & Science Teacher \\
10 & A & M & 9 & 9 & Social Studies Teacher \\
11 & A & M & 13 & 13 & Gang Outreach Director \\
12 & A & M & 9 & 2 & Public Defender Attorney \\
13 & B & F & 20 & 7 & Principal \\
14 & B & M & 5 & 2 & Assistant Principal \\
15 & B & F & 16 & 12 & Instructional Coach \\
16 & B & F & 21 & 5 & Counselor \\
17 & B & F & 8 & 7 & Principal's Secretary \\
18 & B & M & 11 & 11 & Guitar Teacher \\
19 & B & F & 8 & 6 & English Teacher \\
20 & B & F & 9 & 9 & English Teacher \\
21 & B & M & 40 & 31 & Dance Teacher \\
22 & B & M & 9 & 9 & Social Science Teacher \\
& B & M & 10 & 7 & Math Teacher \\
\hline & & & & &
\end{tabular}

\section{Presentation of the Data}

The four research questions will be answered in this section with the presentation of the data gleaned from the examination of the student handbook and the school website of each of the schools as well as the analyzation of the interviews with the 22 participants. To analyze the data, the researcher transcribed and coded the interviews to find correlations between the actions of each principal adhering to the principles of invitational leadership theory while integrating social justice in high-poverty, high-minority, high-needs, urban high schools. 


\section{Research Question One}

What tenets of invitational leadership are evident within the leadership style of the principal?

In their work on invitational leadership, Purkey and Watson (2015) outlines five sections of invitational theory. For this research, the focus was on seeing this potential realized in the 5 P's of invitational leadership: people, places, programs, processes, and policies. The researcher had the respondents, including the principals themselves, respond to open ended questions regarding the level of how intentionally inviting the school leader's actions correlate.

\section{People}

The principal of School A has a background in the hotel industry. He had been a team leader in events that served as many as 22,000 people. The researcher had seen clear evidence how welcoming he was early in their work together. Upon the researcher's first visit, Principal A came out to introduce himself with a handshake and the assistant principal who would be the primary contact with whom the researcher would be working. He would continue on through the three-year relationship with the organization by ensuring that the organization was noted as one of the school partners on the school website, the organization's banner hung in front of the school, offering the school as a site for the organization to hold their training sessions, and being included in the school's yearly fundraising scholarship luncheon. Yet, he did not limit the intentionally inviting aspect to the organization, but to the individual as well by making time for a check-in for every visit, asking for input on school related situations to see what the researcher was seeing in other schools around the country, and making the connection to the city in which the researcher lived and Principal A's visits there. These actions led to the choice of Principal A as one of principal subjects upon whom the researcher would focus. 
Principal A believed the work that he and his staff do should always come from a place of service. He saw the school as being a place where education was a core purpose but had the small-town ethos where the school could be the hub to everything else. "When people come who need something, we see to get them what they need. We embed them in the work as we are always trying to create the communal effort to meet the need." While he identified as White, he was committed not just to coming into the community to serve, but to be of the community as evidenced by the connections that he made bringing in so many partners, being fluent in Spanish, and ensuring that he had translators for the families where Vietnamese may have had been the primary language.

The sentiments experienced by the researcher and put forth by Principal A were echoed by his team that they were all there to serve a need. It was repeatedly stated that the modeling of this practice started with Principal A. When one went to the school, a handshake should have been expected. The staff saw themselves as public servants who understood that they put value in cross-training, so they were able to give service in the quickest and most convenient way to the person needing help. Even when Principal A was in a meeting or on the path to do something else, he would take the time to acknowledge the person who needed support to address their needs immediately, set up a time to give support, or get them connected with the person who could best help. This was not only for adults, but every student in the building as well. Principal A could tell you the story of every student in his building. This was evidenced first-hand by the researcher in his visits to the school and echoed unprompted in seven of the ten interviews.

The staff and partners felt that this intentionality to see each individual supported and develop not only aimed at the students and external stakeholders, but themselves as well. A longtime teacher who had moved into the role as a student advisor shared that she had never seen 
another school where the school leader created such space for her to be who she wanted to be in such intentional support of students. It is common for Principal A to make time for any staff member with an open-door policy including in the middle of lunch. One colleague reflected, "He is so giving to all of us. It is not unlike him to offer half of the meal on his plate to the person in the room without food." A passionate committed teacher who had been run out of a school midyear, and voluntarily stepped away from another that lacked solid leadership was not seen as a threat by Principal A, but an asset. So much so, by her third year in the school she was the lead for the English Language Learner Academy. He did not want challenges to fester, but instead to collaboratively find solutions that would work for the person whom he was serving. When asked what else that the researcher should know about his leadership he pondered, "I have not been able to figure out how to engage the people who will not come through my open door." When the opportunity came to laud what he had accomplished; 16 staff members who had graduated from the school, a staff member so committed that she would drive an hour and a half each way, each day to be a part of the movement of support happening at the school, or families reaching out to him in times of crisis, he humbly focused upon whom he still needed to reach.

As the leader of a performing arts high school, Principal B, a Black woman in her midforties was known by the staff and students as being a triple-threat; she could dance, sing, and act. It was not unlike her to put herself out there with her students to either perform for the community alongside of them or create the space for her staff and students to shine. A visit to the school website was a place where one could see video of Principal B acknowledging there would be challenges ahead in this form of virtual learning during a pandemic only to be followed by a video of the teachers in the dance community are giving individualized attention to students all 
over the city through a virtual screen and a Stevie Wonder Tribute band made up of the school staff and alumni.

Principal B knew that her population of students and those drawn to teach them may be considered by many in mainstream thinking to be a bit different, even a bit "weird." However, Principal B wanted every one of her staff and students to know that they were encouraged to be their authentic selves. They should have come as they were and they would be supported at the school, her alma mater. She led by being herself with her vibrant personality where she acknowledged that she was outgoing, loved to be the life of the party who brought everyone in, while holding the right balance of getting done what needed to be done and having fun at the same time. One of the staff members interviewed who graduated with her in high school with her described her as being the same person in this way for the previous 25 years.

The balance also came in the ability to slow down enough to see each person in the building. The penultimate example of this was a literal, "I See You!" campaign where she announced to her principal peers at a district level meeting that they all needed to ensure that all 20,000 plus students were seen in the district during that academic year. She knew this deep within her soul as when she was in high school, her parents were dealing with addictions and the family bouts of homelessness, it was her teachers who saw her. The superintendent loved the idea and challenged her to go do something about it. Not one to back down as a "triple threat", she accepted the challenge only to humbly stand in front of her staff a few hours later to share with them what she did, and she needed help. The project resulted in the theme of the year being the "I See You!" campaign where students were met on the first day of the year with every staff member wearing the mantra and all 400 students consistently being seen throughout the year in a plethora of ways. 
The staff appreciated her ability to be present. She was a listener who was willing to go to bat for the team when edicts came down from the larger district. A department in the school had been ensuring culturally relevant pedagogy was being taught in their building to engage their students with relevant content. The district then came with a structured program that took away autonomy from the teachers. Principal B advocated for the teachers and the instruction in the building and they were able to continue with their instruction as they had been. When she realized that the challenges of primary and secondary trauma were heavily affecting her students and staff, having been a survivor herself, she created a "Peace Room" where the ambiance was set for meditation, praying, resting or whatever else was needed to gain the tools to be resilient and go about the educational, artistic, and community tasks at hand. The level of invitation at the school may have best been told by a 75-year-old teacher who pounded his desk in emphatic support as he shared his desire to teach at least 5 more years under Principal B's leadership.

She goes over and beyond to fight for the students and teachers for the exposure of what they need. You do it for sports, you can do it for performing arts. You know you are coming to a place where the arts are just as important as academics. This is your home away from home. A certain percentage of student that the children have makeshift homes. I used to wonder why kids did not want to go home. That is because these kids do not always have things at home. Some do not have food, social life, a mother, or father. She makes sure that what this place was for her, it is for them. They are exposed to new things and they are learning every day.

A district teacher of the year reflected on the level of professional trust and allocated resources: 
When a new teacher comes, they are given over to the team. It has to do with the trust that I feel from (Principal B). I stay for this reason. I was asked to lead a PD session with 10 teachers from the district. I saw other schools were being micromanaged. We are not the norm, but the exception. We are strong school and a strong department within the school. It is the little things. (Principal B) has our back. We had a PD day a few weeks into this year. We had a check in of how we are feeling. We became a bit negative. We felt overwhelmed. We are teaching 3 hours a day but spending 6-8 hours a day on paperwork. She asked, "Why do you think you have to do that. If you can tell me why you have a better use of your time, I will represent that voice at that the district level." If (Principal B) ever left, I would have to strongly consider jumping to a surrounding district that would allow me to have more financial resources.

A teacher who was so popular within the staff, he was mentioned in 6 of the 11interviews shared:

You could walk into many urban high schools and there is an attitude of the administration that the teacher hired had better figure it out or get out. That is not the case with (Principal B). There is a lightness of touch, a warmth and trust that is given until there is a reason not to. Before she came, it was not a warm welcoming place. The administration before was leading at a challenging time where the school may have needed to be shut down. It got turned around. Then (Principal B) came and it feels much more welcoming now.

The essence of Principal B's desire to be personally and professionally inviting to others did not stop at the building where she worked. She informed her staff it was the expectation that they work in the best interest of all students. She created a Facebook group for Black female 
educators to support one another in their growth, something that was noted that she may not have been willing to do earlier in her career. The day before the researcher interviewed Principal B, a book she had written was published. She wanted to share her journey and the lessons she had learned growing from a childhood impeded by the challenges of homelessness, sexual abuse, and drug abuse to moving from a substitute teacher to a principal in a six-year period to earning a doctorate that allows her to do the "heart work" to sustain as an urban high school principal.

\section{Places}

The researcher was familiar with both schools so descriptors in the interview were used to confirm some things that were already known, and new perspectives were added. School B allowed itself to be known in the community from with a painting of active performing arts student silhouettes immersed in the school's acronym that takes up half the three-story wall. The near one-hundred-year-old building, described by one staff member "as a disaster of a building," could have easily fell into self-induced squalor. However, as noted by Purkey and Novak (2015), "Even if a school building is ancient, it is still possible to create a clean, attractive, and inviting physical environment." (p.6) School B does just that. Due to district-wide safety policiesstudents and visitors do have to go through a metal detecting screening. In many schools people are met with a security officer barking directives, however it was noted by both the researcher and interviewees that the security officers were some of the most intentionally inviting people as they welcome each visitor to the school and direct them where to go next.

While sharing the right side of the building with another school that was focused on ROTC theme, if one walked left, they could get the feel that they were in an art gallery with a mixture of hung paintings, direct on the wall and lockers murals, and posters advertising upcoming or celebrating past events. One of the murals grew each year as each graduating class 
was allotted a space to leave their mark through their artwork. The main entrance to the building was adorned with the pre-COVID-19 theme of the "I See You" campaign as Principal B stated, "Even in these times, we want anyone who does come in our building to know they are seen." Amid other spaces within the halls were bully boxes where students could identify the need for support, data walls celebrated academic growth of students, and reminders in the unapologetic belief that as Principal B noted, "Some of the most talented students in the country go here."

The crown jewel of the building's structure is the state of the art performing arts theater. While it served as the home for performances that welcomed the community in for dance, singing, and strings performances, it was also proudly used by the area's most pre-eminent youth theater company. Of note, in a highly racially segregated school system, many of the youth performers from the enrichment theater company do not demographically mirror the students who attend the school. As noted by one of the staff members, "When the district wants to showcase programs or space, our school is often chosen."

School A was like many open-air California school grounds. There were not tight hallways, but classroom doors that opened to the outside air. Over the thirteen years that Principal A had been there, several bond measures had passed. Where it was once a school that was filled with 800 square foot classrooms that lacked windows, had lights that took several minutes to warm up to light the dark places, and void of any type of collaborative space, those same spaces had been transformed into buildings where classrooms were 1200 square feet, every 3 rooms had a common workspace for teachers, and windows adorn classrooms not only to the outside, but shared lights and vision between the rooms. The principal's administrative assistant described the transformation of the school that her own children attended, "I used to work in the 
bookroom that did not have a window, but instead had a cage, bars, and plexiglass. It gave me the feeling of being incarcerated when in there. All of those places are gone now."

The benefit of having a principal exceed the two-year average tenure at an urban high school (NASSP.org, 2020) like this was evident in this physical plant transformation that had happened with this school building. Where many schools will justify putting the money first into athletic fields, Principal A worked closely with the district to ensure that it would be prioritizing turning the academic classrooms into inviting learning space be the priority. The symbolism (Bolman \& Deal, 2008) of this commitment was magnified when the absolute last piece of construction to the primary physical plant was the administration building. During the time that upgrades were happening other places, the administrative team continued to work in the oldest building on campus, then moved into a backroom in the library during construction.

Notably for an urban school, the school did not have a security checkpoint that they had to pass through daily. Instead, they had staff posted at all entry points before and after school as well as during each passing period. Each time the researcher had gone to visit, he was met by a staff member welcoming him first before asking where he was looking to be directed. At the point of the entry into the office is where the bell must be rung, and the visitor's business stated before being welcomed in. Security also drives the campus on a regular basis.

While the school does have a multi-purpose room and a student run bookstore, the most welcoming place on campus may have been the library. This was the hub of where students gathered during the times before and after school, lunchtime, and other open periods. What was unique about what went on during this time as noted by a staff member is that students were not buried in their phones but buried in conversations with one another. The researcher and another 
observer visited during an observation and both noted the sense of the community that was created in that space and that around it.

The courtyards were also filled with motivational quotes and student created murals. Throughout these spaces there were flyers posted for opportunities for students to join in a variety of different programs, extra-curricular activities, and academic opportunities. Students had their areas of where they gathered and due to the consistency of where the adults gathered, they engaged in community with them as well. One staff member noted that when he coached, he would let his six and eight-year-old children roam freely on the campus. When he was once questioned by another staff member whether or not he should allow this he responded, "They are going to have to learn how to move about on their own and I can think of no place safer than I believe the culture of our campus to be.”

\section{Programs}

Programs were explored through the opportunities shared on the website as well as what the staff members shared through the interview process. The researcher found that programs were abundant to meet the needs of the diverse and high needs populations of their schools. While both schools were intentionally inviting, each of the two schools had its own distinct approach.

School A, led by their principal, had an approach that if the building was needed and the space was available the building was shared. The programs were run by the staff internally as well as external partners who needed the space. Principal A saw the physical space as a connection point for the supportive actions of the staff and the community members who had an aim to serve. He noted that while they had formal programs, they had even more informal ones. Families trusted the school so when there was a need, the school is where they went. Whether it 
was immigration issues, the need for food or Covid-19 testing, or a to skateboard around, the community saw it as a safe space to be.

When A became principal of the high school, the school was averaging $800-900$ suspensions per year. In the 2019-20 school year that number was down to just 22. Principal A shared that it took many supports from many different areas including mindset shifting with the staff and additional supports for students and their families as programs were integrated in to replace the harsh punishments of the zero tolerance policies that were inherited when Principal A came in. One of the programs included what will be referenced as the "Zip Code Program" where leaders in the school were working to eradicate the disproportionality of children of color being ensnared by the juvenile justice system. In the program they partnered with law enforcement, gang prevention program, and the public defender's office to offer students supports that would leave to behavioral adjustments that would lead to more positive outcomes. The school shifted away from citing low-level offenses. They worked with students to become justice involved by better understanding how to advocate for their needs with authority figures. The school also had mental health counselors who spoke the first language of the home, whether it was, Spanish or Vietnamese. As noted by the ELL teacher, "When so many of the students have trauma they were dealing with, it is made that much easier to confront when someone is helping in your first language." Every Thursday, a consistent attorney from the public defender's office was on campus for students to come ask questions that may pertain to them, a relative, ora friend of concern. The director of the gang intervention program started a handball league. Principal A and the director met with each gang, talked about what they needed, and were able to create a space where people put down their weapons and instead engaged in pro-social activities where northern and southern gangs challenged one another in a peaceful and respectful way. 
The staff took great pride in the unofficial programs within the school community. The grounds were described as a public park where the back fields have holes in the fences, yet those who use those thresholds are not chased away, rather reminded to take care of the space as they use it. Neighbors call the school if they see a student cutting a class. The school is host to flea markets, church, and "cafecitos" or "coffee talks" for the community to come in to meet with the school leadership. Alumni come back to school on a regular basis to join in on a class, support current students, or just to be present in the supportive space. Thirty to forty students came back each summer to support in the Summer Bridge Program for incoming first year students. Open spaces were used for voices to be heard and healing to occur after social injustices were taking place among them. On more than one occasion, fundraisers were held for the funerals of former students whose families came to Principal A for help after losing an alumnus too soon.

While Principal B aimed to ensure that programmatic opportunities were alsomaximized, she was a bit more selective in guiding the culture in who they were going to let in for program originating outside of the school. There were two things that she wanted to ensure were in place. The first was that their vision for the program they wanted in their school was going to be a benefit for her students and it was aligned with school's vision to accept all students for who they were and how they came to school each day. She knew that the students in her schoolwould fit in categories of, "otherness" in characteristics including, but not limited to race, sexuality, gender, personal appearance, socio-economic status. The programs were not going to be open to any outside entities who may come in judgement or to "influence students to be anyone other than their authentic selves." The second was working through the democratic ethos that the staff members believed that it was going to be good for their students. She noted to the researcher, "When your organization approached us, I needed to ask my team if this was a partnership that 
they believed was going to benefit our staff and students. Thankfully, they did. However, had they not, then (your program) would not have been here."

School B also ensured that they had programs to support the social-emotional health of their students who come from a community that regularly ranks in the top ten for violent crimes. They had a care team who handled referrals from staff or students for students who may have needed additional support. A male school leader was encouraged to start a club for male students who needed the same. The students who came to the invite skewed mostly being straight Black males who felt they did not have a place in the school. Principal B reflected that this left her White male students out and that the school would need to find a way to ensure those students had support in the school. A female group was also created as an affinity group to instill additional peer support and personal pride.

The programs that are the greatest lynchpin within the community are the performing arts programs. It was noted by several staff members that when their students were going to be performing there were people in the community, well beyond their family members, who madeit a point to attend. The talents of the students are on display whether are the dancers were performing in a theater, the guitar group at a community festival, or the painted artwork was shared at a local street fair. To excite other young people, the students from High School B regularly visited younger students in the district's elementary and middle schools. The emotional expressions of the students were shown through their art as exemplified by murals created in their community as another person of color was killed in their community. A very influential arts organization whose members were predominantly White, wanted to support the school financially by holding a fundraiser. While this was going to be great for their school as the $\$ 300$ tickets were going to raise a great deal of funds, Principal B let the organization know that 
attending such an event was going to be unattainable for the families of their students. "Our children were not even invited to eat at the dinner. I was ready to pull out.”

Several other programs were in existence to help get additional resources in the school. There was a trivia night, a book drive for the school without a full functioning library, and a partnership with a local church who found ways to help with the little things that were needed by the staff or students including winter coats for students and a coffee maker for the teachers. While there are these fundraisers in existence, there is still a need for even more funds to support their students. Yet, even with this need, it was made clear that Principal B and her staff were going to ensure that each program was the best for their students, no matter how much money was being brought to the table as she stated, "Our children are not going to be exploited."

\section{Processes}

In the tenets of invitational education, “.... a democratic ethos, collaborative and cooperative procedures, and continuous networking among teachers, students, staff, parents, and community should characterize the process that give life to the school (Purkey \& Novak, p. 23, 2015)." Each of the schools displayed a commitment to democracy and the feedback of stakeholders engaged in collective ownership of creating the way things are done at each of their schools.

At School B, students were encouraged to find the support they need to maximize their experience at their school. If they wanted to start a club, Principal B told them that they needed to find an adult sponsor in the school, and she would help them find the resources to make it happen. As a small school where arts are the focus, they did not have the resources for interscholastic sports, so the students worked with the school to have intramural sports in the school. Students who wanted to maximize their academic talents were encouraged to enroll in an 
Advanced Placement course. Unlike other schools, there were not processes that were designed to keep students out of harder classes, but instead designed to keep inviting them in. The challenge to this was the ability to find teachers in the math and science areas. At the quarterly talent show, students can select themselves to perform without a laborious try-outprocess.

Principal B worked with her teachers to ensure that they made decisions in the best interest of their students. Processes were evaluated collaboratively with the teachers including what classes should be offered, content resources that could be used as long as state standards were being met and academic skills being built, a book-room being started, student-support themes like the, "I See You" campaign, and what school partnerships should happen. "She (Principal B) is unafraid to advocate for her teachers and students and allow them to advocate for themselves." The evidence was consistent in the resources in the school being maximized.

At School A, processes are built to include rather than exclude as noted by one teacher, "Processes are set up to bring people in." Another teacher noted, "To a fault, he (Principal A) runs under a democratic process. He really values feedback from multiple groups before he moves on." Referenced as evidence of this was a program that would have allowed for greater technology in the building. It seemed clear to the teacher who shared the story that Principal A wanted to bring the program in. The teacher wanted it. Yet, when the staff voted, there were not enough votes that would lead to staff ownership of the new system. It did not go through.

While stakeholders knew that there was a line of command, they also recognized they were encouraged to advocate for what they believed to be right for students. Principal A said of his mindset regarding processes, "We need to open doors, open access, then use relationships." The evidence of the principal's open door came through the voices of most interviewed, most succinctly summarized by a staff member who shared, "People know there is a line of command. 
Whether teachers or students, they know they will be listened to when they are advocating for themselves. There is something about that, that seems so empowering to me."

Examples of processes being followed to get things started for which they advocated included the "Zip Code Project" that brought together the school, the police, anti-gang organizations, and community groups to keep young people from getting ensnared in the criminal justice system; restorative practices replacing punitive practices; getting an in-school academy created for English language learning students in just three years; teachers being able to offer a class if they got enough students and the content could fit into the requirements of the state; grant money found to pay teachers to start clubs; created a school response to support Black students and students of color in response to the killing of George Floyd. As noted by one respondent, "He (Principal A) is not the only one who comes up with all of the ideas, however if someone can show why it is good for our students, he will do everything he can to support it to become part of our school."

\section{Policies}

Most significantly studied was the mission and vision of the schools to draw the correlation between what the mission espoused was to happen at each school and what those participating in the shared.

School A's mission statement read as follows:

(High School A's) mission is to provide a safe, caring learning environment where students achieve the academic, aesthetic, personal and social development required to continue learning, pursue post-secondary education, compete in a changing job market, and participate in a multicultural democratic society.

The reflections of the staff aligned with that the policies "... are set up to bring people in." 
They referenced the use of restorative practices over zero-tolerance; the ability to enroll in advanced academic courses over gate-keeping for the perceived elite students; grading practices not locked in mantras of "this is the way we have always done it," but instead reflecting upon how to create an anti-racist grading system; facilities being shared rather than held back due to bureaucratic paperwork; and most importantly was the unofficial open-door policy of the administration. The "safe, caring learning environment" that will lead to options in an everchanging world was apparent throughout the research.

School B's mission statement reads as follows:

Our Mission: (School B) High School creates an environment where students receive an exemplary academic and artistic education that showcases their talents and preparesthem to meet the challenges of our dynamic global society.

Our Vision: The vision of (High School B) is to raise to the highest level possible the academic and artistic achievements of all its students. The educational program is designed to create a nurturing environment where students receive quality academic and artistic education that prepares them to compete successfully at the post-secondary level or to perform competently in the world of work. In addition to the development of academic and artistic knowledge and skills, students will be provided an environment where they learn to communicate effectively, enhance their physical and emotional wellbeing, acquire a passion for life-long learning and demonstrate the ability to do critical thinking and be creative.

It was apparent there was a necessity for strong policies during the previous administration who was trying to get the school back from the brink of closure due to a lack of success. Several participants in the study believed that they were needed at the time, however that culture had made a shift for the better. The attitude toward policies of the staff was best summarized by a teacher who stated, "She (Principal B) gets rid of the policies that hold people back." Another referenced how she adjusted the entrance policy as the Black male demographic was disproportionately keeping students out. Principal B noted, "We have a district code of conduct which we follow. However, we are going to look closely at the data to see if we are 
applying them fairly. Some things are situational." School B recognized that if they were to, "raise to the highest level possible the academic and artistic achievements of all its students," as stated in their mission statement, they were going to have the students in school and engaged. As summarized by one teacher, "We have this incredible group of professionals, the admin, the teachers, the two counselors who are therapists, a parent liaison, and a social worker. We are looking for ways to support kids.”

\section{Research Question Two}

How do the tenets of invitational leadership style of the principal impact the retention of teachers within a high poverty school setting?

Each of the principals in the study worked from a sustaining invitational stancecomposed of elements of invitational leadership, “...reflecting optimism, trust, respect, care, and intentionality (Purkey \& Novak, 2015, p. 13)." In the recruitment of teachers at School A there had been a great shift under the leadership of Principal A. When he first started out in the principal's role, he scoured job fairs and resumes to find people who he believed would put students and their families first. He stated, "We have always been coming from a place of service. When we go to find a teacher, I am not looking for saviors, I am looking for allies.” By 2020, the school no longer needed do those things to find teachers as they had built a culture of which the teachers and community are proud. When there was an opening, there was a person who was somehow connected to a person at the school or who graduated from the school who knew what was happening there and wanted to give back to the community.

Principal B did not find herself to be a great recruiter of teachers yet. "I rely on the teachers and the students to be the great selling point of why a teacher would want to come work at our school." Teachers felt they were brought in on the process a bit later, but believed that the 
leverage and trust that was given to them, they could help integrate teachers into a culture of support that was spearheaded by Principal B. In the final stage of the interview process, candidates were welcomed into the school and given the opportunity to talk with the teachers in the absence of the principal. As stressed by one teacher, "She does not hide anything in the interviews." Another teacher shared, "It is well established that this work is going to be hard. New teachers come in expecting that they must do well, but there is not the pressure to be perfect. No one beats you down if things do not go well. It is a culture that is constantly accepting people who are trying new things that are best for kids."

\section{Optimism}

At the time of the interview, School A was a month into their school year where on-line learning was taking place due to social distancing. While this could have been a time where the principal could have lamented about how bad things were, he instead saw it as a time of great opportunity.

In the time of Covid, we are all learning together. The way the system has been built, it has not been working for everyone. This is the time to ask the questions. We try to work a collaborative group who will find the answers for our students.

Principal A acknowledged that there were challenges that his students and staff had yetto overcome, yet he still believed that he had the people who could change the trajectory of the lives of young people, including the young people themselves as evidenced by him stating, "We have the mindful populous." Each year the school hosts a holiday luncheon that serves as both a fundraiser for college scholarships and an opportunity to celebrate with the community great things that were happening at the school. The tone was celebratory with a retired teachercoming 
back to be the master of ceremonies, students who had found success integrating the academic and personal skills learned at School A shared their gratitude for scholarship support, PrincipalA recognized the accomplishments of the staff and students, and the vision for the school was shared. His optimistic approach is supported by a teacher who shared, "He is unwavering on what he wants us to do what is best for kids."

"When you walk out of her office, you know you can do better!" was the reflective thought of a staff member who had just met with Principal B the day of our interview. When one walked into the building at High School B, they were going to see one or both signs that served as a call to the possibilities of all who cross the thresholds. They say, "I see you!" and "You are free to be the person you want to be!" Each of these messages were seen as expansive by the staff and students. She modeled a desire to be a continuous learner through going into classes to engage at the student level, stand in front of her entire staff to admit that even after several years as the principal of the school, she had not been doing a strong enough job as a straight cisgender Black woman to lead her students who identify as LGBTQIA, or taking the chance herself tohire a writing coach to write a book of her own. As a product of the high school, she knew what education had done for her life and she wanted education to play that same role with her students.

\section{Trust}

When Principal B took over in the role of principal at the school she noted, and confirmed by those hired by the principal before her that she was following a leader who led "a tight environment wrapped in fear." She knew she had to shift the culture by treating them as professionals and trusting what they were doing in their classrooms, she had them lead professional developments, gave them the resources needed to start clubs to support the students, 
and when a teacher let her know that students wanted to protest on the main road outside of their building, she worked with the teacher to get what was needed for them to do it safely. It was through her proximity and presence that teachers knew she saw what they were doing and could move forward in confidence. As supported by one teacher, "I feel I have a great deal of independence. I do not feel micromanaged in any sort of way."

The story of professional trust given by Principal A to his teaching staff was best told by a teacher:

Everything he does is giving us professional trust. We meet monthly as department chairs. He does not dictate those meetings. He is there, but we will decide what we want to do as departments and academies. Things may come down from him, but nothing ends with him without the opportunity for feedback.

As noted by a teacher turned administrator, "In the classroom teachers are left to do what they need to do. There is not micromanagement. There is a school vision and staff values we have created. Teachers work from there." If Principal A knew a teacher was struggling, he would find ways to support, whether it was ensuring that they know his door is open, allocating resources for additional pay opportunities or training, or even jumping in the classroom himself so the teacher can take care of a personal need. He knew he could not do it alone as noted by an office professional, "He uses the personal strengths of others to make sure the place runs smoothly. It runs like a machine and he knows its parts." Another teacher noted that while there was a curriculum from the district, she has been entrusted to use the curriculum she is creating as she knows it is best for her kids. 


\section{Respect}

Having started his career in another industry, Principal A moved into education as a teacher in a continuation school where he taught 17 to 20 year old students who had not had success in several years before becoming a teacher at School A, then to assistant principal, then to principal. He kept in the front of his mind just how hard the profession is daily. "I did notwant to be anything other than a teacher leader, but I knew we were a staff who were building some great things at our school and if someone else came in, they may not give the staff the respect to continue creating what we were." The recognition that he needs talented professionals whom he respects was further clarified when he stated, "I include our teachers and staff in decisions that affect their livelihoods. We honor the art of teaching. We are not going to be prescriptive. We are creating collaborative and sustainable practices."

The respect for professionals did not stop with just his staff. When the attorney for the public defender's office called over twenty schools in the area with whom to work to slow the school to prison pipeline, there was not another school that responded and acted upon the invitation for the collaborative project like School A. Each Thursday when the attorney came to the school, he knew that Principal A would have questions for him to elicit his advice. When the director of an anti-gang organization was looking to partner with schools he knew the right partner was Principal A as there was such evidence of respect for the viewpoints of others in a culture where respect is a main currency.

When I first started, we were both very new in our roles. Multiple fights were happening in the school every day. Shootings were in the area. It was pretty bad. We met one another. I noticed he was willing to learn, but not dictate. He learns from the kids, the community. He is willing to try what others suggest. 
Principal B saw daily the talent in her staff. She not only had them lead staff meeting and professional development, but supported creating platforms where they can share their talent in the school community through having performances in the school courtyard or in times of social distancing, a Stevie Wonder alumni and staff tribute band perform on the school webpage. A teacher expressed, "Teachers are allowed to be their authentic selves and in turn this makes students feel safe to be themselves. We have a teacher with purple hair and it is not a problem." In the professional development sessions, it was noted how effectively Principal B engaged right at the table with the teachers and staff as a learner herself. "Because we know our voice will be respected, we will go talk to her about our ideas and things will happen." While there were questions by some about the focus being more strongly on self-care than academics, the overall vision and follow-through allowed space for both. As noted by an instructional leader, "Our greatest strength is our focus on culture. We understand that we are part of the solution. We are considered to be one of the best places for teachers and students."

\section{Care}

"This is my family!" Principal B stated. Coming from a leader who had gone to the school at a time of great challenge in her own life, there was an even more believable nature to that statement. As one interviewee affirmed, "She is here because she sees herself in every one of these kids. She knows the power of our staff and the difference that we can make together." When the 2020-21 academic year had started off with stressful challenges Principal B took the time to listen to her staff. She found out that some of the district mandates for paperwork were weighing them down and advocated for them to minimize the amount. "She has a way of making the person to whom she is talking feel like they are the most important person. She does not seem in a rush, yet she seems everywhere." 
Principal B also showed her care by doing the little things to make the staff and students feel valued. She created a "Peace Room" where people could go when the stresses of the day felt too much. She created videos for the staff, students, and community where she acknowledged the challenges of the disruptions brought on by the pandemic of 2020 while offering solutions to ease the burdens. She ensured that her teachers were celebrated at the building and district level for putting in the hard work that they do. They had district level award winners at the administrator, counselor, and teacher levels in the three-year span leading up to this research. The level of care that she had for her school community was recognized by a staff member who stated, "She has the talent that she could go anywhere, but as an alumni, she is so passionate about this school and this district that not only is she here, but her three daughters have also gone through this district."

The care of Principal A was most evident from those from the community who had gone to School A and returned to work there. "(Principal A) is not from here. But he has embraced it as his own. This Italian guy who speaks Spanish, understands how immigrants can be treated from his own family's experience so he is going to take care of them." Another, who bid her time at another school until there was an opening to return to her alma mater and work for the principal whom she loved as a student, “In my eyes, I don't see anything wrong with (Principal A)." Principal A's caring response to the civil unrest in his community in the spring of 2020 in response to the killing of George Floyd was a point that he saw the need for the school to take a stand to show they cared about their minority Black students and how if one group was affected from his school they all were. He made copies of Ibram X. Kendi's book How to be an AntiRacist available to staff members. When the students marched, he marched right along with his 
staff and his students. He cared enough about his students to make it clear publicly in person, on the internet, and on paper that he believed Black lives mattered and he would stand with them.

\section{Intentionality}

"Intentionality enables people to create, maintain, and enhance total environments that consistently and dependably invite the realizations of human potential (Purkey \& Novak, 2015, p. 3)." The potential of humans can be best realized through designing places, policies, processes, and programs to be personally inviting to each educational leader and all with whom they come in contact. With the researched evidence share in the responses to questions one and two of this research it was evident that the goal of each school leader was to be intentional in these areas. Furthermore, through using the snowball method to interview individuals who had been working with the school for an extensive number of years, the intentionality of the leaders was confirmed. Principal A ensured to meet people at the door where he began to share a vision that the school is there to serve the young people of the community. While they would be unable to control what happens outside of school, the school would work with partners on the local, state, and national levels to get the students the support they needed. In turn teachers who joined for the mission wanted to stay to be a part of that team. As posited by a long-time teacher,

If you are bought in for the mission and want to be a part of social change, then you absolutely want to be here. What makes you want to work for him is that he is working harder than you. Whether that is reading to learn the best practices, spending time in meetings that teachers are leading or directly connecting with students and their families, we all know that no one is working harder than him."

Ten out of ten interviewees responded that his leadership plays a major role for the 
reasons they stay. Five of them mentioned they will strongly consider leaving when he does unless the replacement's leadership is aligned with his.

Principal B had that same level of support as nine out of ten respondents state that she was a reason that teachers stayed while the tenth state that, "She is so teacher centered focused on supporting the self-care of the teachers that while I believe teachers come for the kids, she is not going to be the deterrent that would make some leave like our last principal." Principal B stated, "I want them to be free to be themselves, to have professional autonomy, to seize opportunities to lead, and I am sure to respect them as people and professionals." A highly regarded teacher emphasized,

There is not a week that goes by that we do not talk about how lucky we are to be at this school. The inner-city is a hard place to teach, but she makes it lighter. The teachers I respect stay at (our school). I would put our staff up against any in the country.

A remaining teacher shared the story of a teacher who left to move to another state. In two years, she has now been at multiple schools and recently called the interviewee with emotion in her voice as she worried that she would never find another school like School B in which to work. Four teachers brought up on their own that when Principal B leaves, they will consider moving on as well. As a teacher who had recently left the school to accept a job at a major tech company described how intentionally supportive Principal B was to the staff he reflected that, "The only reason good teachers leave the school is because they go on to bigger and better things. If the job at the school could have paid me what this tech company is, I would have never left." Yet, even as intentional as each administrator was in being invitational it was evident that their intentionality did not stop there. 


\section{Research Question 3}

What behaviors of the principal demonstrate the desire to act in the orientation of social justice?

The two school leaders had a commonality for the reasons they each wanted to work in a school where their students came from under-resourced populations. For Principal B, it was the school from where she graduated. When she was going through school as a teen, her family did not have the capacity to give her the support that she needed. There were times that she felt alone. She spoke of never wanting any of her students to have that same feeling that she had. She recognized that it was her school community that was the constant for her, and she was willingto do anything to pay that forward. "Everything is not about money. It is about inner peace. It is an honor and a blessing to work at the school from where I came. There is something magical working with individual who are so talented."

Principal A came from a place of service in the hotel industry. While he knew that he wanted to continue to serve people, he had a deeper desire than just bringing them their food or their sheets to those who could afford it. He saw an opportunity to be more deeply fulfilled by serving students who had not found success in school as he prepared them for their general equivalency diploma. His career then continued to stair step into the next level of service as a classroom teacher, teacher leader, assistant principal, before landing in the principal role. While he never wanted to be more than a teacher leader, he was not willing to let go of the work of the collective group in the high school where he was working, so he would step forward and take each new role. While he had many opportunities to continue to move up the ladder into the central office level, he had not moved. "I do not see a bigger impact being further away from the community. I want the ability to have an impact. I don't want to serve a community at another 
school. This group of student and group of families make it fulfilling. More money would not be more fulfilling."

\section{Arrogant Humility}

As one teacher joked,

Her passion is social justice! She links the social and the justice. We are a performing arts school. Nothing about this school is humble. The kids are trained to be in your face. Our Principal is a triple threat who can dance, sing, and act. So of course, she is going to be arrogant.

Principal B responded to having arrogant humility with this:

I could always use more work in humility. I am always reminded of my past. I think of those humble beginnings. I can listen to a parent and open my heart to show empathy. I am good at it. It is still a growth area, but I think I am good. I keep learning from team members.

Her team members echoed that about how much they loved the arrogance she carried about their school. In every presentation she gave, whether to the district, the families, the students, or the community, she reminded everyone that she had the best school in the city. She knew there was work to be done, but consistently reminded her team of their greatness. She had made staying confident in your school a cornerstone of the book she wrote to help other educators who worked in a high needs schools. She encouraged them to beyond hard work, it is "heart work." As stated confidently by one teacher, "Arrogant humility is (Principal B). She possesses a fierce tenacious energy as she sees every kid in our school as being her. She wants to give them what she needed." 
While the arrogance was evident in such a positive way, the humility was just as evident. As shared by one teacher, "She has plenty of awards that she has won, but that is not what she stands in front of our staff to talk about. She is in front of us being vulnerable about a challenge that she or the staff is facing and looking for ways to improve." She had been a fierce advocate for adjustments to be made to more intentionally inviting of Black males when the data told her that they were disproportionately being suspended or not getting in due to certain standards.

As the researcher was reading the tenets of social justice leadership as being key to the teacher retention challenge and read of arrogant humility, it was Principal A who then becamean obvious choice to be a target in this study. As echoed by his staff, Principal A proudly shares about the great things the school is doing. He shared about the partnerships in the community, the talent of the staff, and the brilliance of the students with great confidence. He consistently stood in front of his staff with the latest research on what is best for their students while he left the door opened to be questioned. As one counselor noted, "He knows what he wants, but will relook at it so it will work for so many more." When asked how he fit into Theoharis's (2007) description of a social justice leader he responded in a humble tone, "Sometimes, I feel arrogant." This was backed by his admission that while he wanted to support teachers, he also did not back down from releasing a tenured teacher if what they were doing was hurting kids. It was shared by those interviewed that his arrogance came in good ways including ensuring they were going to do what is best for kids, a conviction that he was going to learn what he needed to learn as he was willing to put in the time to do it. "He loves squeezing banana juice out of lemons." 
The arrogance was consistently counterbalanced with humility throughout the interviews best summed up on the story about a program that Principal A was interested in having brought to the school.

There was this proposal for new technology. (Principal A) knew that our staff could successfully implement it really well. It was comprised of project-based learning and team teaching. He fought for it, but there were enough teachers that did not buy in, so he said that is fine. He did not pressure anyone. He did not tell anyone who did not want it to leave. The exact opposite happened in another school I am aware of. That school was not as well suited. It passed and teachers left. They have had 3 principals since then in less than five years.

Others noted him being the most vulnerable principal they had ever come across. "He does not have all the answers. He is reflective. He opens the opportunity for others to carry a meeting. He is a nurturer who is willing to push."

\section{Passionate Visionary Leadership}

The first time the researcher ever talked to anyone at School A it was about the partnership that his organization was going to have with the school it was an assistant principal. He kept speaking of the vision of Principal A that was set for the school to reach every student. Consistently, this vision has been continued to be shared. The participants in the study talked about his sharing of the mission statement of the school regularly. He puts letters and videos on the website to let the community know that the school is there to be a resource. Staff members who had him at School A when he was a teacher shared that he was the first person who truly made them believe that they could go to college. Other talked about him recognizing what each 
person could bring to be a part of the solution at the school. "Legitimately, with what the wants to do, he is the reason a lot of us are still here. We will go far beyond because of him. When he leaves, there could be an exodus." The gang outreach director expressed gratitude when sharing, "He wants to work with the families who need him most. He knows he cannot change people, but he can help them make changes in their time. He heart is big for these kids and theirparents." It was shared repeatedly that he was going to challenge himself to learn the most and work the hardest of anyone in the building, yet what he wanted to continue to share was how hard heknew the jobs of his staff were. It was acknowledged by participants that the level of drive expected out of the staff at times would lead some good people to leave, yet they still were committed to the mission set forth. As stated by a committed teacher, "At the end of the day, he is here for the kids."

Passion was a word often used to describe Principal B over and over in the interviews before even arriving at this question. The seed of the passion were driven by many things including her upbringing, her seeing every child as her own, her commitment to the community, the drive to develop the best teaching staff possible, the desire to make the world that much better for her three daughters, and to maximize her own skills in supporting others. She seized each opportunity to use her triple threat skills to share her passion for the school and the vision they must support each student who comes through their door. She knew that she could not do it alone, so she focused on bringing in the talents of the stakeholders including staff, students, and community members as supported by one of the teachers as he discussed he ability to guide while still giving autonomy, "She keeps her hands off while knowing where to go." She consistently shared the vision for the school in staff meetings, school performances, at central office, and in the book that she had just written. 


\section{Tenacious Commitment to Justice}

Principal B knew the students of their school have a voice and are going to want to use it. "They just announced the charges against the police who killed Breonna Taylor. When situations like this happen, our children want to respond. It is our job to teach them how to have a voice and move in the right ways." The government teacher echoed, "We have the freedom to discuss the relevant issues of the day. (Principal B) trusts me to have the conversations with ourstudents. I can guide them. She allows a fair amount of protesting for students to voice about justice and equity in society." Another teacher shared, "She has a commitment to justice. When she saw the challenges of Black males, she challenged and supported a young Black male teacher to be a mentor. It resulted in a group for those young men to be heard." Her openness on exploring her own blind spots regarding the LGBTQIA students was modeling of how to self-reflect and be vulnerable in front of the staff as a learner was appreciated by many staff members. One teacher shared,

She had to learn about her own homophobia. She has been reading and bringing in speakers. She listened to students. She cut the Chick-Fil-A fundraiser off due to their policies against those students. She opened herself and the school to learn about the LGBTQIA community.

Principal B's tenacious commitment to justice could be summed up in her ownwords.

Our students have gifted brains. It is these brains that heal the world. Some mayconsider them weirdos, but it is those weirdos like Michael Jackson and Prince who they turn to heal and make sense of the world that we live in. I am a social justice advocate. I encourage our students to empower them. I know our student leaders who we can give 
the space to do it. No one was taking African-American Literature, so when they pushed to have it, we gave it to them. I want them to become critical conscious thinkers. We need to give them the space to do that. We may have to reel them back in if they are going off the rails, but we can guide them.

There is not a story that captures the tenacious commitment to justice exemplified by Principal A than that shared by his assistant principal.

He knows that it should not be this way. He started in a continuation school. He knows what it looks like for a school system to fail kids. He has a collage of student photos, but he keeps all kids in mind. Like a kid who was a gang member. The rule was you fight, you are expelled. He questioned the zero-tolerance policy. The student left the school, and he was killed. Vito keeps that student's picture up as a reminder that when we treat a kid as a throw away kid, bad things can happen. He knows, feels their stories, and believes in their humanity. He knows they deserve better. He thinks, "I cannot retire until someone is going to pick up that work up." He is close to being eligible to retiring, but he cannot leave until he has it figured out. He will hang on until we are in good hands.

The tenacious commitment to justice came out in story after story of Principal A stepping up in ways that could be unpopular for people in mainstream positions of power to speak out for the marginalized. The work that he had done in the summer of 2020 in supporting the Black Lives Matter movement was unwavering when it began with him listening to students and staff as to what they needed in a response. Then responding by sending out a letter to the community clarifying the school's stance of support coupled with Principal A sending out a video of himself on social media backing each claim made in the letter. The combination of his spoken words, 
posting of the points and symbolism left no room for interpretation as to where the school stood. This was followed by his support of a march from the school to the city hall to the university where he walked with his students and his own daughter before speaking to the entire crowd to ensure they knew where the school stood in supporting their students of color. When ICE raids were rumored to be happening in the community to find undocumented families, Principal A went on the school intercom system to make it clear that their school was a safe place. If their families were having challenges, they were to come to the school to get the help that they may need. Principal A himself noted his commitment to social justice early in the interview when he admitted,

I am not driven by education. I am driven by education as a social justice tool. Using education as that step. If we are getting 230 kids to college rather than 70 (the number when he took over), we have students who can break the cycle of poverty and injustice.

In all twenty-two interviews done for this study, as they were asked the question of tenets of social justice leadership being arrogant humility, passionate visionary leadership, and a commitment to justice, there was only once that an interviewee stated that not every descriptor fit. Overwhelmingly the response to whether or not the principals acted with a social justice orientation was met with quotes like, "Everything you described here fits her," "From these three points, I see my principal,” or “ Those three things summarize him.”

\section{Research Question 4}

How are the tenets of invitational leadership and the orientation of social justice displayed within the school community by the stakeholders (principal, teachers, and community)? 
In each of the schools the tenets of invitational leadership and the orientation of social justice were evident. Each of the schools were chosen due to the researcher's previous visits to get more students into advanced academics. The invitational pieces were evident in walks through the schools, the study of the policies in regard to advanced academics, the processes followed to get teachers and students engage, and most apparent was the level of service the researcher received in each place. From security guards to staff to students, people consistently greeted a stranger as he walked in to help guide him where he needed to be. The partnership of the school and the researcher's organization is based in social justice in the belief that the pathway to greater options in life to solve the world toughest challenges happen through education. Through the study, it was found that the tenets of invitational leadership and the orientation of social justice were entrenched well beyond just the school leader.

Through the study it became apparent that the community saw School A as a community school. It was a place where the stakeholders knew that they had a voice whether it was teachers giving feedback on a certain program that would be implemented in the school, students working to get the support they needed academically or socially, or community members coming to the school to get food or testing for Covid-19. The school and community had a common vision that they would help students graduate with positive options. The people support comes through the student advisor meeting students at the door as they come in late to ensure they have the support they need ready to start the day, a restorative circle was held after school when the political rhetoric was perceived as hostile toward their Latinx and immigrant community, working in partnership with the public defender's office or a gang outreach organization to explore option than being a conduit in the school to prison pipeline. A two-year study done by a local university shared the school had elements of "familial carino de familia" which translates to a love of the 
family. The students took great care of the grounds as open-air lunches were not littered with trash at the sound of the bell. The walls were painted with student murals. It was evident that it was an environment that the research participants wanted to be in and believed that their students did as well.

The social justice orientation at the school is also alive and well. Students are openly willing to take part in restorative circles rather than seeing punishments. The know that they must have a voice. On a visit from the mayor to the part of town where the school is located, a female student confronted him. She asked him what he would do for the east side. When he gave what she deemed a political answer without any real substance she shot back, "Oh, I thought you wanted to come to the east side to hear from us." She then went on to demand that he should hear from the community members to which he complied. The staff was committed to ensuring that students came to the school as their authentic selves. A teacher reflected,

We work to make all of our students feel welcome and know they belong. I don't think there is a person on campus who would make an undocumented student or a student dealing with gender identity feel unwelcomed on our campus.

Another spoke of a counselor working with ELL students, "Our counselor believes in our students. She asks, 'How can we make this the best experience possible for all of our kids?' while she explores the best opportunity that exists for undocumented students." One teacher wanted to offer a more culturally relevant sociology class in ethnic studies. What started as a first year offering with 55 sophomore students has now morphed into a class that is taken by every freshman in the school. As it meets the state standards and the students now see themselves reflected in the coursework, schools in the area are following suit. 
The staff members of School B take great pride in how welcoming they are. They have taken pride in ensuring that they see every person who comes into the building in the spirit of the "I See You" campaign. While the message was not scripted, it was consistent in the study the role of every staff member in the school was to make people feel safe and welcome. It started with the security officer in the front, worked its way through all administrators and the several noted how it has moved its way down to the students. It was perceived that many of the students come to the school to feel safe as they come from communities that are not always. They are dealing with issues of identity related to gender, sexual and/or racial identity. It is the juniors and seniors who often keep the culture of support moving through the student body. Instead of always talking directly to a student who was having a tough time, teachers referenced how they could point out to student leaders who may be struggling, and the elder student would get them back on track. The staff engages in discussing how they can be more welcoming and overcome their own biases. When the staff has these tough discussions, people are not belittled for sharing where they are in their growth, instead they are supported. This allows the teachers to grow as noted by one veteran teacher, "We will do this without an attitude. I did not know I was not being accepting about sexual-change, race, behavior, or disabilities. She (Principal B) broke it down to me about a student's medicine and how it affects him." Teachers recognized that their students dealt with a great amount of trauma, so they worked to make it an environment that made it feels safe. Additional ways this was done included allowing students to find a sponsor to create a supportive club, visual artistic expression painted or sculpted throughout adorning the halls, and invitational posters of performing arts performances were throughout the building.

The social justice orientation was also integrated into the daily lives of the stakeholders in School B. The content of the coursework was intentionally, culturally relevant to their students. 
In their government and history classes they intentionally correlated happenings of the past to what was happening in the present, while questioning the things that have worked in government in an equitable way toward the demographics of their student population and what has not. The English curriculum ensured that the characters in their works included a balance of characters who their student population. Even the math and computer classes had a history of delving into the statistical data to explore the effects of the social media influences on the election of 2016, statistical anomalies in lending practices for housing, and the how facial recognition technology does not recognize the faces of Black people effectively, especially Black women. After one of judicial system decisions to allow the officer who shot Michael Brown to go free, the students let their government teacher know that they wanted to march. The administration collaborated with the teachers who collaborated with the students to ensure safety for all, while still allowing space for their voices to be heard. Principal B called the superintendent to ensure he know what was happening, the city police department came to ensure everyone stayed safe, and the student complied to have their voices heard peacefully on along of the city's busiest thoroughfares. The staff was committed to continual learning. In the fall of 2020, many White staff took up the offer from Principal B to engage in a multi-racial book study of White Fragility by Robin DiAngelo. The study elicited many other stories of the practices that had clear examples of invitational leadership and a social justice orientation that drove the themes that came out of the writing.

\section{Discussion of the Findings}

The title of this research poses the question as to how a principal's action as an invitational leader with a social justice orientation can serve as a factor in recruiting and reciprocally retaining teachers at high-poverty, high-minority, high-needs urban high schools. To answer this overarching questions, four sub questions were explored and analyzed to find the 
major themes that supported the answer to how a principal's actions can serve as a factor in reciprocally retaining teachers in the targeted demographic group of schools. In this section, the five themes arrived through analysis and coding are presented. The themes of the intentional invitational action, social justice as a driving force, collective learning, humanity, and commitment to students and community will serve as a base upon which principals, novice and veteran can integrate into their practices to increase their chances of reciprocally retaining teachers in the high-poverty, high-minority, high-need urban high schools who need them most.

\section{Theme: The Actions of the Principal Being Intentionally Inviting}

Purkey and Novak (2015) shared the four levels of the invitational ladder moving from intentionally disinviting to intentionally inviting through using the focused elements of care, trust, respect, optimism, and intentionality with a focus in the five domains of people, places, policies, programs and processes. The evidence was abundant in each of the researched schools that while neither principal nor study participants were familiar with the tenets of invitational leadership, they were effective in their integration of the common practices. Detailed in Figure 1 are the commonalities seen in both schools regarding the 5 P's of Invitational Leadership. 


\begin{tabular}{|c|c|c|}
\hline $\begin{array}{l}\text { Domains of } \\
\text { School A and } \\
\text { School B }\end{array}$ & $\begin{array}{c}\text { Domain Descriptors } \\
\text { Purkey and Novak (2008) }\end{array}$ & $\begin{array}{c}\text { Evidence of Principal Actions } \\
\text { being Intentionally Inviting } \\
\text { Purkey and Novak (2008) } \\
\end{array}$ \\
\hline People & $\begin{array}{l}\text { Unconditional respect for everyone, } \\
\text { intentional caring, honoring diversity } \\
\text { who is given to developing a trusting, } \\
\text { optimistic, and courteous stance for } \\
\text { everyone (p. } 21 \text { ). }\end{array}$ & $\begin{array}{l}\text { - } \quad \text { Available to staff and students } \\
\text { - Shared decision making } \\
\text { - Support for individual and } \\
\text { - Collective learning } \\
\text { Commitment to social justice } \\
\text { and diversity }\end{array}$ \\
\hline Places & $\begin{array}{l}\text { Welcoming environment where } \\
\text { careful attention is given to the } \\
\text { aesthetic, clean, functional, and } \\
\text { efficient qualities of the school (p. } \\
\text { 22). }\end{array}$ & $\begin{array}{l}\text { - } \text { People met kindly at the door } \\
\text { - Student work represented } \\
\text { throughout. } \\
\text { - } \quad \text { Spaces kept clean } \\
\text { - Campus spaces available for } \\
\text { students and staff to } \\
\text { maximize learning and social- } \\
\text { emotional well-being with } \\
\text { common areas }\end{array}$ \\
\hline Policies & $\begin{array}{l}\text { Include official mission statements } \\
\text { and the directives, codes, and rules, } \\
\text { written and unwritten, use to regulate } \\
\text { the schools. (p. 22) }\end{array}$ & $\begin{array}{l}\text { - Stated desire to maximize } \\
\text { learning and options for all } \\
\text { students. } \\
\text { - } \\
\text { Restorative practices over } \\
\text { zero tolerance policies } \\
\text { - Inclusivity, interventions and } \\
\text { support over exclusivity, } \\
\text { disqualifications, and labeling } \\
\text { as failure. }\end{array}$ \\
\hline Programs & $\begin{array}{l}\text { Formal or informal, they work for the } \\
\text { benefit of everyone while } \\
\text { encouraging active engagement with } \\
\text { significant content. (p. } 23 \text { ) }\end{array}$ & $\begin{array}{l}\text { Aim to have something for } \\
\text { everyone. } \\
\text { - Students have voice and } \\
\text { choice. } \\
\text { - Adults willing to share their } \\
\text { talents. } \\
\text { - Community steps forward to } \\
\text { lead to share their talents. } \\
\text { - Finds ways to meet the most } \\
\text { basic of needs through } \\
\text { support. }\end{array}$ \\
\hline
\end{tabular}




\begin{tabular}{|c|l|l|}
\hline Processes & $\begin{array}{l}\text { Democratic ethos, collaborative and } \\
\text { cooperative procedures, and } \\
\text { continues networking among } \\
\text { teachers, students, staff, parents, and } \\
\text { the community that give life to the } \\
\text { school. (p.23) }\end{array}$ & $\begin{array}{l}\text { Voice and choice given in } \\
\text { academic instruction and } \\
\text { extra-curricular interests. }\end{array}$ \\
& $\begin{array}{l}\text { Listening sessions for staff, } \\
\text { students, and community } \\
\text { members. }\end{array}$ \\
& $\begin{array}{l}\text { If it is deemed best for } \\
\text { students, a can-do attitude } \\
\text { finds the resources needed for } \\
\text { success. }\end{array}$ \\
\hline
\end{tabular}

Figure 1 - The 5 P's aligned with common actions of researched principals

Purpose and direction are given through invitational leadership with the five elements that sets an implementer in an inviting stance (Purkey \& Novak, 2008). In Figures 2 and 3 below, each of the elements is noted along with a descriptor and a vignette of each principal's orientation to social justice.

\begin{tabular}{|c|c|c|}
\hline $\begin{array}{l}\text { Element of } \\
\text { Invitational } \\
\text { Leadership - } \\
\text { Principal A }\end{array}$ & $\begin{array}{c}\text { Descriptor of Invitational } \\
\text { Element (Purkey and Novak, } \\
\text { 2015) }\end{array}$ & $\begin{array}{c}\text { Vignette Representing Principal } \\
\text { Action }\end{array}$ \\
\hline Care & $\begin{array}{l}\text { Genuine desire to care about oneself } \\
\text { and others. Ingredients include } \\
\text { warmth, empathy, and positive } \\
\text { regard to be a beneficial presence. } \\
\text { (p. 2) }\end{array}$ & $\begin{array}{l}\text { He could look at any person in his } \\
\text { courtyard during the lunch-hour and } \\
\text { tell a detailed story regarding their } \\
\text { challenges and their growth. }\end{array}$ \\
\hline Trust & $\begin{array}{l}\text { In recognition of human existence is } \\
\text { a cooperative activity that is } \\
\text { interdependent. It is built upon } \\
\text { invitations sent, received, and acted } \\
\text { upon successfully. Environment } \\
\text { created to allow each person to } \\
\text { pursue his or her own best way of } \\
\text { being and becoming. (p.2) }\end{array}$ & $\begin{array}{l}\text { If students were late to a class, } \\
\text { Principal A had a culture that an adult } \\
\text { will walk up to the student to see what } \\
\text { support they may need. He had built } \\
\text { the trust that there must be something } \\
\text { wrong if they are unable to live up to } \\
\text { the expectation to be in class. Teachers } \\
\text { are given the autonomy to do what } \\
\text { they feel best is right in their } \\
\text { classrooms. }\end{array}$ \\
\hline
\end{tabular}




\begin{tabular}{|c|l|l|}
\hline Respect & $\begin{array}{l}\text { People are able, valuable, and } \\
\text { responsible and should be treated as } \\
\text { such through positions of equality } \\
\text { and shared power. (p. 3) }\end{array}$ & $\begin{array}{l}\text { Democratic in all decisions that were } \\
\text { made. Before any action was taken } \\
\text { school-wide or in sub-groups, those } \\
\text { who will be affected were engaged. }\end{array}$ \\
\hline Optimism & $\begin{array}{l}\text { Recognizing no clear limits of } \\
\text { human potential have been } \\
\text { discovered. One must move beyond } \\
\text { just inviting, but hold hope for } \\
\text { change to be better (p. 3) }\end{array}$ & $\begin{array}{l}\text { While carrying himself with a funny } \\
\text { sense of humor, he also carried himself } \\
\text { with belief that he would not be } \\
\text { pushed off his vision that adults can } \\
\text { support every student to maximize } \\
\text { what is possible for each. }\end{array}$ \\
\hline Intentionality & $\begin{array}{l}\text { Enables people to create, maintain, } \\
\text { and enhance total environments that } \\
\text { consistently and dependably invite } \\
\text { the realization of human potential. } \\
\text { (p.3) }\end{array}$ & $\begin{array}{l}\text { Relationships were built through an } \\
\text { open-door policy, meeting teachers } \\
\text { and students where they are, and } \\
\text { opening of himself. Each year a } \\
\text { graduation party is held at Principal } \\
\text { A's house for the entire staff. }\end{array}$ \\
\hline
\end{tabular}

Figure 2 -Elements of Invitational Leadership with Vignettes of Actions of Principal A

\begin{tabular}{|c|l|l|}
\hline $\begin{array}{c}\text { Element of } \\
\text { Invitational } \\
\text { Leadership - } \\
\text { Principal A }\end{array}$ & $\begin{array}{c}\text { Descriptor of Invitational } \\
\text { Element (Purkey and Novak, } \\
\text { 2015) }\end{array}$ & \multicolumn{1}{c|}{$\begin{array}{c}\text { Vignette Representing Principal } \\
\text { Action }\end{array}$} \\
\hline Care & $\begin{array}{l}\text { Genuine desire to care about oneself } \\
\text { and others. Ingredients include } \\
\text { warmth, empathy, and positive } \\
\text { regard to be a beneficial presence. } \\
\text { (p. 2) }\end{array}$ & $\begin{array}{l}\text { Realizing that the young males needed } \\
\text { an outlet, she encouraged and } \\
\text { mentored a young Black teacher to } \\
\text { start a group for them. The group was } \\
\text { successful as many young Black males } \\
\text { came, but she was still asking herself, } \\
\text { "What do we have for our White } \\
\text { males?" }\end{array}$ \\
\hline Trust & $\begin{array}{l}\text { In recognition of human existence is } \\
\text { a cooperative activity that is } \\
\text { interdependent. It is built upon } \\
\text { invitations sent, received, and acted } \\
\text { upon successfully. Environment } \\
\text { created to allow each person to } \\
\text { pursue his or her own best way of } \\
\text { being and becoming. (p.2) }\end{array}$ & $\begin{array}{l}\text { Principal A was confronted in their } \\
\text { community with an officer not being } \\
\text { charged for killing another person of } \\
\text { color in their community. The teachers } \\
\text { shared that the students were very } \\
\text { emotional and needed a way to express } \\
\text { their feelings. She trusted the teachers } \\
\text { could teach the students to do it the } \\
\text { right way and the students could }\end{array}$ \\
\hline
\end{tabular}




\begin{tabular}{|c|c|c|}
\hline & & $\begin{array}{l}\text { handle using their voices to share their } \\
\text { outrage in a safe way. }\end{array}$ \\
\hline Respect & $\begin{array}{l}\text { People are able, valuable, and } \\
\text { responsible and should be treated as } \\
\text { such through positions of equality } \\
\text { and shared power. (p. } 3 \text { ) }\end{array}$ & $\begin{array}{l}\text { When a new teacher came to the } \\
\text { school, she would make herself } \\
\text { available for whatever they needed, yet } \\
\text { trusted her team of teachers to } \\
\text { welcome the teacher in and support } \\
\text { their transition. If her teachers said } \\
\text { they needed to teach a certain way or } \\
\text { end spending hours on paperwork sent } \\
\text { down from the district, she would be } \\
\text { the voice of advocacy for her teachers. } \\
\text { "We know we are heard." }\end{array}$ \\
\hline Optimism & $\begin{array}{l}\text { Recognizing no clear limits of } \\
\text { human potential have been } \\
\text { discovered. One must move beyond } \\
\text { just inviting, but hold hope for } \\
\text { change to be better (p. } 3 \text { ) }\end{array}$ & $\begin{array}{l}\text { She led by modeling ways that she } \\
\text { could become better. While not a } \\
\text { mathematician, she would go to the } \\
\text { math class to take part as a student. } \\
\text { She got a writing coach. She shared } \\
\text { these stories with the staff and students } \\
\text { to show them that as a graduate of the } \\
\text { school, she continued to push them to } \\
\text { do great things and every student they } \\
\text { have at School B could do the same. }\end{array}$ \\
\hline Intentionality & $\begin{array}{l}\text { Enables people to create, maintain, } \\
\text { and enhance total environments that } \\
\text { consistently and dependably invite } \\
\text { the realization of human potential. } \\
\text { (p.3) }\end{array}$ & $\begin{array}{l}\text { She never seemed to be in a rush. "She } \\
\text { will spend the time to make the person } \\
\text { she is speaking with the most import } \\
\text { person around." She has a way with } \\
\text { "proximity and presence to let you } \\
\text { know you are supported." }\end{array}$ \\
\hline
\end{tabular}

Figure 3 -Elements of Invitational Leadership with Vignettes of Actions of Principal B

\section{Theme: Social Justice Orientation Created a Vision Team Members Wanted to be}

\section{Committed to Realizing.}

Each of the principals embodied the Theoharis (2008) defined descriptors of being a social justice leader through carrying themselves with arrogant humility, passionate visionary leadership, and a tenacious commitment to justice. It was Principal A standing in front of a Black 
Lives matter rally validating to his students of color that the system is not equitable one day and inviting his entire staff to join him in reading Ibrahim X Kendi's book, How to be an Anti-Racist. It was Principal B standing in her staff announcing to her staff in one meeting that they will see every student in their building while owning her past failures of approaching her LGBTQIA students with a "you do you" attitude before digging deep within herself to recognize that she needed to embrace all students in their authenticity. It was each of the principals working with their staffs and students to live each word of their school mission statements each day. At the same time, they were prepared to work to maximize their own talents as a model for those whom they led to that vision. It was Principal A partnering with his staff, a former gang member turned anti-gang director, the police, the community and the public defenders office to not accept that his school has to be a conduit in the school to prison pipeline, but instead a place to be exposed to the vista of possibilities of what their life could become. Gone were the days of 800 suspensions as a teaching tool, replaced by just 22 in a symbolic move that certain behaviors leave decision makers with no other options. It was Principal B allowing for the "weirdos" to make their feelings heard through song, dance, spoken word, painting or protest as they try to heal another injustice in their community. She elicited the power within them through the simple act of listening then moving with her staff, students, and community to options of change, healing, and personal and academic growth.

The possessed orientation to social justice by both principals was a strong contributing factor for most study participants as to why they continue to work with the school. At School B, teachers who left the school with the previous administration came back under her. They recognized her commitment to the school and the community from where she came. The selfdescribed agitators knew that she was going to fight for them and their students when they were 
going to go up against others with positional power. The staff and students at School B followed the lead of their principal in creating spaces for social justice. If the wealthy Whites of the city wanted to have a fundraiser, there was going to be a place at the table for the students and their families who qualified for free and reduced lunch to be a part of the celebration. Students were going to be taught a curriculum that reflected them. While they may have let their state-of-the-art auditorium be used by organizations whose families could pay a great deal for artistic enrichment, they would ensure their students got it every day. They recognized the challenges of their community but saw their students and their families as partners in creating a space for their young people to flourish.

2,000 miles away spaces were being created for social justice in the same ways. Whether you were the outsider Italian-American principal, a person who grew up blocks away who had become a staff member, or an attorney for the public defender's office, you were part of a movement where social justice was going to be achieved through education. It came in many forms using the school as the center point. It was a handball tournament for the gangs from opposite end of town to see that they could engage and value one another without violence. It was an open AP program where any student who wanted to challenge the highest-level classes were going to be invited, welcomed, challenged, and supported. It was going to be volunteers from the staff and community handing out hundreds of lunches to the community when the district lunch program went on hiatus only to turn around, go back in and have more basic needs packed up for the migrant farm workers in the central valley of California. It was in the staff agreeing to revise their entire grading system to ensure that they did not contribute to inequitable grading practices based in euro-centric power or implicit biases. 
In each of the schools, the drive for social justice that had full engagement from the principal level was where they wanted to be. The voices of those in the study inferred that each leader was the glue.

\section{Theme: Collective Learning}

Each of the administrators in this study were seen by the participants as people who were on a self-selected continued growth trajectory. They aspired to be the lead learners in their building and showed this through sharing their learning both personally and professionally. They were also consistent in their learning sources being going to professional development training, engaging with the talents of their own staff leading professional development, and taking the time to directly learn from people. The consistent message to teachers in both schools was they should try things that were best for their students. A counselor at School A said of her principal, "He always has this frame of mind of let's try and if does not work, we figure out what to do better." At School B it was shared, "There is no pressure to be perfect. No one beats you down if things do not go well. It is an environment that is constantly accepting people for trying new things as long as we are doing it in the best interest of kids."

Each of the schools had a specific topic that collective learning that was happening in the building. Principal B had led her team in studying social justice learning in the last five years, however in the last two it has been focused more on social emotional learning and the challenges being faced by marginalized people. This is where the ideas for the Peace Room and the "I See You" campaign were originated. At School A the staff was targeting heavily on how to confront racism. There was an optional book study in Ibrahim Kendi X's How to be an Anti-Racist. The work did not stop there as they moved onto how they can create grading practices that will be 
equitable and fair for all students based on their academic skills represented rather than their compliance skills to the power paradigm.

\section{Theme: Humanity}

While the themes of humanity came about in interview after interview, there was a participant at each school who shared a story that embodied just how vital humanity was in the leadership of each of the principals.

The story of Principal B's humanity was shared by a White woman with long, flowing, blonde hair.

(Principal B) changed to the dress code policy. From the time I started there were limitations as to what kids could wear to school, but she opened it up. She allows hats and hoods. Kids were skipping school due to not having money to get their hair done. They could not wear a hat. She then came to us and asked, 'What would you rather have, a girl with a bonnet on or a boy with a hood or neither of them being here? I don't care what they are wearing as long as they are doing their stuff.' In that moment, it was so obvious, but none of us have thought about it. My privilege is my ponytail.

In the spring of 2020, like schools across the country, School A had to close in-person activities due to the Covid-19 pandemic. The senior class was going to be denied the opportunity to graduate in person. Principal A and his staff's reaction were shared by a participant in the study.

His passion oozes from his soul. We had to shut down because of Covid. All of California was. The seniors were devastated about graduation. The suggestion was that we are going to make a video with diplomas. (Principal A) was like, "We are not going to 
do that. Our kids deserve better." He got a group together and laid out, "Here are the governor's rules and the district rules." Then he asked us, "What can we do?" We ran with it, he was with us each step of the way, often leading the charge. It was an 8-hour graduation. Everyone wore a mask. Most beautiful graduation I have ever been to. You can see the story about it on YouTube. Our community has the highest levels of Covid-19 because it is our Latino and migrant families who are the hourly workers. We wanted to give them joy. They deserved joy.

\section{Theme: Commitment to Students and the Community}

There was a reciprocity in the commitment of the stakeholders of administration to teachers to students to community. "I am here because of (Principal A)." was the consistent summarizing message shared by the staff. Yet as Principal A stated, "This is where the work needs to be done. The students and community we serve, they deserve to be treated differently by our society." The staff “...feels like we are a part of something bigger.” This is anchored in the leadership of Principal A as shared by another leader in the school, "He knows and feels their stories. He believes in their humanity. He knows they deserve better. He will not retire until he knows until someone is going to pick this work up." The staff was working vigorously in making that happen in their level of commitment. For this research, using the snowball method, the researcher invited more than the eleven that he was able to interview, yet he did also receive four messages back of the invited declining due to their inability to break away from the hours of commitment to the time with the students. The staff shared their reasons for being at that school was their value of the community and their desires to see better for it. "The system sets us up at a disadvantage." "Poverty is not a money thing. It is a mindset thing. We can help them with that." "I love the staff, kids, parents, and community. I have lived here my whole life." "I waited six 
years for this position at this school to open up. My kids went here and now I drive a long way to get here each day." "The people in this community, they are the best teachers that we can have." "Nobody wants to fail, drop out of high school, say 'Fuck it! I don't have any dreams.' These kids were trauma affected. I am not the visionary to think about how to make the change, but I want to be in the place to make it."

At school B, the summarizing statement of the level of commitment to the school and community was stated by Principal B herself, "It is an honor and a blessing to work at the school from where I came.” This sentiment was backed by staff members discussing the authentic relationships that she has with the staff, students, and community. "It's almost like she just fits at our school. She seems to have a genuine joy at this hard place." Yet, it did not stop with the committed passion of the principal. There was a consistent mantra of people believing that they were all there to serve in the mission of the school to help students who were not getting it from other places. "We are part of the solution," stated one participant in a tone that made it sound not even optional. They saw the possibilities of what could become as stated by another teacher, "The time that we spend and dedicate here, where we make decisions together will create a program that will continue long after we are gone." They know they could have left, but there was something to special to allow that to happen, "I could make a bit more money, but there is too much good at this school and this community to walk out now."

There is a dearth of young people going into the profession of education to meet the needs to effectively staff our schools (Sutcher, et al., 2016). The funding formulas and inherent challenges of under-resourced schools serving a population of students coming from underresourced communities leave the schools who need the most skilled teachers often left with a rotating door of underqualified, new to the profession teachers reinventing what will be taught 
year over year (Bornman \& Dowling, 2008; Heineke et al. 2014; Hughes, 2012; Ng, 2003; Petty, et al., 2012; Sachs, 2004; Simon \& Johnson, 2015; Stotko et al., 2007; Waddell, 2010). This same rotating door exists for the school leadership (Clotfelter et al., 2007; Levin \& Bradley, 2019). However, as exemplified by the two principals and their reciprocally retained teachers, there is a model, which was first combined in the research of Martin and Miller (2017), working in two disparate communities where the principal's action as an invitational leader with a social justice orientation can serve as a factor in recruiting and reciprocally retaining teachers at highpoverty, high minority, high needs urban high schools.

\section{Implications for Practice}

To create a learning environment that embraces equity and social justice for all students a principal must demonstrate the use of invitational leadership characteristics. By doing so this will result in a myriad of implications for practice. One implication would be for universities to emphasize the tenets of invitational leadership within their leadership preparatory training programs for educational leaders. Another implication is for school districts to provide ongoing training in invitational leadership, coupled with a social justice emphasis not only for educational leaders but also teachers. A third implication is for invitational leadership and social justice theories be in the forefront of all critical discussions in urban settings when they are visiting their mission statements or planning their professional development for teachers and leaders.

In summation, to create an effective learning environment in urban school settings that will support all teachers, a leader must exhibit the characteristics of an invitational leader with a focus on social justice orientation. The leader must be intentional in all daily actions to be demonstrating equity, trust, respect, and optimism. By undertaking such intentionality, the school will be enriched by the spirit of a partnership between all educators that is upholding trust and 
respect, resulting in the educators being passionate about social justice and equity for all students. Specifically focusing on the five P's of invitational leadership (people, policy, places, processes and programs) this ethos of equity can permeate throughout the school. In the end, if a leader seeks an inviting learning environment, one that creates a climate of inclusiveness and equity, then ultimately all students will experience the social justice they so deserve.

\section{Recommendations}

Whether a novice principal or a seasoned principal who is exploring ways to more effectively retain the teachers that children need most, here are the recommendations based off the learning of this study.

Recommendation one. Start with humanity - Every adult needs to value every child in the school for who they are in their authenticity. It is incumbent upon adults to explore their implicit biases to better understand what could possibly hold them back from fully supportingthe growth of each child. Principal B recognized that she was not sharing her whole self with the students and staff members from the LGBTQIA community. She was vulnerable in front of her staff in recognizing she needed to work more intentionally to understand and support stakeholders in this group. No longer was she going to accept from herself that she would move about the world in, "simply allowing them to do them, while I do me."

Recommendation two. Commit to Collective Learning - Each of the school leaders modeled such effective practices in continued learning with their staffs. Not only were they willing to take the lead on learning to invite people in, but they also consistently valued what others could teach them. Principal A was ready to lead the charge in their work to confront racism from every angle within their school. He was consistently asking staff, community 
members, and partners what they could do better to serve the students and community. This included asking the public defense attorney each week what they could do to help a student, asking teachers what is the best thing to teach in the social sciences strand which led to every student having an ethnic studies class in the ninth grade, and national organizations like the researcher's what really were the best pathways for their student.

Recommendation three - While neither principal in the study was familiar with invitational leadership introduce themselves to the tenets of invitational leadership as outlined below (Purkey \& Novak, 2015) they were both actively integrating the tenets into the daily practices in the buildings they led. The goal of every school in the nation should align with William Purkey and John Novak's call to “intentionally summoning people to realize their relatively boundless potential in all areas of worthwhile human endeavor. (2015, p. 1). Introducing the practices of Invitational Theory, as exemplified in the following diagram, to the staff and integrating them into your school culture will allow for each person to have the opportunity to reach their boundless potential. 


\section{Invitational Theory}

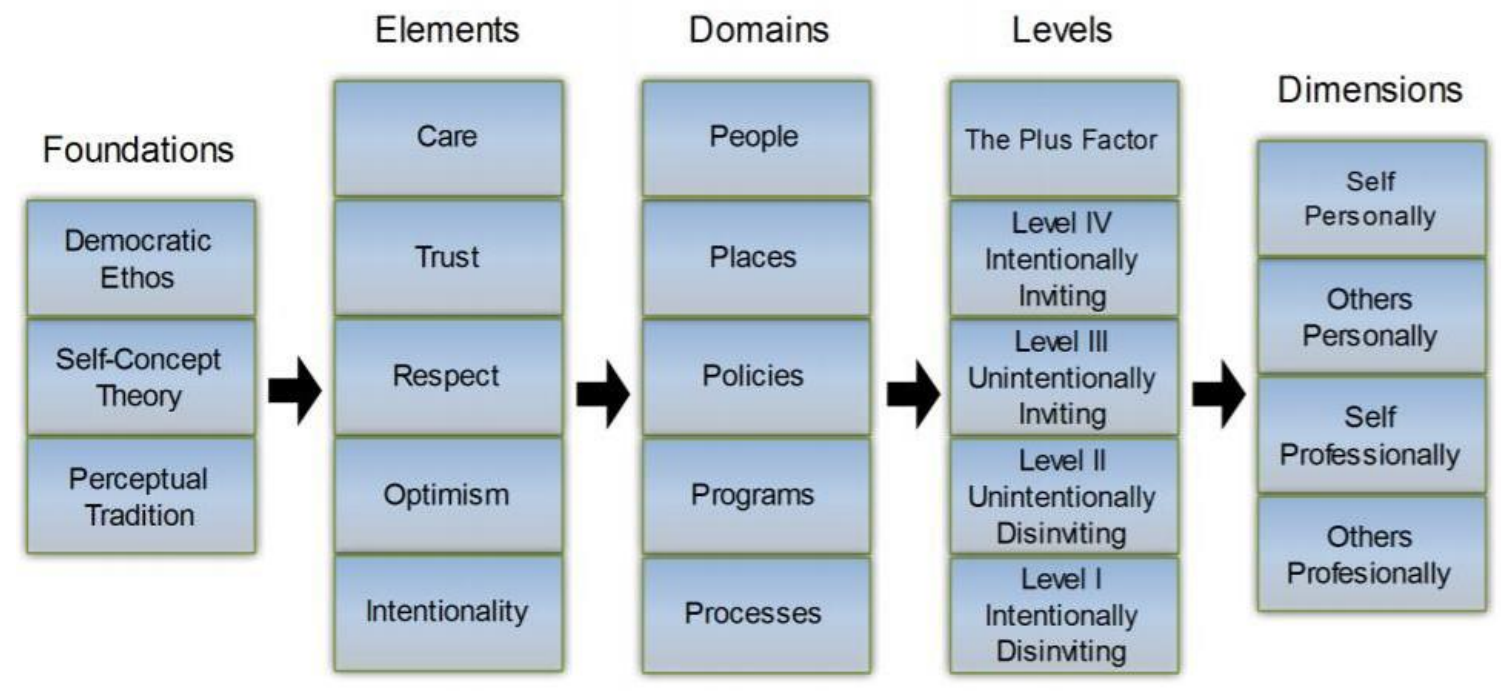

Recommendation four: Keep the tenets of social justice leadership as defined by Theoharis (2008) at the front of mind. Our schools remain largely separate and unequal. "More than half of the nation's schoolchildren are in racially concentrated districts, where over 75 percent of students are either white or nonwhite." Teachers and students need a leader to intentionally reflect on how they can act with arrogant humility, passionate visionary leadership, and a tenacious commitment to justice.

- Arrogant humility: Leaders hold a headstrong belief that they are the rightperson to lead the team toward the vision of social justice for the students and families they serve while paradoxically being filled with self-doubt. They are humble enough to know after self-reflection when they need to admit when they are wrong. They wonder if they indeed are the right person for the role of principal.

- Passionate visionary leadership: These social justice principals stand as transformational leaders who are driven by such deep care, commitment, and 
enthusiasm toward championing a strong vision. These components become realized in such a passion that there is a tightly interwoven connection between the principal position and the person doing that job.

- Tenacious commitment to justice: The leader maintains a fierce and sustaining commitment to equity and justice not only for their staff but also forthemselves (p. 17).

When Principal A and Principal B from this study were asked if they thought any or all of these descriptors could be ascribed to them, neither would anoint themselves, yet both saw these descriptors as ones to which they aspired. Conversely, they were aspirations that the participants overwhelming shared were not only present in the leadership of each principal, but a reason as to why those teachers, staff, and community members stayed working at each of the schools with those principals.

Recommendation five. Start a "Grow Your Own" teacher program from your current student body. We know the pipeline is not full enough to mee the needs of our students in our overall school populations and that our schools serving high-poverty, high-minority populations are going to have some of the greatest deficits in meeting the needs (Sutcher, et al., 2016). In both schools we saw a great number of teachers and educators come back to the school where they went to be a part of the solution. In School A, over twenty teachers and staff members had gone to school there. School B was not only being led by an alumnus, but also had a counselor and a teacher who were alum who were key figures in their success. Programs are starting in schools across the country. Kansas City Public Schools has one and states like Illinois have full organizations dedicated to this movement (Grow Your Own, 2020). 
Recommendation six. Both school leaders were extremely effective models of moving beyond simply coming into their communities for their professional duties. They expanded beyond to make their lived experience in all aspects of life take place in the community where their schools were located. Principal B not only was committed to working in the community at the school level she lived in the community and had her three daughters go through the school system. She is now working to start support groups for women in education who serve the community. While Principal A is of Italian American descent, his consistent engagement with the community and ability to speak the Spanish language of his predominantly Latinx community has many, "considering him on of our own." Each of the principals knew their community extremely well from immersing themselves in it which not only allowed them to better understand the challenges within their communities, but also how to take an inviting stance and be trusted as part of the solution.

With the economic challenges expected due to the pandemic caused by COVID-19, a shortage of teachers in the pipeline that was already a challenge (Podolsky et al, 2016; Sutcher et al, 2016) is expected to get worse (Page, 2020). There are tough challenges in schools throughout the country as evidenced by the two schools profiled. Yet, this research found the actions of two principals using the tenets of invitational leadership with a social justice orientation cannot only bring the teachers in who the leader and community want in the school, but play a major role in them staying.

\section{Plan for Dissemination of Practitioner Contribution}

Following the oral defense and the approval of the research, the researcher plans to submit the finding to various organizations and conferences. First, it will be presented to the administrative team of each school as each school leader agreed to be the focus of this qualitative 
study with the caveat that I share the findings with them individually and also through the collective learning of their developing administrative teams. Because this is an issue that is also affecting students of color, a proposal will be made to both the Preparate and the A Dream Deferred Conferences of the College Board. Both conferences focus on how schools are creating access through increasing their Advanced Placement Course offerings. Since school A serves a predominantly Latinx population, the Preparate Conference focuses upon offering Advanced Placement to Latinx students. And since school B serves a predominantly Black population, the A Dream Deferred Conference focuses upon offering Advanced Placement to Black students. The high-poverty, high-minority communities, served by both conferences also have the challenge of high teacher turnover (Podolsky et al. 2016; Sutcher et al., 2016; Waddell, 2010), which is also a good fit for the distribution of these findings.

The concepts will also be integrated into the National Math and Science Initiative Leadership Development Summer Series and 365 Days of Support for School Leadership Teams. The researcher serves as the Senior Manager, Leadership Development, who serves as the lead designer and trainer for content development at the National Math and Science Initiative. As the organization's goal is to serve students furthest from the opportunity, the need to recruit and retain teachers for their advanced academic coursework will be vital to meeting the shared goals of the partnership.

A proposal will also be made to present at the 2021 World Conference for the International Alliance for Invitational Education. With the stated goal of creating inviting work and learning environments for individuals to achieve their full potential, the finding of the work may be of great benefit to leverage into the schools having the most significant challenges recruiting and retaining teachers. 


\section{Executive Summary}

\section{How a Principal's Action as an Invitational Leader with a Social Justice Orientation Can Serve as a Factor in Recruiting and Reciprocally Retaining Teachers at a High-Poverty, High- Minority, High-Needs Urban High Schools}

The teacher shortage was predicted to meet crises levels by the start of the 2020 academic year (Sutcher, et al., 2016). With the arrival of the Covid-19 pandemic, this may be exacerbated even further by early retirements and people leaving the profession due to the stressors caused through hybrid teaching (Page, 2020). In several studies (Greenlee \& Brown, 2009; Ingersoll, 2003; Roenfeldt, et al., 2013) it has been shown that those schools who serve populations of highminority students from urban, low socio-economic and low academic achievement backgrounds have higher rates of turnover than schools in more affluent, higher academic achieving predominantly White schools. Principal actions do matter considerably with ideas in hiring and personnel management, induction and support, and school-working conditions (Burkhauser, 2016; Grissom, 2011; Sutcher et al., 2016; Waddell, 2011; Watkins, 2005). Martin and Miller (2017) aligned invitational leadership with a social justice orientation in relationship to principal preparation to leading diverse student populations. Further exploring this connection between invitational education (Purkey and Novak, 2011) and social justice leadership as defined by George Theorharis (2008), it was the goal of the researcher to answer the overarching question:

Can a principal's action as and invitational leader with a social justice orientation serve as a factor in recruiting and reciprocally retaining teachers at a high-poverty, high-minority, high-needs, urban high school?

The following questions drove the study when answering the larger question:

1. What tenets of invitational leadership are evident within the leadership style ofthe principal?

2. How do the tenets of the invitational leadership style of the principal impactthe retention of teachers within a high poverty school setting?

3. What behaviors of the principal demonstrates the desire to act in the orientation of social justice?

4. How are the tenets of invitational leadership and the orientation of social justice displayed within the school community by the stakeholders (principal, teachers, and community)? 


\section{Conceptual Framework}

\section{Social Justice Leadership}

Arrogant Humility, Tenacious Commitment

to Justice, Passionate Visionary Leadership

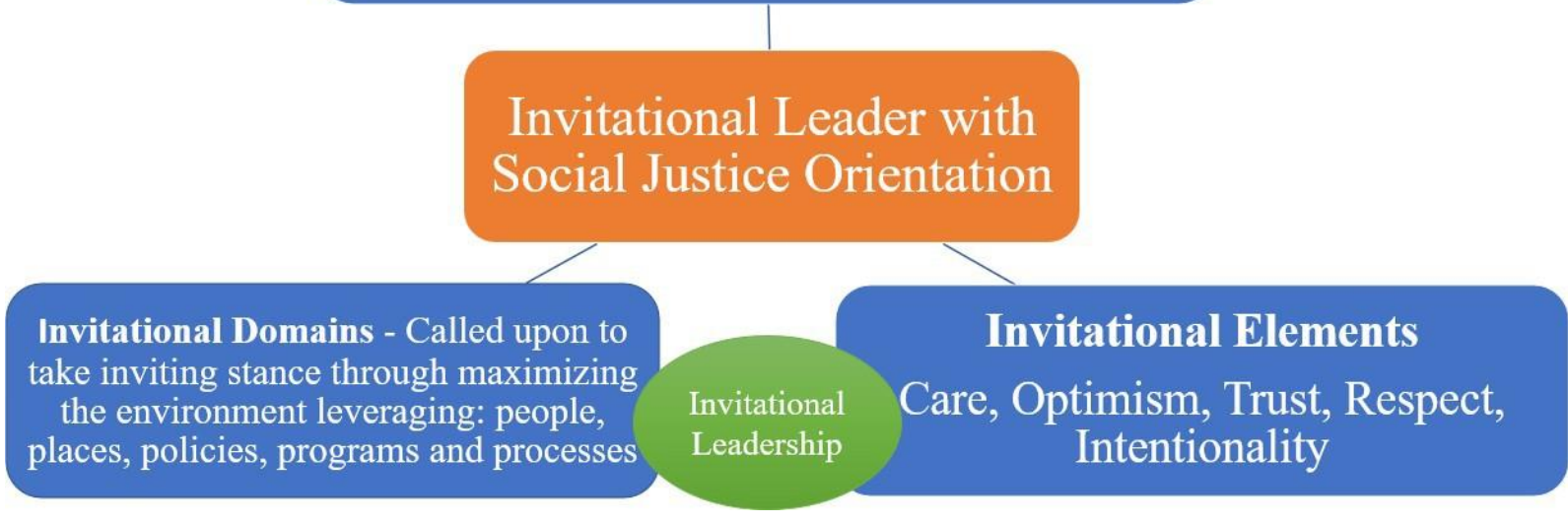

\section{Description of organizational setting for the research}

School A is located in a major city in the Silicon Valley of California where, according to bestplaces.net, the median home cost is over a million dollars and more than four times the $\$ 231,200$ home price cost in the United States. According to the 2018 Silicon Valley Dichotomy Study (Keen, 2018), the Latino and Black populations of the area are decreasing due to the low wages for less educated people, making it challenging to meet the economic demands of day to day living. Other at-risk groups include the immigrant Vietnamese and Filipino populations. The ability to move up the socio-economic ladder for these minority groups is complicated as many families lack the financial capital to invest in their career goals and are unable to get the required training or entry-level jobs into the jobs in the high paying, high-skills industries in the area. Accordingly, there is evidence of employment opportunities being unequal based on race compiled with time and fiscal deficits disallowing educational opportunities. In an atmosphere where "working harder wasn't enough to achieve self-sufficiency" (Keen, 2018, p.17), families are left working multiple wage jobs, having numerous families living in single dwelling units, cutting back on non-housing goods and services, and investing less in education. In the 25 to 29 age group, only $22 \%$ of native-born and $9 \%$ of foreign-born Latinos have a higher degree, juxtaposed against $70 \%$ of non-Hispanic White immigrants having a higher degree. Within this setting, the opportunity gap is stark, and the need for inviting social justice leaders is vital for the populations lacking in opportunity.

School B is in a large mid-western city in an area that has suffered through significant disproportionality in school funding, racial segregation, and teacher turnover throughout its history (Kozol, 2005). At the district's height of enrollment in the district, there were over 115,000 students. Unfortunately, the city also served as a model for red-lining and segregation (Rothstein, 2014). The consequences were devastating to Black students, noted as a "separate 
and unequal system" by the former head of the American Federation of Teachers, Local 420 (Bryant, 2017). The finances to compete are not in the district favor as the tax base continues to dwindle as the city was once home to twenty-three Fortune 500 Companies is now down to nine, while aid from the state is 9 percent below the state's average (Bryant, 2017). The resources of the city are further dispersed on the state ruling in 1998 that charter schools were able to open in only that district and the other significant, predominantly minority, the low-socioeconomic district in the state. To keep students in the district, they have gone to a magnet model where 13 schools are selective admission (Bryant, 2017). School B is one of them.

Table 1: Demographic of Schools

\begin{tabular}{cccccccc}
\hline School & Enrollment & $\begin{array}{c}\text { Students } \\
\text { Prevalent } \\
\text { Race }\end{array}$ & $\begin{array}{c}\text { Socio- } \\
\text { Economically } \\
\text { Disadvantaged }\end{array}$ & $\begin{array}{c}\text { Total } \\
\text { Teachers }\end{array}$ & $\begin{array}{c}\text { Average } \\
\text { Years } \\
\text { Experience }\end{array}$ & $\begin{array}{c}\text { Years at } \\
\text { Site }\end{array}$ & $\begin{array}{c}\text { Highest } \\
\text { Degree } \\
\text { Earned }\end{array}$ \\
A & 1,388 & Latinx & $85.4 \%$ & 80 & 14 & 7 & Masters \\
B & 400 & Black & $91 \%$ & 29 & 13 & 13 & Doctorate
\end{tabular}

While the themes and recommendations presented below appear in and order, they are not in any specific order of importance.

\section{Themes from Data Analysis}

Actions of the Principals
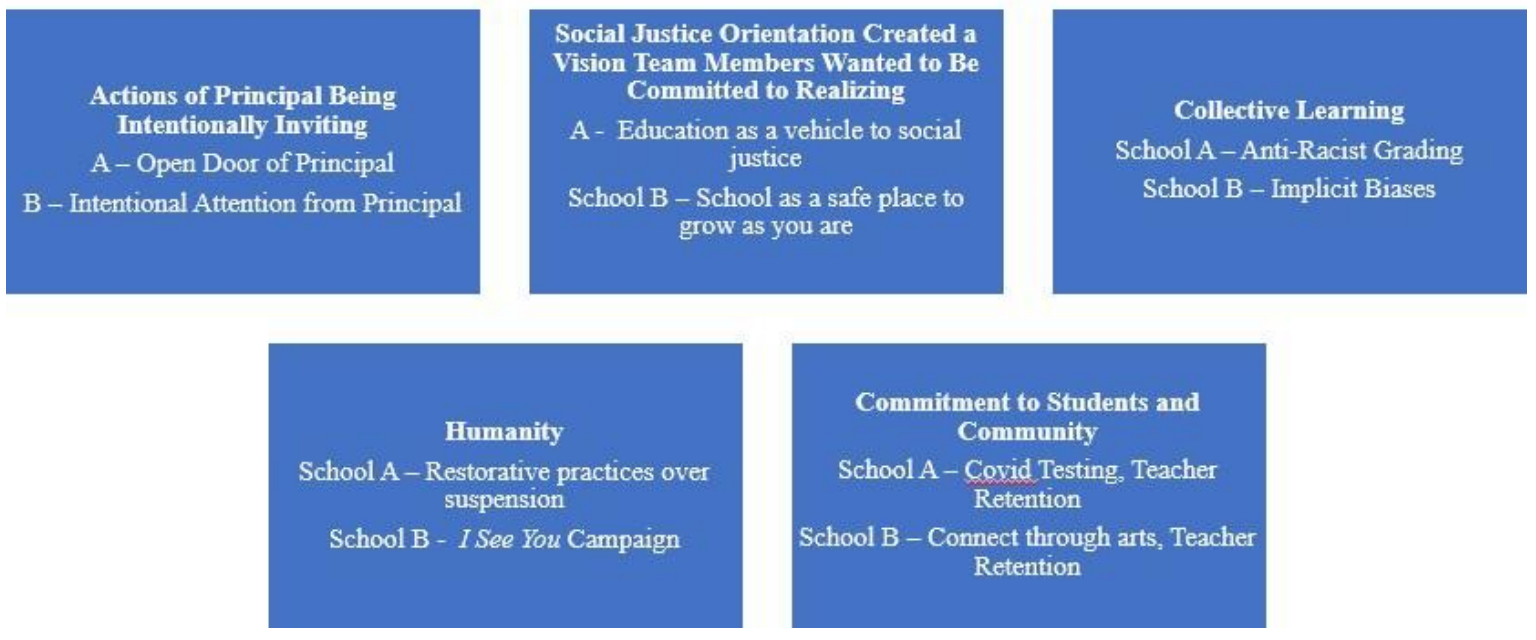


\section{Recommendations}

The recommendations below are based on the themes and the practices elicited from the study.

1. Start with humanity - Every adult needs to value every child in the school for whothey are in their authenticity. It is incumbent upon adults to explore their implicit biases to better understand what could possibly hold them back from fully supporting the growth of each child.

2. Commit to collective learning - Explore what learning you want to bring to your staff and community while being open to what they want to bring to you. Learning canhappen through studies, but during interactions as well. Take the time to listen to what your stakeholders are trying to teach.

3. Learn and integrate the sections of Invitational Theory into the school culture There is a great deal to learn

4. Explore the social justice orientation using the definition set by George Theoharis The positional power afforded in the role can send the symbolic message to the community that all will be valued.

5. Create a "Grow Your Own" program - Seize the energy of the current generation of students' desire to be a part of the solution. As noted by Principal A, "I am driven by education as a social justice tool."

6. Be of the Community - Move beyond just being in the community during school hours or for work related duties. Use the stores, visit the churches, and bring your family to the parks and community centers. 
The guiding diagram at the center intentionally places the Principal in the middle to symbolize the reciprocal area of intentional action of which the principal needs to take. In return, the researcher contends these will be the drivers that will reciprocally keep the principal surrounded by support in the community.

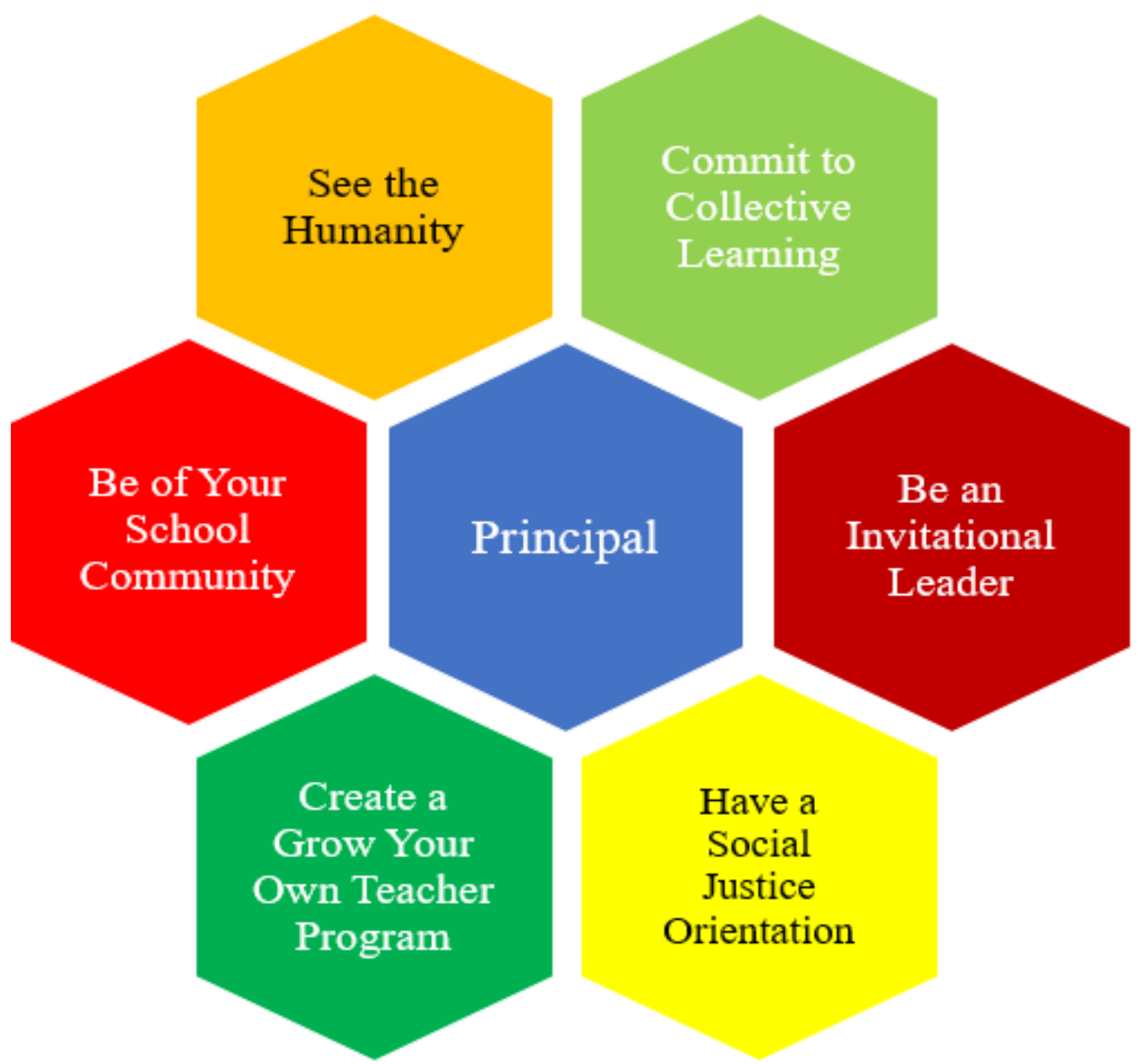


SECTION FIVE:

CONTRIBUTION TO SCHOLARSHIP 


\section{Target Journal}

The Journal of Education and Culture Studies will be the targeted publication for article submission. The research builds upon the work of Martin and Miller (2017). Attempting to be published in the same journal where this work was published will allow easier access for those with the desire to learn more about the effectiveness and possibilities of invitational practices with a social justice orientation in schools. The journal is also an open-access journal that aims to disseminate excellence of the professional issues that reflect the diversity in the education field. The journal includes, but is not limited to:

- English education

- Education method

- Cultural studies

- Cultural history

- Arts and leadership

- Educational technology

- Religions

- Films and fashions

- Communication studies

- Political science

- English literature and linguistics

- Gender and education

- Training, teaching, and learning

- Translation 
Another targeted journal selected for article submission is Urban Education. The selection of the journal was due to the two schools being targeted are both considered inner-city, urban schools. The journal touts its focus on critical issues facing inner-city schools (Urban Education, 2019). Besides, the journal has eight interdisciplinary focus areas:

- Curriculum and Instruction

- Counseling and Social Services

- Education Policy

- Equity in Urban Education

- Leadership

- Psychology and Human Development

- Special Education

- Teacher Education

Papers should not exceed 11,000 words, including references, abstracts, and table figures, and should follow the American Psychological Associations (APA) format. Manuscripts should be submitted online. (Urban Education, 2019). 


\title{
HOW A PRINCIPAL'S ACTION AS AN INVITATIONAL LEADER WITH A SOCIAL JUSTICE ORIENTATION CAN SERVE AS A FACTOR IN RECRUITING AND RECIPROCALLY RETAINING TEACHERS AT HIGH-POVERTY, HIGH-MINORITY, HIGH NEEDS URBAN HIGH SCHOOLS
}

by

\author{
William E. McDowell
}

\begin{abstract}
Will McDowell is the Senior Manager of Leadership Development at the National Math and Science Initiative. Having spent time as a teacher, school principal, professional developer, and educational consultant in an array of schools of all demographics and levels around the country, he has seen the positive effect a school leader can have. Introduced to Invitational and Social Justice Leadership theories by his professor Dr. Barbara L. Martin, he has integrated the tenets of Invitational Leadership in the training of over 200 schools nationally on ways they can engage students furthest from opportunity in advanced academics.
\end{abstract}




\begin{abstract}
The number of individuals going into the teaching profession was dwindling at a time when the rate of retirement and people leaving the profession was increasing. Sutcher et al. (2016) noted that in 2015-16, the United States was short 64,000 qualified teachers. They predicted this to grow to as much as 300,000 teachers needed per year by 2020 and up to 316,000 by 2025. The COVID-19 pandemic may exacerbate this challenge even more (Page, 2020). Teachers need to be recruited, supported, and retained in high-poverty, high-minority, highneeds, urban high schools (Freedman \& Appleman, 2008; Greenlee \& Brown, 2009; Hughes, 2012; Petty, et. al, 2012; Podolsky, et. al., 2016; Simon \& Johnson, 2015; Stotko, et. al., 2006; Waddell, 2010). In a time when inequities are being exacerbated in the field of education, the principals and the teachers will be called upon to do more with less (Page, 2020). Empowerment of school principals who are willing to take on the schools that are the most challenging (Bartanen, 2019; Levin \& Bradley, 2019) is needed. They must to be trained to demonstrate leadership dimensions and supporting actions (Martin \& Miller, 2017) that can guide them to build a team of team of irreplaceable teachers (The Irreplaceables, 2012), which will build collective efficacy (Hattie, 2016) to help students furthest from opportunity reach their high potential in academic and personal achievement. In the contention of Martin and Miller, (2017) aligning the dimensions of invitational leadership (Purkey \& Novak, 2016; Purkey \& Siegel, 2003) with action and self-reflection of social justice leadership for principal leadership will better prepare principals leading schools with diverse populations. This study further contends that if the principal's action as an invitational leader with a social justice orientation it will serve as a factor in recruiting and retaining teachers in the schools where they are needed most.
\end{abstract}




\section{Key Terms}

Disproportionality, High School, Invitational Education, 5 P's of Invitational Education, Principal, Reciprocal Teacher Retention, Social Justice Leadership

\section{Introduction}

In October of 2016, a research team working with the Learning Policy Institute (LPI) out of Stanford University created two seminal reports regarding the supply and demand of educators entering and staying in the teaching profession. The team from LPI, including long time social justice education advocate Linda Darling-Hammond, sounded the alarms of a teacher pipeline that was quickly dwindling and needed answering. With the publishing of A Coming Crisis in Teaching?: Teacher Supply, Demand, and Shortages in the U.S. (Podolsky et al., 2016) and Solving the Teacher Shortage: How to Attract and Retain Excellent Educators (Sutcher, DarlingHammond, \& Carver-Thomas, 2016) the team identified the problem of the teacher shortage with the reasons why it exists and detailing solutions. While their research added to a heavily researched topic searching for these answers of teacher shortage, recruitment and retention (Bornman \& Dowling, 2008; Heineke et al. 2014; Hughes, 2012; Ng, 2003; Petty, et al., 2012;

Sachs, 2004; Simon \& Johnson, 2015; Stotko et al., 2007; Waddell, 2010), these studies offered a one-stop, cumulative, extensive resource. The reasons they gave for the teacher shortage included among others the projected supply and demand, increased demands of teachers, the pressure of accountability measures, cost of entry into the profession, decision-making power, experiences with professional development, and lack of parental support or involvement. They would go on to argue that attrition was most significant in high poverty schools due to lower salaries and more impoverished working conditions (Podolsky et al., 2016, Sutcher, et al., 2016). Made were policy recommendations to turn the tide to more effectively recruit and retain 
teachers in the following five areas: Salaries and compensation; Preparation and costs to entry; Hiring and personnel management; Induction and support for new teachers; and, Working conditions, including school leadership, professional collaboration, shared decision-making, accountability systems, and resources for teaching and learning (Sutcher et al., 2016).

Consequently, while the principal may not influence each on these suggestions, their actions do matter considerably with ideas in hiring and personnel management, induction and support, and school-working conditions (Burkhauser, 2016; Grissom, 2011; Sutcher et al., 2016; Waddell, 2011; Watkins, 2005). Sutcher et al. (2016) validated this observation:

A comprehensive research review of attrition in high-poverty schools finds that the most significant workplace conditions associated with teacher attrition are teachers' perceptions of their principal, collegial, and school culture.... When teachers strongly disagree that their administrator encourages and acknowledges staff, communicates a clear vision, and generally runs a school well, turnover rates for movers and leavers jump to nearly one in four, more than double the rate of those who feel their administrators are supportive (p. 51).

Unfortunately, the rate of principal turnover in high-poverty, high-minority, and highneed urban high schools was also significant (Clotfelter et al., 2007). In fact, by 2022, the demand for k-12 principals had increased by six percent nationwide due to population increases. Similarly, while the cost to recruit, hire, prepare, mentor, and continue training principals cost the typical high poverty, high-minority, high-needs urban principal $\$ 75,000$ to qualify (NASSP.org, 2020). Meanwhile, during the 2016-17 academic year, more than a third of principals did not surpass two years at the same school. Conversely, only eleven percent stayed at the same school for a decade or more (Levin \& Bradley, 2019). Additionally, in the ranking of 
252 influences and effect sizes related to student achievement, student mobility ranks $248^{\text {th }}$, one step worse than corporal punishment in the ranking (Hattie, 2018). This agitated school principals, teachers, and students in high needs schools.

This mix of principals, teachers, and students in and out of the school led the researcher to examine whether there is a connection between the leadership practices of two principals in low-income, high-minority, urban settings. One high school had a predominately Latino population in California, and the other school demographic was predominantly Black, in a Midwestern city. Each school possessed a lower teacher turnover rate, as compared to similar schools within their region, and thus were selected as the cases examined within the inquiry.

Presented within this chapter is the problem, and the purpose of the research, along with the research questions to guide the study. As well, discussed is the conceptual framework, research design, research methodology, and significance of the study.

\section{Statement of the Problem}

The number of individuals going into the teaching profession was dwindling at a time when the rate of retirement and people leaving the profession was increasing. Sutcher et al. (2016) noted that in 2015-16, the United States was short 64,000 qualified teachers. They predicted this to grow to as much as 300,000 teachers needed per year by 2020 and up to 316,000 by 2025 . These numbers would put the United States at an average shortage of 112,000 teachers per year with the main drivers of this being a decline in teacher preparation enrollments, district efforts to return to pre-recession pupil-teacher ratios, increasing student enrollment, and high teacher attrition (Sutcher et al., 2016). 
The schools serving high-poverty, high-minority, high-needs populations are some of the hardest hit by these teacher shortages where up to one-half of the teachers leave within the first five years (Ingersoll, 2001). In several studies (Greenlee \& Brown, 2009; Ingersoll, 2003; Roenfeldt, et al., 2013) it has been shown that those schools who serve populations of highminority students from urban, low socio-economic and low academic achievement backgrounds have higher rates of turnover than schools in more affluent, higher academic achieving predominantly White schools. This level of turnover becomes extremely expensive and diverts money away from other school needs that could support students (Shernoff et al., 2011). Additionally, having waves of new teachers created a myriad of other problems including staff reconfiguration, novice teachers tried to help other novice teachers learn the job, inability to build sustaining collegial relationship among staff or trusting relationships with students, and a lack of social capital where teachers were willing to take on leadership roles (Simon \& Johnson, 2015). Similarly, Borman and Dowling (2008) explored several factors that catalyzed teacher turnover including student body characteristics such as race, socioeconomic status, achievement abilities; teacher demographics such as gender, race, and age; the level of training, experience, and expertise of the teacher; and contextual factors of the school like class size, school location, working conditions, and teacher salary.

Notably, while educators had more than half a century of efforts to integrate student populations, still more students attend racially concentrated schools where the student population was either more than $75 \%$ White or $75 \%$ of students of color than those who did not (Edbuild.org, 2019). Considering an overwhelming 84\% majority of the teaching population in the United States was White, while the student population is $47 \%$ of students of color could create challenges (Waddell \& Ukpolodu, 2012). Many of these teachers come from middle-class 
backgrounds, and their ability to relate to students becomes difficult (Fergus, 2017; Kozol, 2005). When matching the demographics of the teachers available being White middle class with the demographics of most high poverty, urban high schools being students of color there needs to be time to develop skills to overcome general biases such as deficit thinking, colorblindness, and racial discomfort that negatively correlate with a teacher's self-efficacy (Fergus, 2017). One must be intentional over time to be able to learn how to be a culturally responsive educator where one understands how to engage students in the productive struggle to close the achievement gap while the students become independent learners (Hammond, 2015, p. 12). The opportunity to build the needed professional capital of teachers that would have a historical context of the school, community, and students is not there from year to year. As a result, a majority of new staff must reinvent what the school will do to serve that year's cohort of students (Hargreaves \& Fullan, 2012).

The supports teachers want to include school leadership, collegial relationships, and elements of school culture (Simon \& Johnson, 2015, p. 5). Burkhauser (2016) argued the person who can play a more significant role than any other in creating a school environment where teachers will want to stay with the principal. Fullan (2014) noted that two of the criteria that are most important for teachers to stay is the quality of their colleagues and the quality of school leadership, "Humans are fundamentally motivated by two factors: doing things that are intrinsically meaningful to themselves, and working with others - peers, for example - in accomplishing worthwhile goals never before reached" (2014, p. 7). This is echoed by Buckingham and Goodall (2019) when they found that people would come for the mission but stay for the team with whom they worked. They went on to note when teams share vision and values, they engage and accomplish at higher rates, 
This inquiry aims to examine the connection of a leader's commitment at a high-poverty, high minority urban school to following the tenets of invitational leadership. Furthermore, this examination will attempt to reveal how that connection leads to a commitment from teachers, parents, outside stakeholders, and the principal to continue to engage in the development of students beyond the two-year tenure of many high needs schools (Bradley \& Levin, 2019). There have been inquiries regarding the benefits of invitational leadership within high needs urban high schools (Martin \& Miller, 2017), and examinations of what principals can do to attract and retain excellent educators in high needs urban schools (Burkhauser, 2016; Johnson \& Simon, 2015; Podolsky et al., 2016; Waddell, 2010). Little has been studied on the connection between the retention of teachers in high poverty settings due to the tenets of invitational leadership, integrating the actions of a social justice leader being present through the principal's leadership.

Specifically, the purpose of this research was to determine the connection between adherence of the school leader to the principles of invitational leadership theory, while integrating social justice in high poverty urban high schools.

\section{Research Questions}

Within the context of this study using qualitative inquiry, the researcher seeks to answer the following research questions:

1. What tenets of invitational leadership are evident within the leadership style ofthe principal?

2. What behaviors of the principal demonstrates the desire to act in the orientation of social justice? 


\section{Conceptual/Theoretical Framework}

Intending to realize fully and provide the framework needed to understand the significance of this study, presented are two separate frameworks: social justice leadership (Theorharis, 2007) and invitational leadership (Purkey \& Novak, 2016). Martin and Miller (2017) recognized the connection between the two when one of the emerging themes in their work included, “Addressing Social Justice Inequities through the Six P's." The six P's is a reference to the six P's of invitational education (Purkey \& Novak, 2016). Following their line of inquiry, this research will have a greater focus on the connection of sustained engagement through invitational leadership practices employed by the school principal. This focus on two high poverty, high minority, high needs urban high schools also invites the exploration into the principal's engagement in socially just leadership practices. Presented below are the two frameworks.

\section{Social Justice Leadership}

In much of the high poverty, high minority, urban high schools, the proportion of White females teaching Black, Latino, and Native American students has increased while Black and Latino students were primarily attending schools with only Black and Latino students has risen (Fergus, 2019). Therefore, teachers in these schools need leaders grounded in social justice, as defined by Theoharis (2007). The latter, "make issues of race, class, gender, disability, sexual orientation, and other historically and currently marginalizing conditions in the United States central to their advocacy, leadership, practice, and vision" (p. 223). Accordingly, the social justice theory will be an overarching theory further explored. Theorharis's (2008) definition of social justice leadership "...is to mean that these principals advocate, lead, and keep at the center 
of their practice and vision issues of race, class, gender, disability, sexual orientation, and other historically and currently marginalized conditions in the United States" (Theoharis, 2008, p. 5).

The conditions in highly segregated, high poverty schools led to teachers leaving the profession early or at least not staying multiple years (Grissom, 2011; Podolsky et al., 2016; Stotko, 2006). With so much focus on this turnover of teachers, few had noticed that the principal turnover rate surpassing the teacher turnover rate (Bartanen, Grissom, \& Rogers, 2019). Consequently, the turnover with a principal exacerbated the rate at which teachers left, creating a level of adult professional unrest that unsurprisingly coincided with student test scores falling in a school (Bartanen et al., 2019). Compile this with high poverty schools (Samuels, 2012; Podolsky et al. 2016) it becomes vital that the school finds a leader who is willing to build a team where teachers will come for the mission while staying for the team (Buckingham \& Goodall, 2019).

Compared to other leadership theories, the social justice theory in educational leadership literature was comparatively new (Bogatch, 2000). Bogatch sought the creation of a comprehensive view of different perspectives, such as what social justice leadership should entail. He argued that the ongoing struggle for social justice in education has gone on for decades. He saw that in educational leadership, “an individually-minded principal is often called a maverick; an individually-minded teacher leader is called a trouble-maker. Neither are included under the banner of loyalty to the system" (2000, p.6). He challenged educational leaders to create social and political space for social justice advocacy by arguing four parameters in the name of educational leadership. These parameters are:

5. There can be no fixed or predictable meanings of social justice beforeactually engaging in social and academic discourses; 
6. The center or unity of any educational reform is so dynamic that it cannothold together for long;

7. The result of our work (just and unjust) are always fragile and fleeting; and,therefore,

8. All social justice/educational reform efforts must be deliberately andcontinuously reinvented and critiqued - again and again. (Bogatch, p.10)

For Bogotch (2000), one could not challenge themselves to be a real educational leader without advocating for social justice. "And at every step, articulate how our actions connect to social justice inside and outside of schools" (p.10).

Subsequently, Theoharis (2008) conveyed the following leadership traits were evident in principals following the ethos of social justice leadership.

4. Arrogant humility: Leaders hold a headstrong belief that they are the right personto lead the team toward the vision of social justice for the students and families they serve while paradoxically being filled with self-doubt. They are humble enough to know after self-reflection when they need to admit when they are wrong. They wonder if they indeed are the right person for the role of principal.

5. Passionate visionary leadership: These social justice principals stand as transformational leaders who are driven by such deep care, commitment, and enthusiasm toward championing a strong vision. These components become realized in such a passion that there is a tightly interwoven connection between the principal position and the person doing that job.

6. Tenacious commitment to justice: The leader maintains a fierce and sustaining commitment to equity and justice not only for their staff but also for themselves (p. 17). 
These sentiments were further echoed when Santamaria (2014) in referencing the concept argued during a 2011 ruling by Supreme Court Justice Sonia Sotomayor when she stated, "Inequality in education is the most pressing issue in diversity in the United States" contributes to, “...make educational equity and diversity mainstream issues for practitioners, scholars, and policymakers to consider" (p. 247). Social justice leadership is an inclusive leadership that engages relationships not only in dialogical, collaborative, reciprocal, and horizontal ways; they also promote equity and justice through caring fluid relationships among various leaders (Wang, 2018).

Any principal in a high-poverty, high-minority, high-needs, urban high school is taking on a role where persistent inequalities concerning distinguished groups, including among others race, sexual orientation, ethnicity, social class, and language of origin continue to exist (Dantley \& Tillman, 2010). Yet, the promising literature on social justice leadership lacked in specific skill sets employed by these leaders (Furman, 2012). Therefore, within this inquiry, it was contented the social justice leader would be recognized as a maverick, while also needing many troublemakers as denoted by Bogatch (2000). Therefore, he or she must have taken an invitational posture to gain the vision, buy-in, and clear structure needed to retain teachers within the high-poverty, high-minority, high needs urban high school (Novak, 2001; Purkey \& Novak, 2016).

\section{Invitational Leadership}

Considering the desire for accessible actions, invitational leadership (Novak \& Purkey, 2001, 2016) became the primary theory used for this study. Invitational leadership affords a school leader an immediate structure to work through an inviting stance after which the actions 
are taken to affect the people, place, policies, programs, processes, and politics of the school building lead to an inviting environment (Martin \& Miller, 2017). If the schools are going to find success, teachers in high need, high poverty communities, must stay for at least five years (Stotko, 2007).

The solutions offered to retain teachers in high needs schools include culture (Borman \& Dowling, 2006; Ingersoll \& Smith, 2003; Watkins, 2005), structures for leadership opportunities (Yonezawa et al., 2011), collegial support (Simon \& Johnson, 2015), and the chance to shape and influence within the school (Rice, 2010). This, coupled with working conditions cited by Podolsky et al. (2016), included school leadership, professional collaboration, and shared decision-making, accountability systems, and resources for teaching and learning (Podolsky et al., 2016, p. 8). Addressing all these variables was the framework of invitational leadership (Purkey \& Novak, 2016).

Being an invitational leader encompasses all aspects of one's life as the leader calls forth all around them to pursue a life of purpose when they "invite their colleagues, family, friends, loved ones, and community to do the same" (Purkey \& Siegel, 2003, p.3). A school's climate contributes to psychological well-being, student achievement, positive youth development, and how stakeholders perceive the school (Anderson, 2019; Heineke et al., 2014; Kardos \& Johnson, 2007). An inviting educational environment will carry themes of passionate partnership, motivational inspiration, and organic nous of affinity (McKnight \& Martin, 2013). The high school principal can have the most significant effect of any individual on the school to create such an environment (Borman \& Dowling, 2006; Ingersoll \& Smith, 2003; Watkins, 2005). The principal can influence a productive school climate through "the leaders' demonstrated 
emotional self-control and emotional management of others" (Anderson, 2019, p. 47). A leader can do this by following the tenets of Invitational Education theory.

Novak (2002) referenced, “... being an invitational educational leader is like being on a tennis court with another" (p. 70). The leader controls what can be controlled then delivers the idea or concept to the other. The goal is to make solid contact, then in a dialogical fashion, allow the other to receive it. The leader bases this in an inviting stance (Novak, 2002). Novak defined the principles of invitational leadership to be:

Care - $\quad$ Possessing full receptivity to the other through de-centering oneself and listening for interests and meaning expressed by the other.

Respect - Give the other person time to own their part of the relationship.

Trust - Recognize the interdependence of people. Possessing confidence and predictability of others' abilities and integrity.

Optimism - Understanding that human potential is untapped, and there is a better chance of good things happening if there are a positive mindset andbelief of others.

Intention - Leaders know the direction they are going while being proactive usinga variety of methods, yet self-correcting. (p.72)

The principal can integrate these principles into his or her stance through ensuring the most intentionally inviting environment using the Five Ps: people, places, policies, programs, and processes. (Novak \& Purkey, 2001, p.12). Educational leaders at the principal level have an opportunity not to limit themselves to live in this inviting stance at the professional level, yet inviting educational leadership seeks human potential in all areas of the leader's life in these 
domains. (Novak, 2002, p. 14; Novak \& Purkey, 2001, p. 16 - 19). These domains within the invitational leadership framework are:

People - $\quad$ People are the emissaries of the school. They create and maintainthe environment where relationships are built on a sense of collegiality.

Places - The area that is the easiest to change, the landscape, and upkeep of the school can announce that inhabitants of the school are invited and welcomed.

Policies - $\quad$ A significant influencer on how the school is perceived concerning fairness, inclusivity, democracy, and respectfulness.

Programs - Formal or informal, the programs must work for the benefit of everyone where they reflect an invitational environment.

Processes - Created using a democratic process where the end-users are involved in their creation and ongoing revisions creating an attitude of, "We are all in this together." (Novak \& Purkey, 2001, p. 19)

Furthermore, explored were the levels of functioning within invitational leadership (Purkey \& Novak, 2001, p. 20). Examples of these functions are: Intentionally Disinviting Level 1 People are pushed to the out group through the leader purposefully devaluing the human spirit. Unintentionally Disinviting Level 2 Leaders are unaware of the harm they are causing through insensitivity, abruptness, or lack of forethought.

Unintentionally Inviting Level 3 Leaders carry a great spirit, however they lack in intentionality and commitment. When the 
magic wears off and they do not know why, they begin to disengage.

Intentionally Inviting

Level 4 Leaders are intentional with their practices to ensure a deep commitment to caring and democratic purposes. They carry and appreciation for people and their development. (p. 20)

Being an invitational leader gave the leader direction, purpose, and skill in their actions (Purkey \& Siegel, 2003), while leading with social justice orientations (Furman, 2012; Martin \& Miller, 2017), where they carried themselves with arrogant humility, passionate vision, and a tenacious commitment to justice (Theoharis, 2008). Therefore, invitational leadership as the overarching theoretical framework combined with social justice theory will be the preeminent and most concise lens in which to address the problem of practice for this research study.

\section{Discussion of the Findings}

The title of this study poses the question as to how a principal's action as an invitational leader with a social justice orientation can serve as a factor in recruiting and reciprocally retaining teachers at high-poverty, high-minority, high-needs urban high schools. To answer this overarching questions, four sub questions were explored and analyzed to find the major themes that supported the answer to how a principal's actions can serve as a factor in reciprocally retaining teachers in the targeted demographic group of schools. In this section, the five themes arrived through analysis and coding are presented. The themes of the intentional invitational action, social justice as a driving force, collective learning, humanity, and commitment to students and community will serve as a base upon which principals, novice and veteran can 
integrate into their practices to increase their chances of reciprocally retaining teachers in the high-poverty, high-minority, high-need urban high schools who need them most.

\section{Theme: The Actions of the Principal Being Intentionally Inviting}

Purkey and Novak (2015) shared the four levels of the invitational ladder moving from intentionally disinviting to intentionally inviting through using the focused elements of care, trust, respect, optimism, and intentionality with a focus in the five domains of people, places, policies, programs and processes. The evidence was abundant in each of the researched schools that while neither principal nor study participants were familiar with the tenets of invitational leadership, they were effective in their integration of the common practices. Figure 1 details the commonalities seen in both schools regarding the 5 P's of Invitational Leadership.

\begin{tabular}{|c|c|c|}
\hline $\begin{array}{c}\text { Domains of } \\
\text { School A and } \\
\text { School B } \\
\end{array}$ & $\begin{array}{c}\text { Domain Descriptors } \\
\text { Purkey and Novak (2008) }\end{array}$ & $\begin{array}{l}\text { Evidence of Principal Actions } \\
\text { being Intentionally Inviting }\end{array}$ \\
\hline People & $\begin{array}{l}\text { Unconditional respect for everyone, } \\
\text { intentional caring, honoring diversity } \\
\text { who is given to developing a trusting, } \\
\text { optimistic, and courteous stance for } \\
\text { everyone (p. } 21 \text { ). }\end{array}$ & $\begin{array}{l}\text { - } \text { Available to staff and students } \\
\text { - } \quad \text { Shared decision making } \\
\text { - } \text { collective learning } \\
\text { - Commitment to social justice } \\
\text { and diversity }\end{array}$ \\
\hline Places & $\begin{array}{l}\text { Welcoming environment where } \\
\text { careful attention is given to the } \\
\text { aesthetic, clean, functional, and } \\
\text { efficient qualities of the school (p. } \\
\text { 22). }\end{array}$ & $\begin{array}{l}\text { - } \text { People met kindly at the door } \\
\text { - Student work represented } \\
\text { throughout. } \\
\text { - } \text { Spaces kept clean } \\
\text { students and staff to } \\
\text { maximize learning and social- } \\
\text { emotional well-being with } \\
\text { common areas }\end{array}$ \\
\hline
\end{tabular}




\begin{tabular}{|c|c|c|}
\hline Policies & $\begin{array}{l}\text { Include official mission statements } \\
\text { and the directives, codes, and rules, } \\
\text { written and unwritten, use to regulate } \\
\text { the schools. (p. 22) }\end{array}$ & $\begin{array}{l}\text { - Stated desire to maximize } \\
\text { learning and options for all } \\
\text { students. } \\
\text { - Restorative practices over } \\
\text { zero tolerance policies } \\
\text { - Inclusivity, interventions and } \\
\text { support over exclusivity, } \\
\text { disqualifications, and labeling } \\
\text { as failure. }\end{array}$ \\
\hline Programs & $\begin{array}{l}\text { Formal or informal, they work for the } \\
\text { benefit of everyone while } \\
\text { encouraging active engagement with } \\
\text { significant content. (p. } 23 \text { ) }\end{array}$ & $\begin{array}{l}\text { - Aim to have something for } \\
\text { everyone. } \\
\text { - Students have voice and } \\
\text { choice. } \\
\text { - Adults willing to share their } \\
\text { talents. } \\
\text { - Community steps forward to } \\
\text { lead to share their talents. } \\
\text { - Finds ways to meet the most } \\
\text { basic of needs through } \\
\text { support. }\end{array}$ \\
\hline Processes & $\begin{array}{l}\text { Democratic ethos, collaborative and } \\
\text { cooperative procedures, and } \\
\text { continues networking among } \\
\text { teachers, students, staff, parents, and } \\
\text { the community that give life to the } \\
\text { school. (p.23) }\end{array}$ & $\begin{array}{l}\text { Voice and choice given in } \\
\text { academic instruction and } \\
\text { extra-curricular interests. } \\
\text { - Listening sessions for staff, } \\
\text { students, and community } \\
\text { members. } \\
\text { - If it is deemed best for } \\
\text { students, a can-do attitude } \\
\text { finds the resources needed for } \\
\text { success. }\end{array}$ \\
\hline
\end{tabular}

Figure 1 - The 5 P's aligned with common actions of researched principals

Purpose and direction are given through invitational leadership with the five elements that sets an implementer in an inviting stance (Purkey \& Novak, 2008). In Figures 2 and 3 below, each of the elements is noted along with a descriptor and a vignette of each principal's orientation to social justice. 


\begin{tabular}{|c|c|c|}
\hline $\begin{array}{l}\text { Element of } \\
\text { Invitational } \\
\text { Leadership - } \\
\text { Principal A }\end{array}$ & $\begin{array}{c}\text { Descriptor of Invitational } \\
\text { Element (Purkey and Novak, } \\
\text { 2015) }\end{array}$ & $\begin{array}{c}\text { Vignette Representing Principal } \\
\text { Action }\end{array}$ \\
\hline Care & $\begin{array}{l}\text { Genuine desire to care about oneself } \\
\text { and others. Ingredients include } \\
\text { warmth, empathy, and positive } \\
\text { regard to be a beneficial presence. } \\
\text { (p. 2) }\end{array}$ & $\begin{array}{l}\text { He could look at any person in his } \\
\text { courtyard during the lunch-hour and } \\
\text { tell a detailed story regarding their } \\
\text { challenges and their growth. }\end{array}$ \\
\hline Trust & $\begin{array}{l}\text { In recognition of human existence is } \\
\text { a cooperative activity that is } \\
\text { interdependent. It is built upon } \\
\text { invitations sent, received, and acted } \\
\text { upon successfully. Environment } \\
\text { created to allow each person to } \\
\text { pursue his or her own best way of } \\
\text { being and becoming. (p.2) }\end{array}$ & $\begin{array}{l}\text { If students were late to a class, } \\
\text { Principal A had a culture that an adult } \\
\text { will walk up to the student to see what } \\
\text { support they may need. He had built } \\
\text { the trust that there must be something } \\
\text { wrong if they are unable to live up to } \\
\text { the expectation to be in class. Teachers } \\
\text { are given the autonomy to do what } \\
\text { they feel best is right in their } \\
\text { classrooms. }\end{array}$ \\
\hline Respect & $\begin{array}{l}\text { People are able, valuable, and } \\
\text { responsible and should be treated as } \\
\text { such through positions of equality } \\
\text { and shared power. (p. } 3 \text { ) }\end{array}$ & $\begin{array}{l}\text { Democratic in all decisions that were } \\
\text { made. Before any action was taken } \\
\text { school-wide or in sub-groups, those } \\
\text { who will be affected were engaged. }\end{array}$ \\
\hline Optimism & $\begin{array}{l}\text { Recognizing no clear limits of } \\
\text { human potential have been } \\
\text { discovered. One must move beyond } \\
\text { just inviting, but hold hope for } \\
\text { change to be better (p. } 3 \text { ) }\end{array}$ & $\begin{array}{l}\text { While carrying himself with a funny } \\
\text { sense of humor, he also carried himself } \\
\text { with belief that he would not be } \\
\text { pushed off his vision that adults can } \\
\text { support every student to maximize } \\
\text { what is possible for each. }\end{array}$ \\
\hline Intentionality & $\begin{array}{l}\text { Enables people to create, maintain, } \\
\text { and enhance total environments that } \\
\text { consistently and dependably invite } \\
\text { the realization of human potential. } \\
\text { (p.3) }\end{array}$ & $\begin{array}{l}\text { Relationships were built through an } \\
\text { open-door policy, meeting teachers } \\
\text { and students where they are, and } \\
\text { opening of himself. Each year a } \\
\text { graduation party is held at Principal } \\
\text { A's house for the entire staff. }\end{array}$ \\
\hline
\end{tabular}

Figure 2 - Elements of Invitational Leadership with Vignettes of Actions of Principal A 


\begin{tabular}{|c|c|c|}
\hline $\begin{array}{l}\text { Element of } \\
\text { Invitational } \\
\text { Leadership - } \\
\text { Principal A }\end{array}$ & $\begin{array}{c}\text { Descriptor of Invitational } \\
\text { Element (Purkey and Novak, } \\
\text { 2015) }\end{array}$ & $\begin{array}{c}\text { Vignette Representing Principal } \\
\text { Action }\end{array}$ \\
\hline Care & $\begin{array}{l}\text { Genuine desire to care about oneself } \\
\text { and others. Ingredients include } \\
\text { warmth, empathy, and positive } \\
\text { regard to be a beneficial presence. } \\
\text { (p. 2) }\end{array}$ & $\begin{array}{l}\text { Realizing that the young males needed } \\
\text { an outlet, she encouraged and } \\
\text { mentored a young Black teacher to } \\
\text { start a group for them. The group was } \\
\text { successful as many young Black males } \\
\text { came, but she was still asking herself, } \\
\text { "What do we have for our White } \\
\text { males?" }\end{array}$ \\
\hline Trust & $\begin{array}{l}\text { In recognition of human existence is } \\
\text { a cooperative activity that is } \\
\text { interdependent. It is built upon } \\
\text { invitations sent, received, and acted } \\
\text { upon successfully. Environment } \\
\text { created to allow each person to } \\
\text { pursue his or her own best way of } \\
\text { being and becoming. (p.2) }\end{array}$ & $\begin{array}{l}\text { Principal A was confronted in their } \\
\text { community with an officer not being } \\
\text { charged for killing another person of } \\
\text { color in their community. The teachers } \\
\text { shared that the students were very } \\
\text { emotional and needed a way to express } \\
\text { their feelings. She trusted the teachers } \\
\text { could teach the students to do it the } \\
\text { right way and the students could } \\
\text { handle using their voices to share their } \\
\text { outrage in a safe way. }\end{array}$ \\
\hline Respect & $\begin{array}{l}\text { People are able, valuable, and } \\
\text { responsible and should be treated as } \\
\text { such through positions of equality } \\
\text { and shared power. (p. } 3 \text { ) }\end{array}$ & $\begin{array}{l}\text { When a new teacher came to the } \\
\text { school, she would make herself } \\
\text { available for whatever they needed, yet } \\
\text { trusted her team of teachers to } \\
\text { welcome the teacher in and support } \\
\text { their transition. If her teachers said } \\
\text { they needed to teach a certain way or } \\
\text { end spending hours on paperwork sent } \\
\text { down from the district, she would be } \\
\text { the voice of advocacy for her teachers. } \\
\text { "We know we are heard." }\end{array}$ \\
\hline Optimism & $\begin{array}{l}\text { Recognizing no clear limits of } \\
\text { human potential have been } \\
\text { discovered. One must move beyond } \\
\text { just inviting, but hold hope for } \\
\text { change to be better (p. } 3 \text { ) }\end{array}$ & $\begin{array}{l}\text { She led by modeling ways that she } \\
\text { could become better. While not a } \\
\text { mathematician, she would go to the } \\
\text { math class to take part as a student. } \\
\text { She got a writing coach. She shared } \\
\text { these stories with the staff and students } \\
\text { to show them that as a graduate of the } \\
\text { school, she continued to push them to }\end{array}$ \\
\hline
\end{tabular}




\begin{tabular}{|l|l|l|}
\hline Intentionality & $\begin{array}{l}\text { do great things and every student they } \\
\text { have at School B could do the same. }\end{array}$ \\
\hline $\begin{array}{l}\text { Enables people to create, maintain, } \\
\text { consistently and dependably invite } \\
\text { the realization of human potential. } \\
\text { (p.3) }\end{array}$ & $\begin{array}{l}\text { She never seemed to be in a rush. "She } \\
\text { will spend the time to make the person } \\
\text { she is speaking with the most import } \\
\text { person around." She has a way with } \\
\text { "proximity and presence to let you } \\
\text { know you are supported." }\end{array}$ \\
\hline
\end{tabular}

Figure 3 - Elements of Invitational Leadership with Vignettes of Actions of Principal B

\section{Theme: Social Justice Orientation Created a Vision Team Members Wanted to be}

\section{Committed to Realizing.}

Each of the principals embodied the Theoharis (2008) defined descriptors of being a social justice leader through carrying themselves with arrogant humility, passionate visionary leadership, and a tenacious commitment to justice. It was Principal A standing in front of a Black Lives matter rally validating to his students of color that the system is not equitable one day and inviting his entire staff to join him in reading Ibrahim X Kendi's book, How to be an Anti-Racist. It was Principal B standing in her staff announcing to her staff in one meeting that they will see every student in their building while owning her past failures of approaching her LGBTQIA students with a "you do you" attitude before digging deep within herself to recognize that she needed to embrace all students in their authenticity. It was each of the principals working with their staffs and students to live each word of their school mission statements each day. At the same time, they were prepared to work to maximize their own talents as a model for those whom they led to that vision. It was Principal A partnering with his staff, a former gang member turned anti-gang director, the police, the community and the public defender's office to not accept that his school has to be a conduit in the school to prison pipeline, but instead a place to be exposed to the vista of possibilities of what their life could become. Gone were the days of 800 
suspensions as a teaching tool, replaced by just 22 in a symbolic move that certain behaviors leave decision makers with no other options. It was Principal B allowing for the "weirdos" to make their feelings heard through song, dance, spoken word, painting or protest as they try to heal another injustice in their community. She elicited the power within them through the simple act of listening then moving with her staff, students, and community to options of change, healing, and personal and academic growth.

The possessed orientation to social justice by both principals was a strong contributing factor for most study participants as to why they continue to work with the school. At School B, teachers who left the school with the previous administration came back under her. They recognized her commitment to the school and the community from where she came. The selfdescribed agitators knew that she was going to fight for them and their students when they were going to go up against others with positional power. The staff and students at School B followed the lead of their principal in creating spaces for social justice. If the wealthy Whites of the city wanted to have a fundraiser, there was going to be a place at the table for the students and their families who qualified for free and reduced lunch to be a part of the celebration. Students were going to be taught a curriculum that reflected them. While they may have let their state-of-the-art auditorium be used by organizations whose families could pay a great deal for artistic enrichment, they would ensure their students got it every day. They recognized the challenges of their community but saw their students and their families as partners in creating a space for their young people to flourish.

2,000 miles away spaces were being created for social justice in the same ways. Whether you were the outsider Italian-American principal, a person who grew up blocks away who had become a staff member, or an attorney for the public defender's office, you were part of a 
movement where social justice was going to be achieved through education. It came in many forms using the school as the center point. It was a handball tournament for the gangs from opposite end of town to see that they could engage and value one another without violence. It was an open AP program where any student who wanted to challenge the highest-level classes were going to be invited, welcomed, challenged, and supported. It was going to be volunteers from the staff and community handing out hundreds of lunches to the community when the district lunch program went on hiatus only to turn around, go back in and have more basic needs packed up for the migrant farm workers in the central valley of California. It was in the staff agreeing to revise their entire grading system to ensure that they did not contribute to inequitable grading practices based in euro-centric power or implicit biases.

In each of the schools, the drive for social justice that had full engagement from the principal level was where they wanted to be. The voices of those in the study inferred that each leader was the glue.

\section{Theme: Collective Learning}

Each of the administrators in this study were seen by the participants as people who were on a self-selected continued growth trajectory. They aspired to be the lead learners in their building and showed this through sharing their learning both personally and professionally. They were also consistent in their learning sources being going to professional development training, engaging with the talents of their own staff leading professional development, and taking the time to directly learn from people. The consistent message to teachers in both schools was they should try things that were best for their students. A counselor at School A said of her principal, "He always has this frame of mind of let's try and if does not work, we figure out what to do 
better." At School B it was shared, "There is no pressure to be perfect. No one beats you down if things do not go well. It is an environment that is constantly accepting people for trying new things as long as we are doing it in the best interest of kids."

Each of the schools had a specific topic that collective learning that was happening in the building. Principal B had led her team in studying social justice learning in the last five years, however in the last two it has been focused more on social emotional learning and the challenges being faced by marginalized people. This is where the ideas for the Peace Room and the "I See You" campaign were originated. At School A the staff was targeting heavily on how to confront racism. There was an optional book study in Ibrahim Kendi X's How to be an Anti-Racist. The work did not stop there as they moved onto how they can create grading practices that will be equitable and fair for all students based on their academic skills represented rather than their compliance skills to the power paradigm.

\section{Theme: Humanity}

While the themes of humanity came about in interview after interview, there was a participant at each school who shared a story that embodied just how vital humanity was in the leadership of each of the principals.

The story of Principal B's humanity was shared by a White woman with long, flowing, blonde hair.

(Principal B) changed to the dress code policy. From the time I started there were limitations as to what kids could wear to school, but she opened it up. She allows hats and hoods. Kids were skipping school due to not having money to get their hair done. They could not wear a hat. She then came to us and asked, 'What would you rather have, 
a girl with a bonnet on or a boy with a hood or neither of them being here? I don't care what they are wearing as long as they are doing their stuff.' In that moment, it was so obvious, but none of us have thought about it. My privilege is my ponytail.

In the spring of 2020, like schools across the country, School A had to close in-person activities due to the Covid-19 pandemic. The senior class was going to be denied the opportunity to graduate in person. Principal A and his staff's reaction were shared by a participant in the study.

His passion oozes from his soul. We had to shut down because of Covid. All of California was. The seniors were devastated about graduation. The suggestion was that we are going to make a video with diplomas. (Principal A) was like, "We are not going to do that. Our kids deserve better." He got a group together and laid out, "Here are the governor's rules and the district rules." Then he asked us, "What can we do?" We ran with it, he was with us each step of the way, often leading the charge. It was an 8-hour graduation. Everyone wore a mask. Most beautiful graduation I have ever been to. You can see the story about it on YouTube. Our community has the highest levels of Covid-19 because it is our Latino and migrant families who are the hourly workers. We wanted to give them joy. They deserved joy.

\section{Theme: Commitment to Students and the Community}

There was a reciprocity in the commitment of the stakeholders of administration to teachers to students to community. "I am here because of (Principal A)." was the consistent summarizing message shared by the staff. Yet as Principal A stated, "This is where the work needs to be done. The students and community we serve, they deserve to be treated differently by 
our society." The staff “...feels like we are a part of something bigger." This is anchored in the leadership of Principal A as shared by another leader in the school, "He knows and feels their stories. He believes in their humanity. He knows they deserve better. He will not retire until he knows until someone is going to pick this work up." The staff was working vigorously in making that happen in their level of commitment. For this research, using the snowball method, the researcher invited more than the eleven that he was able to interview, yet he did also receive four messages back of the invited declining due to their inability to break away from the hours of commitment to the time with the students. The staff shared their reasons for being at that school was their value of the community and their desires to see better for it. "The system sets us up at a disadvantage." "Poverty is not a money thing. It is a mindset thing. We can help them with that." "I love the staff, kids, parents, and community. I have lived here my whole life." "I waited six years for this position at this school to open up. My kids went here and now I drive a long way to get here each day." "The people in this community, they are the best teachers that we can have." 'Nobody wants to fail, drop out of high school, say 'Fuck it! I don't have any dreams.' These kids were trauma affected. I am not the visionary to think about how to make the change, but I want to be in the place to make it."

At school B, the summarizing statement of the level of commitment to the school and community was stated by Principal B herself, "It is an honor and a blessing to work at the school from where I came.” This sentiment was backed by staff members discussing the authentic relationships that she has with the staff, students, and community. "It's almost like she just fits at our school. She seems to have a genuine joy at this hard place." Yet, it did not stop with the committed passion of the principal. There was a consistent mantra of people believing that they were all there to serve in the mission of the school to help students who were not getting it from 
other places. "We are part of the solution," stated one participant in a tone that made it sound not even optional. They saw the possibilities of what could become as stated by another teacher, "The time that we spend and dedicate here, where we make decisions together will create a program that will continue long after we are gone." They know they could have left, but there was something to special to allow that to happen, "I could make a bit more money, but there is too much good at this school and this community to walk out now."

\section{Recommendations}

There is a dearth of young people going into the profession of education to meet the needs to effectively staff our schools (Sutcher, et al., 2016). The funding formulas and inherent challenges of under-resourced schools serving a population of students coming from underresourced communities leave the schools who need the most skilled teachers often left with a rotating door of underqualified, new to the profession teachers reinventing what will be taught year over year (Bornman \& Dowling, 2008; Heineke et al. 2014; Hughes, 2012; Ng, 2003; Petty, et al., 2012; Sachs, 2004; Simon \& Johnson, 2015; Stotko et al., 2007; Waddell, 2010). This same rotating door exists for the school leadership (Clotfelter et al., 2007; Levin \& Bradley, 2019). However, as exemplified by the two principals and their reciprocally retained teachers, there is a model, which was first combined in the research of Martin and Miller (2017), working in two disparate communities where the principal's action as an invitational leader with a social justice orientation can serve as a factor in recruiting and reciprocally retaining teachers at highpoverty, high minority, high needs urban high schools.

Whether a novice principal or a seasoned principal who is exploring ways to more effectively retain the teachers that children need most, here are the recommendations based off the learning of this study. 
Recommendation one. Start with humanity - Every adult needs to value every child in the school for who they are in their authenticity. It is incumbent upon adults to explore their implicit biases to better understand what could possibly hold them back from fully supportingthe growth of each child. Principal B recognized that she was not sharing her whole self with the students and staff members from the LGBTQIA community. She was vulnerable in front of her staff in recognizing she needed to work more intentionally to understand and support stakeholders in this group. No longer was she going to accept from herself that she would move about the world in, "simply allowing them to do them, while I do me."

Recommendation two. Commit to Collective Learning - Each of the school leaders modeled such effective practices in continued learning with their staffs. Not only were they willing to take the lead on learning to invite people in, but they also consistently valued what others could teach them. Principal A was ready to lead the charge in their work to confront racism from every angle within their school. He was consistently asking staff, community members, and partners what they could do better to serve the students and community. This included asking the public defense attorney each week what they could do to help a student, asking teachers what is the best thing to teach in the social sciences strand which led to every student having an ethnic studies class in the ninth grade, and national organizations like the researcher's what really were the best pathways for their student.

Recommendation three - While neither principal in the study was familiar with invitational leadership introduce themselves to the tenets of invitational leadership as outlined below (Purkey \& Novak, 2015) they were both actively integrating the tenets into the daily practices in the buildings they led. The goal of every school in the nation should align with William Purkey and John Novak's call to “intentionally summoning people to realize their 
relatively boundless potential in all areas of worthwhile human endeavor. (2015, p. 1).

Introducing the practices of Invitational Theory, as exemplified in the following diagram, to the staff and integrating them into your school culture will allow for each person to have the opportunity to reach their boundless potential.

\section{Invitational Theory}

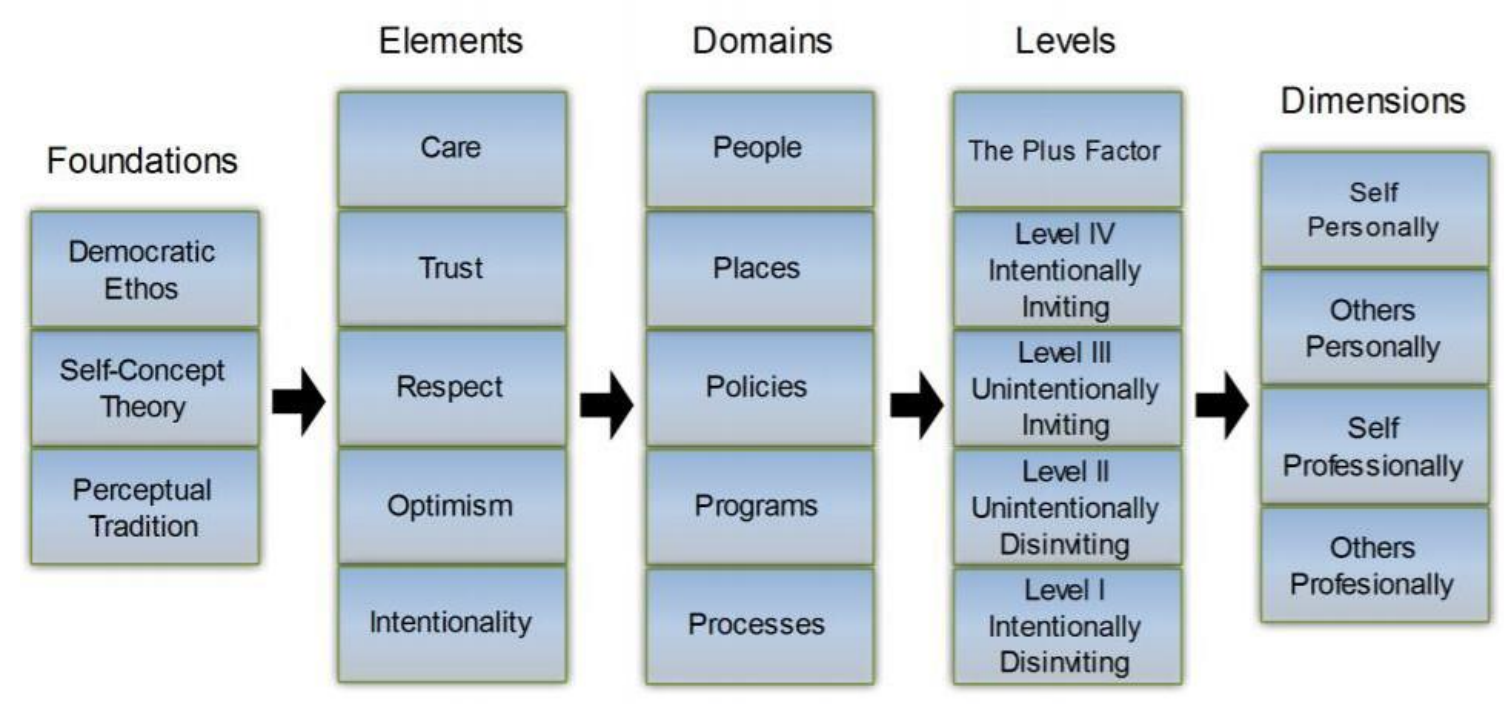

Recommendation four: Keep the tenets of social justice leadership as defined by George Theoharis (2008) at the front of mind. Our schools remain largely separate and unequal. "More than half of the nation's schoolchildren are in racially concentrated districts, where over 75 percent of students are either white or nonwhite." Teachers and students need a leader to intentionally reflect on how they can act with arrogant humility, passionate visionary leadership, and a tenacious commitment to justice. 
1. Arrogant humility: Leaders hold a headstrong belief that they are the right personto lead the team toward the vision of social justice for the students and families they serve while paradoxically being filled with self-doubt. They are humble enough to know after self-reflection when they need to admit when they are wrong. They wonder if they indeed are the right person for the role of principal.

2. Passionate visionary leadership: These social justice principals stand as transformational leaders who are driven by such deep care, commitment, and enthusiasm toward championing a strong vision. These components become realized in such a passion that there is a tightly interwoven connection between the principal position and the person doing that job.

3. Tenacious commitment to justice: The leader maintains a fierce and sustaining commitment to equity and justice not only for their staff but also for themselves(p. 17).

When Principal A and Principal B from this study were asked if they thought any or all of these descriptors could be ascribed to them, neither would anoint themselves, yet both saw these descriptors as ones to which they aspired. Conversely, they were aspirations that the participants overwhelming shared were not only present in the leadership of each principal, but a reason as to why those teachers, staff, and community members stayed working at each of the schools with those principals.

Recommendation five. Start a "Grow Your Own" teacher program from your current student body. We know the pipeline is not full enough to mee the needs of our students in our overall school populations and that our schools serving high-poverty, high-minority populations are going to have some of the greatest deficits in meeting the needs (Sutcher, et al-., 2016). In 
both schools we saw a great number of teachers and educators come back to the school where they went to be a part of the solution. In School A, over twenty teachers and staff members had gone to school there. School B was not only being led by an alumnus, but also had a counselor and a teacher who were alum who were key figures in their success. Young people are energized to act in finding solutions for racial justice (Lumsden, 2020). Programs are starting in schools across the country. States like Illinois have full organizations dedicated to this movement (Grow Your Own, 2020).

Recommendation six. Both school leaders were extremely effective models of moving beyond simply coming into their communities for their professional duties. They expanded beyond to make their lived experience in all aspects of life take place in the community where their schools were located. Principal B not only was committed to working in the community at the school level she lived in the community and had her three daughters go through the school system. She is now working to start support groups for women in education who serve the community. While Principal A is of Italian American descent, his consistent engagement with the community and ability to speak the Spanish language of his predominantly Latinx community has many, "considering him on of our own." Each of the principals knew their community extremely well from immersing themselves in it which not only allowed them to better understand the challenges within their communities, but also how to take an inviting stance and be trusted as part of the solution.

The guiding diagram at the center intentionally places the Principal in the middle to symbolize the reciprocal area of intentional action of which the principal needs to take. In return, the researcher contends these will be the drivers that will reciprocally keep the principal surrounded by support in the community. 


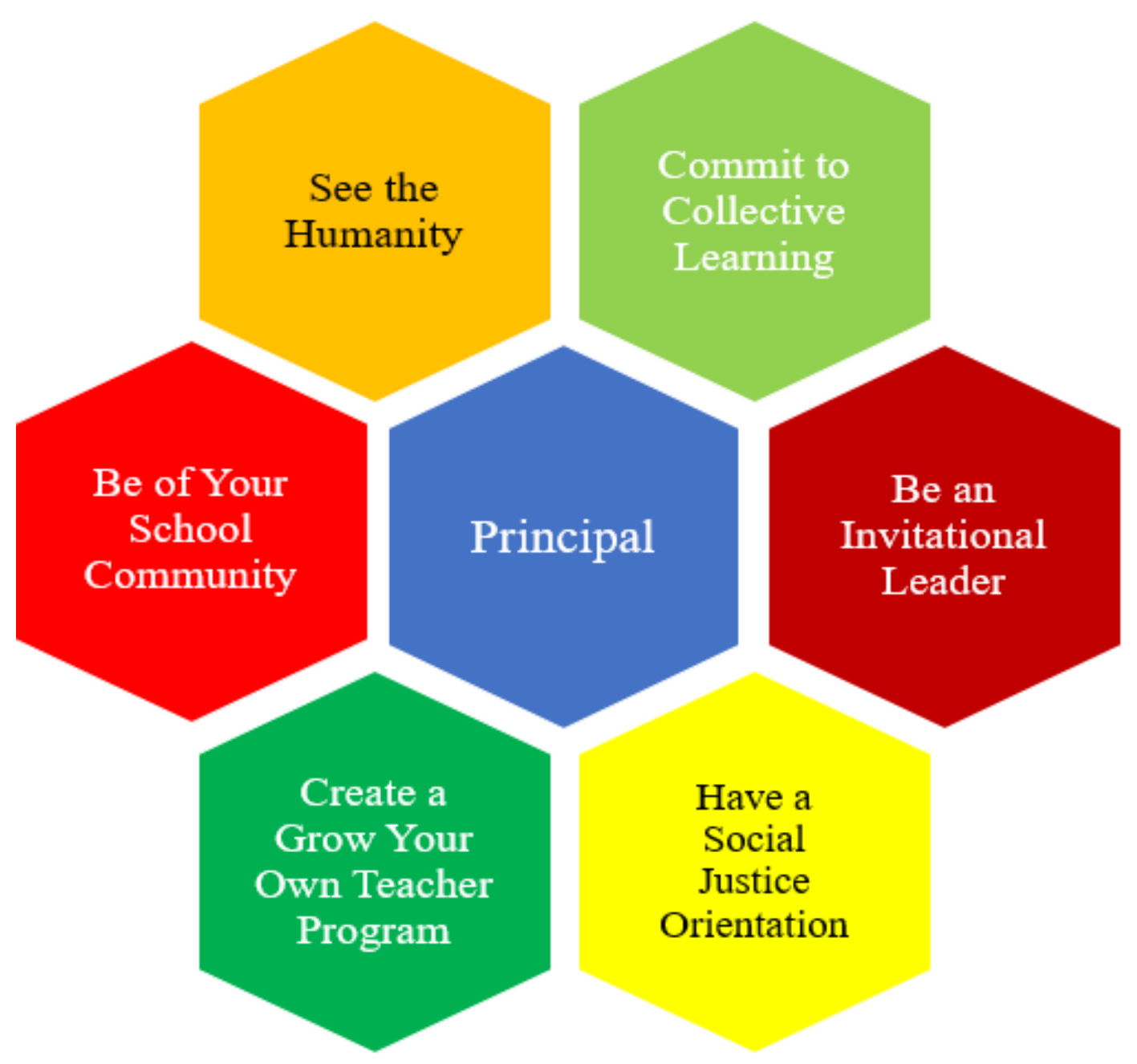

\section{Conclusion}

With the economic challenges expected due to the pandemic caused by COVID-19, a shortage of teachers in the pipeline that was already a challenge (Podolsky et al, 2016; Sutcher et al, 2016) is expected to get worse (Page, 2020). There are tough challenges in schools throughout the country as evidenced by the two schools profiled. Yet, this research found the actions of two principals using the tenets of invitational leadership with a social justice orientation cannot only 
bring the teachers to a high-poverty, high-minority, and high-needs high school that the principal and community want, but play a major role in them staying. 


\section{Journal Article References}

Anderson, C.J. (2019). A leader's emotional self-control and management of others impacts a school's climate. Journal of Invitational Theory and Practice, 25, 39-57

Bartanen, B., Grissom, J.A., \& Rogers, L.K. (2019). The impacts of principal turnover. Educational Evaluation and Policy Analysis, 41(3), 350-374.

Bogotch, I.E., (2000). Educational leadership and social justice: Practice into theory. Journal of School Leadership, 12, 138-156.

Borman, G. D., \& Dowling, N. M. (2008). Teacher attrition and retention: A meta-analytic and narrative review of the research. Review of Educational Research, 78(3), 367-409.

Buckingham, M.; Goodall, A., (2019) 9 Lies about work. Boston, MA: Harvard Business Review Press.

Burkhauser, S. (2016) How much do school principals matter when it comes to teacher working conditions? Educational Evaluation and Policy Analysis, 20(1) 1-20.

Clotfelter, C.; Ladd, H.F., Vigdor, J; and Wheeler, J., (2007). High-Poverty and the Distribution of Teachers and Principals.

Dantley, M., \& Tillman, L. (2010). Social justice and moral transformative leadership. In C. Marshall \& M. Oliva (Eds.). Leadership for social justice: Making revolutions in education ( $2^{\text {nd }}$ ed., pp. 16-29). Boston, MA: Allyn \& Bacon.

Edbuild (2020, October 10) Nonwhite school districts get 23 billion less. Retrieved from https://edbuild.org/content/23-billion

Fergus, E. (2017) Solving disproportionality and achieving equity: A leader's guide to using data to change hearts and minds. Thousand Oaks, CA: Corwin.

Freedman, S. W., \& Appleman, D. (Summer 2008). “What else would I be doing?” Teacher 
identity and teacher retention in urban schools. Teacher Education Quarterly, 35(3) 109126.

Fullan, M. (2001). Leading in a culture of change. San Francisco, CA: Jossey-Bass.

Fullan, M. (2014). The Principal. San Francisco, CA: Jossey-Bass.

Furman, G. (2012). Social justice leadership as praxis: developing capacities through preparation programs. Educational Administration, 48(2), 191-229.

Greenlee, B., \& Brown, Jr., J. J. (2009). Retaining teachers in challenging schools. Education, 130(1), 96-109. Retrieved from http://dx.doi.org

Grissom, J. A. (2011). Can good principals keep teachers in disadvantaged schools? Linking principal effectiveness to teacher satisfaction and turnover in hard-to-staff environments. Teachers College Record, 113(11), 2552-2585.

Grow Your Own Illinois. (2020, October 10). Retrieved from https://growyourownteachers.org/index.php?option=com_content $\& v i e w=\operatorname{article} \& i d=223$ $\underline{\text { \&Itemid }=562 \& \text { lang }=\mathrm{en}}$

Hammond, Z. L. (2015). Culturally responsive teaching and the brain. Corwin Press.

Hattie, J. (2003). Teachers make a difference: What is the research evidence? Australian Council for Educational Research, 1-17.

Hattie, J. (2016) Hattie Ranking: 252 Influences and effect sizes related to student achievement. Retrieved from: https://visible-learning.org/hattie-ranking-influences-effect-sizeslearning-achievement/

Heineke, A. J., Mazza, B. S., \& Tichnor-Wagner, A. (2014). After the two-year commitment: A quantitative and qualitative inquiry of teach for America teacher retention and attrition. Urban Education, 49(7), 750-782. 
Hughes, G. D. (2012). Teacher retention: Teacher characteristics, school characteristics, organizational characteristics, and teacher efficacy. The Journal of Educational Research, $105,245-255$.

Ingersoll, R. (2001). Teacher turnover and teacher shortages: An organizational analysis. American Educational Research Journal, 38(3), 499-534.

Ingersoll, R. M., \& Smith, T. M. (2003). The wrong solution to the teacher shortage. Association for Supervision and Curriculum Development, 30-33.

Kozol, J. (2005). The shame of the nation. New York, NY: Crown Publishers.

Levin, S., \& Bradley, K. (2019). Understanding and addressing principal turnover: A review of the research. Reston, VA: National Association of Secondary School Principals.

Lumsden, C. (2020, June 10) Meet 4 young activists fighting for racial injustice across the nation. Good Morning America. Retrieved from https://www.goodmorningamerica.com/living/story/meet-young-activists-fighting-racialinjustice-nation-71152493

Martin, B. N. \& Miller, C. (2017) Are principals prepared to lead in schools with diverse student populations using invitational leadership? Journal of Education and Culture Studies, $1(2), 198-214$.

Maslow, A. H. (Ed.). (2005). The theory of human motivation. In J. M. Shafritz, J. S. Ott, \& Y. S. Jang (Eds.), Classics of organization theory (6 ed. Pp. 167-178). Belmont, CA: Wadsworth. (Reprinted from Psychological Review, pp. 370-396, 1943).

NASSP. (2020) National association of secondary school principals. Retrieved from: https://www.nassp.org/policy-advocacy-center/nassp-position-statements/principalshortage/ 
Ng, J. C. (2003). Teacher shortages in urban schools: The role of traditional and alternative routes in filling the voids. Education and Urban Society, 35(4), 380-398.

Novak, J., \& Purkey, W. (2001). Invitational education. Bloomington, IN: Phi Delta Kappa Educational Foundation Fastbacks. 488, p7-55

Page, S. (2020, May 24) Back to school? 1 in 5 teachers are unlikely to return to reopened classrooms this fall, poll says. USA Today Retrieved from: https://www.usatoday.com/story/news/education/2020/05/26/coronavirus-schoolsteachers-poll-ipsos-parents-fall-online/5254729002/

Petty, T. M., Fitchett, P., \& O’Connor, K. (2012). Attracting and keeping teachers in high needs schools. American Secondary Education, 40(2), 67-84.

Podolsky, A., Kini, T., Bishop, J., \& Darling-Hammond, L. (2016) Solving the teacher shortage: How to attract and retain excellent educators. Learning Policy Institute.

Purkey, W., \& Novak, J. (2016). Fundamentals of invitational education (2 ${ }^{\text {nd }}$ ed.). Kennesaw, GA: International Alliance for Invitational Education.

Purkey, W.W., \& Siegel, B. (2003). Becoming an invitational leader: A new approach to professional and personal success. Atlanta, GA: Humanics.

Sachs, S. K. (2004, March/April 2004). Evaluation of teacher attributes as predictors of success in urban schools. Journal of Teacher Education, 55(2), 177-187.

Shernoff, E. S., Marinez-Lora, A. M., Frazier, S. L., Jakobsons, L. J., Atkins, M. S., \& Bonner, D. (2011). Teachers supporting teachers in urban schools: What iterative researchdesigns can teach us? School Psychology Review, 40 (4), 465-485.

Simon, N. S., \& Johnson, S. M. (2015). Teacher turnover in high-poverty schools: What we know and can do. Teachers College Record, 117(2), 1-36. 
Stotko, E. M., Ingram, R., \& Beaty-O’Ferrall, M. E. (2007). Promising strategies for attracting and retaining successful urban teachers. Urban Education, 42(1), 30-51.

The Irreplaceables. (2012). Retrieved from http://ntp.org/assets/documents/TNTP_Irreplaceables_2012.pdf

Theoharis, G. (2007). Social justice educational leaders and resistance: Toward a theory of social justice leadership. Educational Administration Quarterly, 43(2), 221-258.

Theoharis, G. (2008). Woven in deeply: Identity and leadership of urban social justice principals. Education and Urban Society, 41, 3-25. https://doi.org/10.1177/0013124508321372

Waddell, J. H. (2010). Fostering relationships to increase teacher retention in urbanschools. Journal of Curriculum and Instruction, 4(1), 70-85.

Waddell, J., \& Ukpokodu, O. N. (2012). Recruiting \& preparing diverse urban teachers: One urban-focused teacher education program breaks new ground. Multicultural Education, $15-22$

Wang, F. (2018). Social justice leadership - Theory and practice: A case of Ontario. Education Administration Quarterly, 53(3), 470-498.

Watkins, P. (2005). The principal's role in attracting, retaining, and developing new teachers: Three strategies for collaboration and support. The Clearing House, 79(2), 83-87.

Yonezawa, S., Jones, M., \& Singer, N. R. (2011). Teacher resilience in urban schools: The importance of technical knowledge, professional community, and leadership opportunities. Urban Education, 46(5), 913-931. 
SECTION SIX:

REFLECTION 


\section{Scholarly Practitioner Reflection}

The idea to take on the opportunity to earn a doctoral degree was first planted in my mind way back in the summer of 2007. I had just started a master's program at Northwest Missouri State. A woman who was leading our college access program, Dr. Carla Mebane shared that she had just finished going through the Educational Leadership and Policy Analysis Program (ELPA) through a joint effort with Northwest Missouri State and the University of Missouri Columbia. In early 2013, as I was amidst my first year as an urban middle school principal I was told that if I ever wanted to be a principal of a larger school, I would need to earn a higher degree, preferably a doctoral degree. In looking around at different programs it was suggested the best opportunity was to go through the ELPA Program at the University of Missouri. I decided that to continue to be able to provide for my family I should apply.

The first hurdle was to get everything in on time. My biggest concern in the application process was the GRE exam. Coming out of high school I was not accepted to the first school to which I had applied because my SAT score was not high enough. I was worried that a test score would hold me back. Thankfully, due to an exceptional college experience at the undergraduate level at Warren Wilson College, the Masters degree I earned at Northwest Missouri State University, and the confidence I had gained as I pushed myself to learn in my professional career, the GRE score was strong enough. On the day I went to get my application in, I was at the post office and I ran into my dear friend and principal of the high school in the district where I worked. I would find out later that she was there sending her application in as well. Crystal Ward and I would go each step of this journey together. 
On the day of the interview in Columbia I do believe many of our nerves were up. The room was filled with many accomplished K-12 educators including teachers, principals, and superintendents as well as several people from the higher education world. It was those who were principals and superintendents that I wanted to catch professionally and getting this degree was going to allow me to do so. In that initial meeting, Dr. Juanita Simmons, shared with us that we were going to have to be ready to make sacrifices. If we were accepted, we should tell our families that there were going to be things that we were going to have to miss to get this done. I remember thinking to myself, "Alright we can do this."

We then had to go into individual interviews. My nerves went a bit higher as I never had to do a personalized interview for my undergraduate of Master's program. In the room I was interviewed by Dr. Paul Watkins as well as another recent graduate. She shared that she had finished the program in three years. In reflection of that room, I wanted to one day rock the sport coat and sound like a wise professor like Dr. Watkins and finish quickly to apply my knew knowledge like the other interviewer. On the ride back to Kansas City, Crystal and I both felt we put our best foot forward and left with a level of confidence. Thankfully, we were right.

When we attended our first satellite class at the University of Central Missouri - Lee's Summit Campus, we met our advisor Dr. Barbara N. Martin. There were two things I remember from that evening. First, I had always told the students with whom I worked that the more educational degrees that they had, the more options they would have. Up to this point I was driven to what next roles this piece of paper at the doctoral level would open for me. Then Dr. Martin warned us that if we are only doing this program for a job promotion, it will never get us through. Thankfully as I am here having done the research and having written the dissertation, I understand now so much more deeply my "why" for completing this degree. The second thing 
was Dr. Martin matched me up with a science-fiction loving counselor to have a breakout discussion. When the conversation started, I wondered what exactly I was supposed to gain from this conversation as we had two totally different career paths. Little did I know that she, Dr. Tina Chaney was going to be the other person with whom I would walk this path toward a doctoral degree.

The cohort model was very effective for me during the classwork. The satellite classes with Dr. Martin were extremely powerful in my becoming a more proficient researcher working in collaborative groups. During the time of our coursework, I was a White male principal in my early forties in a charter school with a $100 \%$ Black student population. Dr. Martin recognized that our class was an opportunity to find researched backed answers that could help us. We did a study on bullying. She guided me to other practitioners who had been through the program. Dr. Hayet Woods introduced me to a completely new way of an approach we would put in place at our middle school to combat bullying based on the research of Dr. Dan Olweus. Four of us worked together to study whether the families of Hogan Middle School wanted to have police officers posted in the school at a time where tensions were high after Michael Brown had been killed by a police officer on the other side of Missouri. I was for it as I had taken a semiautomatic gun off a student the year before and believed it would help ensure safety. 138 families took part in our survey and we learned overwhelmingly that they were in the samecamp as I wanted the officers and our students of color to have positive relationships.

The two years of classes in the summer were beneficial as they allowed me to get the perspectives of professors and educational professionals from around the state. As I look back on the material, it was extremely beneficial. I was able to work on quantitative project where we looked at the disproportionality of suspension rates in our state based on race. There were some 
great thinkers from other cohort groups that I appreciated getting to exchange ideas and challenge one another's thoughts. Dr. Sara Diem was a standout for me in her work on the benefit of mixed racial and socio-economic schooling.

I was also exposed to some culturally insensitive moments where I am hopeful the school is improving. In the summer of 2014, there were two instances that I found extremely disappointing. The first being after an exceptional presentation by Dr. Diem on this topic of the importance of diverse schooling it was turned over to our small groups. I was in a group of five men, four of us were head principals at the time. In the time we were supposed to cover this deeper topic, which was after we had done the study on disproportionality in suspension rates for Black children in our state, I watch three of the men simply get up and walk away instead of engaging in the discussions. To use the teaching of Bolman and Deal, their symbolism told me that they simply did not care. That same summer a group of women of color wanted to have a time for an affinity group. One of the White female professors got wind of it. She pulled them in, told them they were discriminatory, and that they needed to invite all 91 summer participants to be a part of their group. The women complied and invited all to take part. The next evening when the gathering was, only 15 of the over 100 forcibly invited people showed up. If my memory serves me correctly, the professor who required this did not come herself. It still disgusts me to this day that those women were not able to have an affinity group on their own terms and I can only hope that the professor is no longer leading educational leaders.

The fact that I am turning in my dissertation in the final month of the final semester in our allowed timeframe shows my goals on interview day were not realized. I do not have sport coat like Dr. Watkins yet either. While I could berate myself for not finishing it yet, I have learned a great deal about myself through this process. I knew from a clearness committee that 
my order of operations is to be a good husband, a good father, good at my work, and then whatever else. The whatever else part seems to be where I feel I can be most helpful and connect with a group. This has taken the form of helping my children learn to work in physical labor like I did as a snow shoveler. It was in rebuilding the back of my house with my friend Billy, working with our soccer club developing leadership role, and it was helping people when they needed me. I do believe that is why during our years in class with Dr. Martin, feeling a part of a helped me keep pushing forward. It was a very supportive group of seven with a leader who was just the right person for me.

The year after the cohort ended, I had to send my father, who suffered from mental health issues away to live with his sisters. It was too much to balance. Then when I introduced the concept of social justice leadership and my desire to work from a shared leadership perspective to my superintendent, he made some internal hiring decisions that made it clear we were not in alignment. I switched jobs. It was a great year of learning working with the team at the Regional Professional Development Center in Warrensburg. Then a year later I switched again. Then after two years in my role as a program manager at the National Math and Science Initiative, I changed my role. At each job change, I cannot help but wonder if it is like they say it is for students when they change schools, trying to see where you fit for six months. I am grateful for NMSI for allowing me to integrate my study with my work and that Invitational Leadership has been introduced to over 200 schools through this work, four more as recently as this past Thursday.

The journey has been worth it. While it took longer, I do know that I did the right study to align perfectly with my why. I would not have known the right schools had I not had the time to work with them at NMSI. To be here in Kansas City and have access to such great leaders, 
one on the other end of the state and the other on the other end of the country, was truly a gift. The push at the end was needed. My family has let me know they are ready to have me back without the underlying half focus because I knew I could be working on my doctorate. It is time for me to be more fully present with them as this chapter is complete. 
APPENDIX 


\section{Appendix A:}

\section{Gatekeeper Permission for Administrator and Educator Participation Letter}

\section{Dear <name>,}

I would like to request your permission to invite applicable educators in your program to participate in a research study entitled; How a Principal's Action as an Invitational Leaders with a Social Justice Orientation Can Serve as A Factor in Recruiting and Reciprocally Retaining Teachers at High Poverty, High-Minority, High-Needs Urban High Schools, I am examining school principals and his or her impact on a teacher's willingness to return year over year to the same school when invited back due to the actions of the school principal. The information gathered should be beneficial to other school leaders that desire to recruit and retain high quality teachers in urban environments. This study is part of my dissertation research for a doctoral degree in Educational Leadership and Policy Analysis from the University of Missouri-Columbia.

For the study, the participants will be asked to engage in a $45-60$-minute interview around the actions of the principal. No personal or identifying information will be collected from these educators. I am seeking your permission as the district representative to contact the administrators and educators at the high school for their participation in this study. A copy of the interview protocol and informed consent forms are attached for your review.

Participation in the study is voluntary. The participants may withdraw from participation at any time they wish without penalty, including in the middle of or after completion of the interview. Participants' answers will remain confidential, anonymous, and separate from any identifying information. The researcher will not list any names of participants in her dissertation or any future publications of this study.

Please do not hesitate to contact me with any questions or concerns about participation either by phone at (816)377-7095 or by electronic mail atwillmcdowell@ hotmail.com. In addition, you are also welcome to contact the dissertation advisor for this research study, Dr. Barbara Martin, who can be reached at 660543-8823 or by email at bmartin@ucmo.edu.

If you choose to allow me to contact administrators and educators regarding participation in this study, please complete the attached permission form. You should retain a copy of this letter and your written consent for future reference.

Thank you for your time and consideration.

Sincerely,

William E. McDowell

Doctoral Candidate 


\section{Appendix B: IRB Approval}

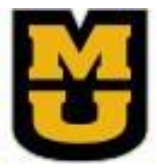

\section{Institutional Review Board}

University of Missouri-Columbia

FWA Number: 00002876

IRB Registration Numbers: 00000731, 00009014
482 McReynolds Hall

Columbia, MO 65211

573-882-3181

irb@missouri.edu

October 02, 2020

Principal Investigator: William E. McDowell (MU-Student)

Department: Educational Leadership-EDD

Your IRB Application to project entitled HOW A PRINCIPAL'S ACTION AS AN INVITATIONAL LEADER WITH A SOCIAL JUSTICE ORIENTATION CAN SERVE AS A FACTOR IN RECRUITING AND RECIPROCALLY RETAINING TEACHERS AT HIGH-POVERTY, HIGH-MINORITY, HIGH NEEDS URBAN HIGH SCHOOLS was reviewed and approved by the MU Institutional Review Board according to the terms and conditions described below:

$\begin{array}{ll}\text { IRB Project Number } & 2031263 \\ \text { IRB Review Number } & 276325\end{array}$

Initial Application

Approval Date

October 02,2020

IRB Expiration Date October 02, 2021

Level of Review Exempt

Project Status Active - Exempt

Exempt Categories

(Revised Common

Rule)

Risk Level

45 CFR 46.104d(1)

Minimal Risk

This letter will be sent to each participant in their being invited to participate in the study. They will be informed that this is a voluntary opportunity in which they can withdraw at any time.

Approved Documents These will be the interview questions for all other subjects other than each school principal.

These will be the interview questions asked of the principals of each of the two schools being researched.

The principal investigator (PI) is responsible for all aspects and conduct of this study. The PI must comply with the following conditions of the approval:

\section{COVID-19 Specific Information}

Enrollment and study related procedures must remain in compliance with the University of Missouri regulations related to interaction with human participants following guidance at research.missouri.edu/about/covid-19-info.php

In addition, any restarting of in-person research activities must comply with the policies and guiding principles provided at research.missouri.edu/about/research-restart.php, including 
appropriate approvals for return to work authorization for individuals as well as human subject research projects.

2. No subjects may be involved in any study procedure prior to the IRB approval date or after the expiration date.

3. All changes must be IRB approved prior to implementation utilizing the Exempt Amendment Form.

4. The Annual Exempt Form must be submitted to the IRB for review and approval at least 30 days prior to the project expiration date to keep the study active or to close it.

5. Maintain all research records for a period of seven years from the project completion date.

If you are offering subject payments and would like more information about research participant payments, please click here to view the MU Business Policy and Procedure: $\underline{\text { ttp: } / /}$

bppm.missouri.edu/chapter2/2_250.html

If you have any questions or concerns, please contact the MU IRB Office at 573-882-3181 or email to muresearchirb@missouri.edu.

Thank you,

MU Institutional Review Board 


\section{Appendix C}

\section{Gatekeeper Permission for Administrator and Educator Participation}

$\mathrm{I}$, , grant permission for administrators and educators within Overfelt High School to be contacted to participate in the study "How a Principal's Action as an Invitational Leaders with a Social Justice Orientation Can Serve as A Factor in Recruiting and Reciprocally Retaining Teachers at High Poverty, High-Minority, High-Needs Urban High Schools" conducted by William E. McDowell, doctoral candidate at the University of Missouri.

By signing this permission form, I understand that the following safeguards are in place to protect faculty choosing to participate:

- All participation is voluntary and may be withdrawn at any point before culmination of the study.

- All responses will be used for dissertation research and for potential future journal publications.

- All identities will be kept confidential in all phases of the research.

- An interview will occur with each administrator, participating staff, or volunteers via videoconference, lasting approximately one hour in length.

- A survey to measure teacher perceptions of social justice leadership and its impacton college readiness will be sent to principals using Google Survey.

Please keep the consent letter and a copy of the signed consent form for your records. If you choose to grant permission for educators in your school district to participate in this study, please complete this Administrative Permission for Program Participation Form, please return it to William McDowell as soon as possible.

I have read the material above, and any questions that I have posed have been answered to my satisfaction. I grant permission for administrators and educators in my program to be contacted and invited to participate in this study.

Signed:

Date:

Title/Position:

Institution:

Please return to: William E. McDowell, 4115 Campbell St., Kansas City, MO64110 Cell Phone: 816-377-7095 Email: willmcdowell@ hotmail.com 


\section{Appendix D \\ Letter of Informed Consent - Educator Participant}

You are being asked to participate in a survey entitled "How a Principal's Action as an Invitational Leaders with a Social Justice Orientation Can Serve as A Factor in Recruiting and Reciprocally Retaining Teachers at High Poverty, High-Minority, and High-Needs Urban High Schools" which is being conducted by William E. McDowell, a doctoral student with the University of Missouri. This interview is anonymous. Your participation is voluntary. You may choose not to take the interview, to stop responding at any time, or to skip any questions that you do not want to answer. Full participation in the interview will be interpreted as your informed consent to participate.

If you have any questions about the research, please contact Will McDowell via email at willmcdowell@ hotmail.com or the faculty advisor Dr. Barbara Martin at bmartin@ucm.edu . If you have any questions regarding your rights as a research subject, contact the MU Institutional Review Board (IRB) at (573) 882-3181.

Please print or save a copy of this page for your records. 


\section{Appendix E \\ Informed Consent from Participant}

$\mathrm{I}$ , agree to participate in the study "How a

Principal's Action as an Invitational Leaders with a Social Justice Orientation Can Serve as A Factor in Recruiting and Reciprocally Retaining Teachers at High Poverty, High-Minority, High-Needs Urban High Schools" . conducted by William E. McDowell, doctoral candidate at the University of MissouriColumbia. I understand the following:

- My participation is voluntary and may be withdrawn at any point before culmination of the study.

- My responses will be used for dissertation research and for potential future journal publications.

- My identity will be kept confidential in all phases of the research.

- An interview will occur either via video conference or telephone at a mutually agreed upon time, lasting approximately one hour in length.

Please keep the consent letter and a copy of the signed consent form for your records. If you choose to participate in this study, please complete the attached signed consent form, seal it in the enclosed envelope or send via email, to Will McDowell as soon as possible. Please to be sure and include contact information so interview plans can be made and communicated to you.

I have read the material above, and any questions that I have posed have been answered to my satisfaction. I voluntarily agree to participate in this study.

Signed: Date:

Title/Position:

\section{Contact Information:}

Phone (circle one)

WORK

HOME CELL

Best time for contact:

E-mail:

Please return to: William E. McDowell, 4115 Campbell St., Kansas City, MO 64110 Cell Phone: 816-377-7095 Email: willmcdowell@ hotmail.com 


\section{Appendix F \\ Head Principal Interview Questions}

\section{Introduction}

Hello, my name is Will McDowell and I first want to thank you for taking time out of your busy schedule to meet with me and answer questions. I am the doctoral student with the University of Missouri who will be conducting the interview. This interview will be audiotaped to ensure my accuracy while interviewing. My questions will focus on the actions of the school principal and how it affects the decisions of the teachers invited back to come back. You have selected as a participant in this study due to your due to your role as a teacher or volunteer at this high school.

The interview will take less than an hour to complete. Please answer the questions as you see fit and keep in mind that there are no right or wrong answers. If any of my questions are unclear please feel free to ask for clarification. If there is anything you would like to elaborate or follow up on, please do so as well.

\section{Head Principal Questions:}

\begin{tabular}{|c|c|}
\hline Questions & Information \\
\hline $\begin{array}{l}\text { 1. Tell me your name, longevity in the profession, time spent in current role? } \\
\text { 2. Why did you originally come into the profession of education? } \\
\text { 3. What made you want to get into school administration? }\end{array}$ & Learn about participants \\
\hline $\begin{array}{l}\text { 4. What are the ways that you model for your staff that you are a learner who seeks } \\
\text { to consistently reinvent himself and grow personally? If not, why not? } \\
\text { 5. What are ways that you recruit teachers to make them feel they are wanted here? } \\
\text { 6. What are some examples that demonstrate to your teachers that you treat your } \\
\text { staff as able, valuable and responsible? } \\
\text { 7. What are the ways that you are intentionally inviting in regard to... } \\
\text { 1. ...the people of the school } \\
\text { 2. ...this place where you connect each day } \\
\text { 3. .... The programs you offer for the community } \\
\text { 4. ... the processes that are followed } \\
\text { 5. ...policies that exist }\end{array}$ & Q1 \\
\hline $\begin{array}{l}\text { 8. What are some ways that you make the school staff feel like they are part of a } \\
\text { community where they belong? } \\
\text { 9. How do you consider yourself a principal that effective teachers want to come } \\
\text { back to work with year over year? What are some of the reasons for your } \\
\text { answer? } \\
\text { 10. What are some actions you have taken to ensure the teachers you want to return } \\
\text { know they are valued and wanted? }\end{array}$ & Q1, Q2 \\
\hline
\end{tabular}


11. Why did you choose to work at this high school where the student demographic Q3 and school community does not have the same level of resources that many other schools in the district and region do?

12. Researcher George Theoharis defines a social justice leader as on whocarries

Q1, Q3 themselves with arrogant humility, passionate visionary leadership, and a tenacious commitment to justice. How do you feel if any, or all these three descriptors apply to you? How so?

13. What actions or policies at your school would you describes as promoting social justice, as you have defined it?

14. We are at a time where actions of social justice are taking place in many organizations and communities. In what ways have you challenged the status quo of the system in the name of social justice here at your school?

15. In what ways do you see the actions you have taken to be intentionally inviting in your school taken hold in your school community with teacher and students?

16. In what ways do you see actions of social justice being carried out in your school by your staff and students?

17. Do you have anything else that you would like for me to know about your leadership?

Q1, Q2, Q3, Q4

Q4 


\section{Appendix G \\ Administrator, Counselor, Instructional Coach, Teacher, Volunteer Interview Questions}

\section{$\underline{\text { Introduction }}$}

Hello, my name is Will McDowell and I first want to thank you for taking time out of your busy schedule to meet with me and answer questions. I am the doctoral student with the University of Missouri who will be conducting the interview. This interview will be audiotaped to ensure my accuracy while interviewing. My questions will focus on the actions of the school principal at your school and how it affects the decisions of the teachers invited back to return. You have selected as a participant in this study due to your due to your role at this school.

The interview will take less than an hour to complete. Please answer the questions as you see fit and keep in mind that there are no right or wrong answers. If any of my questions are unclear please feel free to ask for clarification. If there is anything you would like to elaborate or follow up on, please do so as well.

Administrator, Counselor, or Instructional Coach Interview Questions:

\begin{tabular}{|c|c|}
\hline Questions & Information \\
\hline $\begin{array}{l}\text { 1. Tell me your name, longevity in the profession, time spent in current role? } \\
\text { 2. Why did you originally come into the profession of education? } \\
\text { 3. What made you want to get into your current role? }\end{array}$ & Learn about participants \\
\hline $\begin{array}{l}\text { 4. Are there ways that your principal models for your staff that you are a } \\
\text { learner who seeks to consistently reinvent himself and grow personally? If } \\
\text { so, how so? If not, why not? } \\
\text { 5. What are ways that teachers are recruited to make them feel they are wanted } \\
\text { here? Has your principal had an effect on that? } \\
\text { 6. As a leader of this building are there specific ways that the principal treats } \\
\text { your staff as able, valuable and responsible? } \\
\text { 7. What are the ways that your principal is intentionally inviting in regard to... } \\
\text { a. ...the people of the school } \\
\text { b. ...this place where you connect each day } \\
\text { c. .... The programs you offer for the community } \\
\text { d. ... the processes that are followed } \\
\text { e. ...policies that exist }\end{array}$ & Q1 \\
\hline $\begin{array}{l}\text { 8. What are some ways that your principal makes the school staff feel like they } \\
\text { are part of a community where they belong? } \\
\text { 9. Do you consider your principal a person who is so effective that teachers } \\
\text { want to come back to work with year over year? What are some of the } \\
\text { reasons for your answer? }\end{array}$ & Q1, Q2 \\
\hline
\end{tabular}


10. What are some actions taken in this school to ensure the teachers who are effective to return know they are valued and wanted?

11. Why do you think your principal chooses to work at this high school where the student demographic and school community do not have the same level of resources that many other schools in the district and region do?

12. Researcher George Theorharis defines a social justice educational leader to be one who carries themselves with arrogant humility, passionate visionary leadership, and a tenacious commitment to justice. In what ways may have you seen your principal carry themselves with any or all these descriptors?

13. What actions or policies at your school would you describes as promoting social justice, as you have defined it?

14. We are at a time where actions of social justice are taking place in many organizations and communities. In what ways have you seen the status quo of the system challenges in the name of social justice here at your school?

15. In what ways do you see intentionally inviting actions taken by members of Q4 your school community? Do you consider these actions being a part of the culture created by your principal?

16. In what ways do you see actions of social justice being carried out in your school by your staff and students?

17. Do you have anything else that you would like for me to know about your school principal?

Q1, Q2, Q3, Q4 


\section{Appendix H}

\section{Document Analysis Protocol}

Name of Document:

$\underline{\text { Audience of Document: }}$

Purpose of the Document:

Words and phrases within the document, which are similar to Invitational Leadership and/or Social Justice Leadership Behaviors, supportive retention behaviors, 


\section{References}

Balfanz, R., Herzog, L., \& MacIver, D. J. (2007). Preventing student disengagement and keeping urban students on the graduation path in urban middle-grades schools: Early identification and effective interventions. Education Psychologist, 42(2), 223-235.

Bartanen, B., Grissom, J.A., \& Rogers, L.K. (2019). The impacts of principal turnover. Educational Evaluation and Policy Analysis, 41(3), 350-374.

Beteille, T, Kalogides, D. \& Loeb, S. (2011). Principal career paths and school outcomes. NBR Working Paper. No. w17243

Bogotch, I.E., (2000). Educational leadership and social justice: Practice into theory. Journal of School Leadership, 12, 138-156.

Borman, G. D., \& Dowling, N. M. (2008). Teacher attrition and retention: A meta-analytic and narrative review of the research. Review of Educational Research, 78(3), 367-409.

Brill, S., \& McCartney, A. (2008). Stopping the revolving door: Increasing teacher retention. Politics \& Policy, 36, 750-774. Doi:10.111/j.1747-1346.2008.00133.x

Bruffee, Kenneth. (2002) Toward reconstructing American classrooms: Interdependent students, interdependent world. Teaching Composition: Background Readings. Ed. T. R. Johnson and Shirley Morahan. Boston: Bedford/St. Martin’s 126-143.

Buckingham, M.; Goodall, A., (2019) 9 Lies about work. Boston, MA: Harvard Business Review Press.

Burkhauser, S. (2016) How much do school principals matter when it comes to teacher working conditions? Educational Evaluation and Policy Analysis, 20(1) 1-20.

Burnette, D. (2020, May 8). Devastated budgets and widening inequities: How the coronavirus 
collapse will impact schools. Education Week. Retrieved from:

https://www.edweek.org/ew/articles/2020/05/09/devastated-budgets-and-wideninginequities-how-the.html

Bryant, J. \& Strauss, V. (2017, September 7). The sad story of public education in Saint Louis.

Washington Post. Retrieved from: https://www.washingtonpost.com/news/answersheet/wp/2017/09/07/the-sad-story-of-public-education-in-st-louis/

Cachero, P. (2020, April 12). All but 3 people who died from Covid-19 in St. Louis, Missouri, were black. Business Insider. Retrieved from https://www.businessinsider.com/all-butthree-people-who-died-from-covid-19-in-st-louis-were-black-2020-4.

Capper, C.A., Theorharis, G., \& Sebastian, J. (2006). Toward a framework for preparing leaders for social justice. Journal of Educational Administration, 44(3), 209-224.

Centers for Disease Control and Prevention. (2015). School health policies and practices study. Trends over time: 2000-2014. U.S. Department of Health and Human Services.

Clotfelter, C.; Ladd, H.F., Vigdor, J; and Wheeler, J., (2007). High-Poverty and the Distribution of Teachers and Principals.

Collins, J. (2001). Good to great. New York, NY: Harper-Collins Publishers Inc.

Cooperman, J. (2014, October 17). The story of segregation in St. Louis: Why does race still shape St. Louis? Why was segregation more dramatic here than it was in similar Midwestern cities? And why hasn't it lifted as quickly? St. Louis Magazine. https://www.stlmag.com/news/the-color-line-race-in-st.-louis/ 
Creswell, J.W. (2014). Research design: Qualitative, quantitative, and mixed methods approaches $\left(4^{\text {th }}\right.$ ed.). Sage.

Dantley, M., \& Tillman, L. (2010). Social justice and moral transformative leadership. In C. Marshall \& M. Oliva (Eds.). Leadership for social justice: Making revolutions in education ( $2^{\text {nd }}$ ed., pp. 16-29). Boston, MA: Allyn \& Bacon.

Darling-Hammond, L. (2006). Securing the right to learn: Policy and practice for powerful teaching and learning. Educational Researcher, 35, 13-24.

Donaldson \& Johnson (2011). Teach for America teachers: How long do they teach? Why do they leave? Phi Delta Kappan, 93, 47-51.

DuFour, R., \& Eaker, R. (1998). Professional learning communities at work: Best practices for enchancing student achievement. Alexandria, VA: ASCD.

Dweck, C. (2006). Mindset: The new psychology of success. New York, NY: Ballantine Books East Side Union School District (2019) - Retrieved, https://www.caschooldashboard.org/search?search=East $\% 20$ Side\%20Union\%20\&locatio $\underline{\mathrm{n}=\mathrm{San} \% 20 \mathrm{Jose} \& \text { year }=2019}$

Edbuild (2020, October 10) Nonwhite school districts get 23 billion less. Retrieved from https://edbuild.org/content/23-billion

Fergus, E. (2017) Solving disproportionality and achieving equity: A leader's guide to using data to change hearts and minds. Thousand Oaks, CA: Corwin.

Freedman, S. W., \& Appleman, D. (Summer 2008). "What else would I be doing?” Teacher identity and teacher retention in urban schools. Teacher Education Quarterly, 35(3) 109126. 
Fullan, M. (2001). Leading in a culture of change. San Francisco, CA: Jossey-Bass.

Fullan, M. (2014). The Principal. San Francisco, CA: Jossey-Bass.

Furman, G. (2012). Social justice leadership as praxis: developing capacities through preparation programs. Educational Administration, 48(2), 191-229.

Green, Peter (2019) - Atlantic https://bit.ly/35iuwvh

Greenlee, B., \& Brown, Jr., J. J. (2009). Retaining teachers in challenging schools. Education, 130(1), 96-109. Retrieved from http://dx.doi.org

Greenleaf, R.K. (1970). The servant as leader. Westfield, IN: The Greanleaf Center for Servant Leadership.

Grissom, J. A. (2011). Can good principals keep teachers in disadvantaged schools? Linking principal effectiveness to teacher satisfaction and turnover in hard-to-staff environments. Teachers College Record, 113(11), 2552-2585.

Grow Your Own Illinois. (2020, October 10). Retrieved from https://growyourownteachers.org/index.php?option=com_content\&view=article\&id=223 $\underline{\text { \&Itemid }=562 \& l a n g=e n}$

Haberman, M. (2003). Star teachers: Haberman Educational Foundation.

Hammond, Z. L. (2015). Culturally responsive teaching and the brain. Corwin Press.

Hattie, J. (2003). Teachers make a difference: What is the research evidence? Australian Council for Educational Research, 1-17.

Hattie, J. (2016) Hattie Ranking: 252 Influences and effect sizes related to student achievement. Retrieved from: https://visible-learning.org/hattie-ranking-influences-effect-sizeslearning-achievement/ 
Heineke, A. J., Mazza, B. S., \& Tichnor-Wagner, A. (2014). After the two-year commitment: A quantitative and qualitative inquiry of teach for America teacher retention and attrition. Urban Education, 49(7), 750-782.

Howard, G. R. (2006). We can't teach what we don't know (2 ed.). New York, NY: Teachers College, Columbia University.

Hughes, G. D. (2012). Teacher retention: Teacher characteristics, school characteristics, organizational characteristics, and teacher efficacy. The Journal of Educational Research, $105,245-255$.

Humphrey, D.C., Wechsler, M.E., \& Hough, H.J. (2008). Characteristics of effective alternate teacher certification programs. Teacher College Record, 110, 218-250.

Ingersoll, R. (2001). Teacher turnover and teacher shortages: An organizational analysis. American Educational Research Journal, 38(3), 499-534.

Ingersoll, R. M., \& Smith, T. M. (2003). The wrong solution to the teacher shortage. Association for Supervision and Curriculum Development, 30-33.

Kardos, S. M., Johnson, S. M., Peske, H. G., Kauffman, D., \& Liu, E. (2001). Counting on colleagues: New teachers encounter the professional cultures of their schools. Education Administration Quarterly, 37(2), 250-290.

Keen Independent Research. (2018). 2018 Silicon Valley dichotomy study: Summary report. Retrieved, from Source: https://www.keenindependent.com/wpcontent/uploads/2018/04/Keen-Independent-2018-Dichotomy-Study-Final-Report.pdf

King Jr., M. L. (1962). An address by Martin Luther King, Jr. Cornell College, Mount Vernon, Iowa. Retrieved from http://news.cornellcollege.edu/dr-martin-luther-kings-visit-to$\underline{\text { cornell-college/ }}$ 
Kozol, J. (2005). The shame of the nation. New York, NY: Crown Publishers.

Krueger, R. A., \& Casey, M. A. (2009). Focus groups: A practical guide for applied research (4th ed.). Thousand Oaks, CA: Sage.

Kunjufu, J. (2002). Black students middle class teachers. Chicago, IL: African American Images.

Lee, R. E., Eckrich, L. L., Lackey, C., \& Showalter, B. D. (2010). Pre-service pathways to urban teaching: A partnership model for nurturing community-based urban teacher preparation. Teacher Education Quarterly, 101-122.

Levin, S., \& Bradley, K. (2019). Understanding and addressing principal turnover: A review of the research. Reston, VA: National Association of Secondary School Principals.

Lumsden, C. (2020, June 10) Meet 4 young activists fighting for racial injustice across the nation. Good Morning America. Retrieved from https://www.goodmorningamerica.com/living/story/meet-young-activists-fighting-racialinjustice-nation-71152493

Marinell, W. H. (2011). The middle school teacher turnover project: A descriptive analysis of teacher turnover in New York City's middle schools. The Research Alliance for New York City Schools, 1-52.

Marshall, C. (2004). Social justice challenges to educational administration: Introduction to a special issue. Educational Administration Quarterly, 40(1), 3-13.

Martin, B. N. \& Miller, C. (2017) Are principals prepared to lead in schools with diverse student populations using invitational leadership? Journal of Education and Culture Studies, $1(2), 198-214$. 
Maslow, A. H. (Ed.). (2005). The theory of human motivation. In J. M. Shafritz, J. S. Ott, \& Y. S. Jang (Eds.), Classics of organization theory (6 ed. Pp. 167-178). Belmont, CA: Wadsworth. (Reprinted from Psychological Review, pp. 370-396, 1943).

Matsko, K. K., \& Hammerness, K. (2014). Unpacking the "Urban" in urban teacher education; Making a case for context-specific preparation. Journal of Teacher Education, 65(2), $128-144$.

McKnight, C.P., \& Martin, B.N. (2015). Creating an effective educational environment for adult learners: A qualitative, multi-case study of off-campus center administrator's use of invitational leadership. Journal of Invitational Theory and Practice. 2(1), 48-67.

Mehrabian, A., \& Wiener, M. (1967). Decoding of inconsistent communications. Journal of Personality and Social Psychology, 6, 109-114.

Metropolitan Life Survey (2013). Survey of the American teacher: Challenges for school leadership.

Merriam, S.B. (2009). Qualitative research: A guide to design and implementation. John Wiley \& Sons, Inc.

Milner, H. R. (2015). Reform starts with self. Urban Education, 50(2), 135-138.

Mintzberg, H. (1980). Structure in 5's: A synthesis of the research on organization design. Management Science, 26(3), 322-341.

Mintzberg, H. (2005). The five basic parts of the organization. In J. Mm Shafritz, J. S. Ott, Y. S. Jang (Eds.), Classics of Organization Theory (pp. 219-230). Belmont, CA: Wadsworth.

Napolitano, J. (2020, June 12). 'Defunding the police' - and shifting resources from law enforcement to schools - gains momentum in the wake of protests. The 74 . Retrieved from: https://www.the74million.org/article/defunding-the-police-and-shifting-resources- 
from-law-enforcement-to-schools-gains-momentum-in-the-wake-of-protests-againstpolice/

NASSP. (2020) National association of secondary school principals. Retrieved from: https://www.nassp.org/policy-advocacy-center/nassp-position-statements/principal-shortage/

$\mathrm{Ng}$, J. C. (2003). Teacher shortages in urban schools: The role of traditional and alternative routes in filling the voids. Education and Urban Society, 35(4), 380-398.

Northouse, P. G. (2013). Leadership theory and practice (6 ed.). Thousand Oaks, CA: Sage.

Novak, J., \& Purkey, W. (2001). Invitational education. Bloomington, IN: Phi Delta Kappa Educational Foundation Fastbacks. 488, p7-55

Page, S. (2020, May 24) Back to school? 1 in 5 teachers are unlikely to return to reopened classrooms this fall, poll says. USA Today Retrieved from: https://www.usatoday.com/story/news/education/2020/05/26/coronavirus-schoolsteachers-poll-ipsos-parents-fall-online/5254729002/

Petty, T. M., Fitchett, P., \& O’Connor, K. (2012). Attracting and keeping teachers in high needs schools. American Secondary Education, 40(2), 67-84.

Podolsky, A., Kini, T., Bishop, J., \& Darling-Hammond, L. (2016) Solving the teacher shortage: How to attract and retain excellent educators. Learning Policy Institute.

Purkey, W., \& Novak, J. (2016). Fundamentals of invitational education ( $2^{\text {nd }}$ ed.). Kennesaw, GA: International Alliance for Invitational Education.

Purkey, W.W., \& Siegel, B. (2003). Becoming an invitational leader: A new approach to professional and personal success. Atlanta, GA: Humanics.

Radcliff, R. A., \& Mandeville, T. F. (2007). Teacher preferences for middle grades insights into attracting teacher candidates. The Clearing House, 80(6), 261-266. 
Rector-Aranda, A. (2016). School norms and reforms, critical race theory, and the fairytale of equitable education. Critical Questions in Education. 7(1), 1-18.

Rice, S.M. (2010). Getting our best teachers into disadvantaged schools: differences in the professional and personal factors attracting more effective and less effective teachers to a school. Educational Research Policy Practice. 9(3). 177-192. https://doi.org/10.1007/s10671-010-9085-2

Roenfeldt, M., Loeb, S., \& Wycoff, J. (2013). How teacher turnover harms student achievement. American Educational Research Journal, 50(1), 4-36.

Rothstein, R. (2014). Modern segregation. Economic Policy Institute. Retrieved from https://www.epi.org/files/2014/MODERN-SEGREGATION.pdf

Sachs, S. K. (2004, March/April 2004). Evaluation of teacher attributes as predictors of success in urban schools. Journal of Teacher Education, 55(2), 177-187.

Samuels, C.A. (2012, March 7). Study: Churn in the principal's office bodes poorly for success of schools. Education Week, 31(23), 10.

Shann, M. H. (1998). Professional commitment and satisfaction among teachers in urban middle schools. The Journal of Educational Research, 92(2), 67-73.

Shernoff, E. S., Marinez-Lora, A. M., Frazier, S. L., Jakobsons, L. J., Atkins, M. S., \& Bonner, D. (2011). Teachers supporting teachers in urban schools: What iterative research designs can teach us? School Psychology Review, 40 (4), 465-485.

Shield, C.M. (2004). Dialogic leadership for social justice: Overcoming pathologies of silence. Education Administration Quarterly, (40)1, 109-132.

Simon, N. S., \& Johnson, S. M. (2015). Teacher turnover in high-poverty schools: What we know and can do. Teachers College Record, 117(2), 1-36. 
Sinek, S., (2014). Leaders eat last. New York: Penguin Group.

Spears, L.C. (2002). Tracing the past, present, and future of servant-leadership. In L.C. Spears \& M. Lawrence (Eds.), Focus on leadership. Servant-leadership for the $21^{\text {st }}$ century (pp.116). New York: John Wiley \& Sons.

Stotko, E. M., Ingram, R., \& Beaty-O'Ferrall, M. E. (2007). Promising strategies for attracting and retaining successful urban teachers. Urban Education, 42(1), 30-51.

Sutcher, L., Darling-Hammond, L., \& Carver-Thomas, D. (2016) A Coming Crisis in Teaching? Teacher Supply, Demand, and Shortages in the U.S. Learning Policy Institute.

Taylor, Tim, Martin, Barbara N., Hutchinson, Sandy \& Jinks, Michael (2007) Examination of leadership practices of principals identified as servant leaders, International Journal of Leadership in Education, 10:4, 401 - 419 DOI: 10.1080/13603120701408262 URL: http://dx.doi.org/10.1080/13603120701408262

The Irreplaceables. (2012). Retrieved from http://tntp.org/assets/documents/TNTP_Irreplaceables_2012.pdf

Theoharis, G. (2007). Social justice educational leaders and resistance: Toward a theory of social justice leadership. Educational Administration Quarterly, 43(2), 221-258.

Theoharis, G. (2008). Woven in deeply: Identity and leadership of urban social justice principals. Education and Urban Society, 41, 3-25.https://doi.org/10.1177/0013124508321372

Waddell, J. H. (2010). Fostering relationships to increase teacher retention in urbanschools. Journal of Curriculum and Instruction, 4(1), 70-85.

Waddell, J., \& Ukpokodu, O. N. (2012). Recruiting \& preparing diverse urban teachers: One urban-focused teacher education program breaks new ground. Multicultural Education, $15-22$. 
Wang, F. (2018). Social justice leadership - Theory and practice: A case of Ontario. Education Administration Quarterly, 53(3), 470-498.

WBUR (Oct. 28, 2019). The hidden force behind child poverty rates in the U.S. Here and Now. Retrieved from: https://www.wbur.org/hereandnow/2019/10/28/us-child-poverty-rates

Watkins, P. (2005). The principal's role in attracting, retaining, and developing new teachers: Three strategies for collaboration and support. The Clearing House, 79(2), 83-87.

Williams, D. J. (2013). Urban education and professional learning communities. Delta Kappa Gamma Bulletin - Educational Research.

Yonezawa, S., Jones, M., \& Singer, N. R. (2011). Teacher resilience in urban schools: The importance of technical knowledge, professional community, and leadership opportunities. Urban Education, 46(5), 913-931. 


\section{VITA}

Will McDowell was the fifth child born into his family in 3 years and 18 days. He spent his early years in the small town of Chatham, NY with his four sisters and two brothers. Whenhe was twelve, the challenges of economic opportunity in a small town proved to be too much for a family of seven children. With his parent's marriage ending, Will moved with his siblings where his mother knew there was greater support for her budding teenagers. The family moved into a predominantly Black neighborhood in Troy, NY that would be ranked by a 2015 study by Brandeis and Ohio State Universities as dead last for healthy childhood development of Black children. During this time of "The War on Drugs" and mass incarceration of people of color, Will saw firsthand the inequities along racial lines that existed. His mother Geralyn was his greatest teacher of what it meant to believe and act with a social justice orientation. While there was limited financial wealth in the Section 8 neighborhood where they lived, Geralyn ensured the wealth of her children's childhood and adolescent years included access to others in the social justice movement in experiences that included but were not limited to the Nuclear Freeze campaign, Witness for Peace, partaking in the Nestle boycott, hosting Nobel Peace Prize winner Adolfo Perez Esquivel in their home, advocating for gay rights, calling for racial and socioeconomic equity, and ensuring that her children traveled internationally. It was on a trip to the former Soviet Union, with a national delegation of 15-17 year old students with the Fellowship of Reconciliation, the oldest and largest interfaith social justice organization promoting peace and active nonviolence in the United States, that Will decided that his career would be focused on making a difference in the lives of young people.

Will would leave New York after high school where he went to Warren Wilson College to do his undergraduate work to become an elementary school teacher. While at Warren Wilson 
he was further exposed to how deep relationships with an educational faculty who cared about each individual could turn a B- student like Will into a solid A student who would win both the top athlete and work awards for his graduating class of 1995 . Will would then go on to teach $5^{\text {th }}$ grade in Black Mountain, NC before moving on to teach $6^{\text {th }}$ grade in Hendersonville, NC. Teaching in the two small communities he saw what was possible in integrated racial and socioeconomic schools.

In 2000, Will moved to Spokane, WA where he worked for a corporation who traveled students around the world supporting the vision of Dwight D. Eisenhower that if people could come together, so to would nations. During his four years he traveled to over 20 countries organizing cultural exchange opportunities for young people through sports and service to the communities visiting. In 2004, Will recognized that he was more mission driven that shareholder driven and moved to the non-profit wing of the organization in Kansas City, MO. Knowing that he wanted to live in a diverse neighborhood he settled into living just two blocks from the racial and socio-economic dividing line of Troost Avenue in Kansas City. After takinga group of predominantly White wealthier students to South Africa and recognizing how much work needed to be done in his own community on racial equity and socio-economic work, Will shifted his career focus to be targeted in this way. This included being a Director of Life Skills Curriculum and Instruction for a college access preparatory program at the Kauffman Scholars Program, an instructional coach under the Kansas City educational legend Joyce McGautha at the Urban Community Leadership Academy, becoming an assistant principal, then principal of Hogan Preparatory Academy Middle School for four years.

As the leadership at Hogan was shifting into a more vertical model and further from a social justice orientation with their staff, Will decided to mutually step away from the principal 
role to gain a broader view through working in professional development with the Regional Professional Development Center at the University of Central Missouri for a year before becoming a national educational consultant with the National Math and Science Initiative (NMSI). In these roles, Will was able to identify the most successful schools who were most effectively serving their communities to support all students. He recognized that principals could not do it alone, so he piloted coaching school leadership teams on practices that focused on horizontal leadership with collective teams using a theory introduce to him by Dr. Barbara N. Martin. Using the inviting stance was gaining early success in schools integrating the practices, so NMSI decided that these types of trainings would be valuable for all schools with whom the organization partnered. He was moved to Senior Manager of Leadership Development where he leads a national team of educators in creating and facilitating the training, then integrating the practices of invitational and collective leadership in support of advanced academics in over 150 schools annually around the country.

Will lives in Kansas City, Missouri where, with his beautiful and extremely talented educator wife, Jessica, where they are raising their two children, son Liam (13) and daughter, Winifred (11), to recognize their own socio-economic, racial, and other privileges as we all work for equity at the local and global levels. 